RECEIVED

MAR 211996

\section{OSTI}

NUREG/CR-6246 ORNL-6814

\title{
Effects of Aging and Service Wear on Main Steam Isolation Valves and Valve Operators
}

Prepared by

R. L. Clark

Oak Ridge National Laboratory

Prepared for

U.S. Nuclear Regulatory Commission

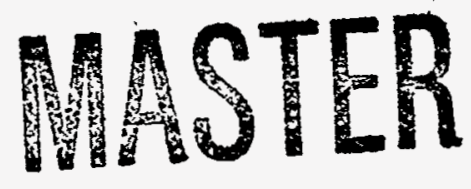

DISTRIBUTION OF THIS DOCWHENT IS UALIMRTED 


\section{AVAILABILITY NOTICE}

Availability of Reference Materials Cited in NRC Publications

Most documents cited in NRC publications will be available from one of the following sources:

1. The NRC Public Document Room, 2120 L Street, NW., Lower Level, Washington, DC 20555-0001

2. The Superintendent of Documents, U.S. Government Printing Office, P. O. Box 37082 , Washington, DC 20402-9328

3. The National Technical Information Service, Springfield, VA 22161-0002

Although the listing that follows represents the majority of documents cited in NRC publications, it is not intended to be exhaustive.

Referenced documents available for inspection and copying for a fee from the NRC Public Document Room include NRC correspondence and internal NRC memoranda; NRC bulletins, circulars, information notices, inspection and investigation notices; licensee event reports; vendor reports and correspondence; Commission papers; and applicant and licensee documents and correspondence.

The following documents in the NUREG series are available for purchase from the Government Printing Office: formal NRC staff and contractor reports, NRC-sponsored conference proceedings, international agreement reports, grantee reports, and NRC booklets and brochures. Also available are regulatory guides, NRC regulatlons In the Code of Federal Regulations, and Nuclear Regulatory Commission Issuances.

Documents available from the National Technical Information Service include NUREG-series reports and technical reports prepared by other Federal agencies and reports prepared by the Atomic Energy Commission, forerunner agency to the Nuclear Regulatory Commission.

Documents available from public and special technical libraries include all open literature items, such as books. Journal articles, and transactions. Federal Register notices. Federal and State legislation, and congressional reports can usually be obtained from these libraries.

Documents such as theses, dissertations. foreign reports and translations, and non-NRC conference proceedings are available for purchase from the organization sponsoring the publication cited.

Single copies of NRC draft reports are available free, to the extent of supply, upon written request to the Office of Administration, Distribution and Mail Services Section, U.S. Nuclear Regulatory Commission, Washington, DC 20555-0001.

Coples of industry codes and standards used in a substantive manner in the NRC regulatory process are maintained at the NRC Library. Two White Flint North. 11545 Rockville Pike. Rockville. MD 20852-2738, for use by the public. Codes and standards are usually copyrighted and may be purchased from the originating organization or, if they are American National Standards. from the American National Standards Institute. 1430 Broadway, New York, NY 10018-3308.

\section{DISCLAIMER NOTICE}

This report was prepared as an account of work sponsored by an agency of the United States Government. Neither the United States Government nor any agency thereof, nor any of their employees, makes any warranty, expressed or implied, or assumes any legal liability or responsibility for any third party's use, or the results of such use, of any information, apparatus, product, or process disclosed in this report, or represents that its use by such third party would not infringe privately owned rights. 
NUREG/CR-6246

ORNL-6814

\section{Effects of Aging and Service Wear on Main Steam Isolation Valves and Valve Operators}

Manuscript Completed: February 1996

Date Published: March 1996

Prepared by

R. L. Clark

Oak Ridge National Laboratory

Managed by Lockheed Martin Energy Systems

Oak Ridge National Laboratory

Oak Ridge, TN 37831-6285

J. Jackson, NRC Project Manager

Prepared for

Division of Engineering Technology

Office of Nuclear Regulatory Research

U.S. Nuclear Regulatory Commission

Washington, DC 20555-0001

NRC Job Code B0828 


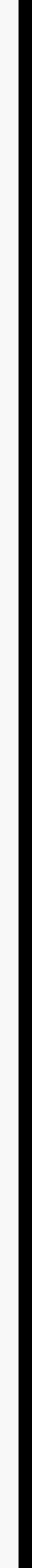




\begin{abstract}
In recent years main steam isolation valve (MSIV) operating problems have resulted in significant operational transients (e.g., spurious reactor trips, steam generator dry out, excessive valve seat leakage), increased cost, and decreased plant availability. A key ingredient to an engineering-oriented reliability improvement effort is a thorough understanding of relevant historical experience. A detailed review of historical failure data available through the Institute of Nuclear Power Operation's Nuclear Plant Reliability Data System has been conducted for several types of MSIVs and valve operators for both boiling-water reactors and pressurized-water reactors. The focus of this review is on MSIV failures modes, actuator failure modes, consequences of failure on plant operations, method of failure detection, and major stressors affecting both valves and valve operators.
\end{abstract}

\title{
DISCLAIMER
}

This report was prepared as an account of work sponsored by an agency of the United States Government. Neither the United States Government nor any agency thereof, nor any of their employees, makes any warranty, express or implied, or assumes any legal liability or responsibility for the accuracy, completeness, or usefulness of any information, apparatus, product, or process disclosed, or represents that its use would not infringe privately owned rights. Reference herein to any specific commercial product, process, or service by trade name, trademark, manufacturer, or otherwise does not necessarily constitute or imply its endorsement, recommendation, or favoring by the United States Government or any agency thereof. The views and opinions of authors expressed herein do not necessarily state or reflect those of the United States Government or any agency thereof. 


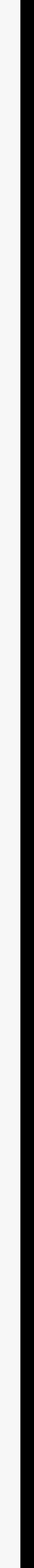




\section{Contents}

Page

Abstract $\ldots \ldots \ldots \ldots \ldots \ldots \ldots \ldots \ldots \ldots \ldots \ldots \ldots \ldots \ldots \ldots \ldots \ldots \ldots \ldots \ldots \ldots$

Contents $\ldots \ldots \ldots \ldots \ldots \ldots \ldots \ldots \ldots \ldots \ldots \ldots \ldots \ldots \ldots \ldots \ldots \ldots \ldots \ldots \ldots$

Figures $\ldots \ldots \ldots \ldots \ldots \ldots \ldots \ldots \ldots \ldots \ldots \ldots \ldots \ldots \ldots \ldots \ldots \ldots \ldots \ldots \ldots \ldots \ldots$

Acknowledgments $\ldots \ldots \ldots \ldots \ldots \ldots \ldots \ldots \ldots \ldots \ldots \ldots \ldots \ldots \ldots \ldots \ldots \ldots \ldots \ldots$

Acronyms $\ldots \ldots \ldots \ldots \ldots \ldots \ldots \ldots \ldots \ldots \ldots \ldots \ldots \ldots \ldots \ldots \ldots \ldots \ldots \ldots \ldots \ldots \ldots$

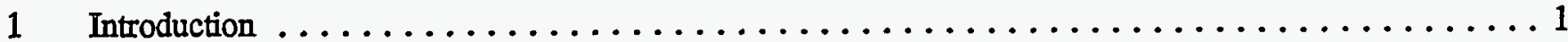

2 Main Steam System General Description . . . . . . . . . . . . . . . . . . 3

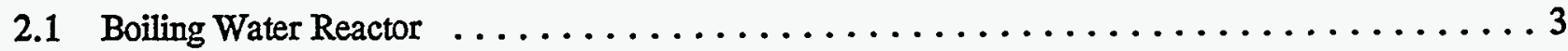

2.1.1 Major Components . . . . . . . . . . . . . . . . . . . . . 3

2.1.1.1 Elbow Flow Taps $\ldots \ldots \ldots \ldots \ldots \ldots \ldots \ldots \ldots \ldots \ldots \ldots \ldots \ldots$

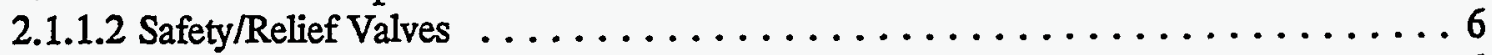

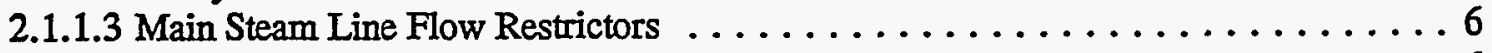

2.1.1.4 Main Steam Bypass Valves . . . . . . . . . . . . . . . . . 6

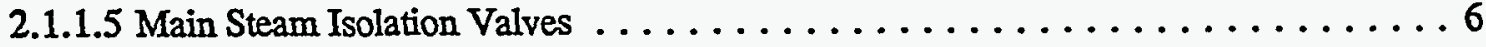

2.1.1.6 Main Turbine Stop and Control Valves $\ldots \ldots \ldots \ldots \ldots \ldots \ldots \ldots \ldots \ldots \ldots \ldots$

2.1.1.7 Main Turbine . . . . . . . . . . . . . . . . . . . . . . .

2.1.1.8 Auxiliary Steam Loads . . . . . . . . . . . . . . . . . 8

2.2 Pressurized Water Reactor $\ldots \ldots \ldots \ldots \ldots \ldots \ldots \ldots \ldots \ldots \ldots \ldots \ldots \ldots$

2.2.1 Major Components . . . . . . . . . . . . . . . . . . . . 8

2.2.1.1 Main Steam Line Flow Restrictors . . . . . . . . . . . . . . 8

2.2.1.2 Steam Generator Code Safety Valves . . . . . . . . . . . . . . 10

2.2.1.3 Power-Operated Relief Valves . . . . . . . . . . . . . . . . 10

2.2.1.4 Main Steam Isolation Valves . . . . . . . . . . . . . . . . . 10

2.2.1.5 Main Steam Line Nonreturn Check Valves . . . . . . . . . . . . . . 11

2.2.1.6 Main Steam Isolation Bypass Valves $\ldots \ldots \ldots \ldots \ldots \ldots \ldots \ldots \ldots \ldots \ldots \ldots$

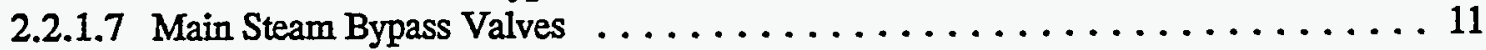

2.2.1.8 Main Turbine Stop and Control Valves $\ldots \ldots \ldots \ldots \ldots \ldots \ldots \ldots \ldots \ldots \ldots \ldots \ldots$

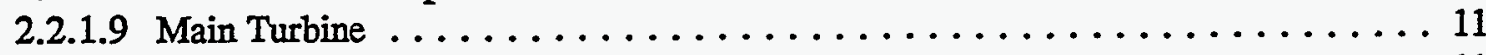

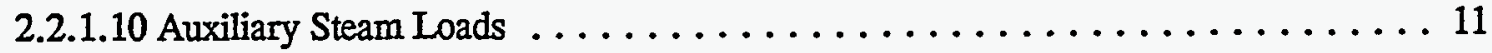

3 Main Steam Isolation Valve and Valve Operator Descriptions $\ldots \ldots \ldots \ldots \ldots \ldots$

3.1 BWR MSIV $\ldots \ldots \ldots \ldots \ldots \ldots \ldots \ldots \ldots \ldots \ldots \ldots \ldots \ldots \ldots \ldots \ldots \ldots \ldots$ 


\section{Contents}

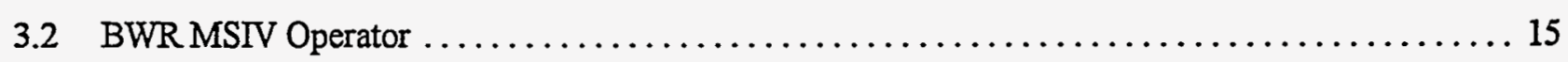

3.2.1 Electrical and Pneumatic System Components .......................... 15

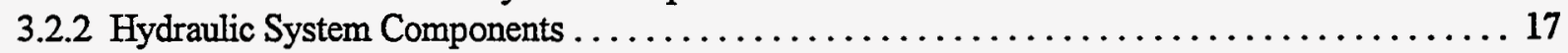

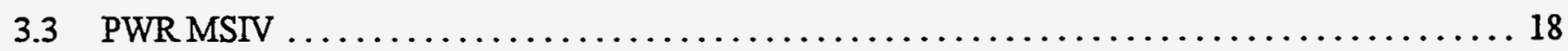

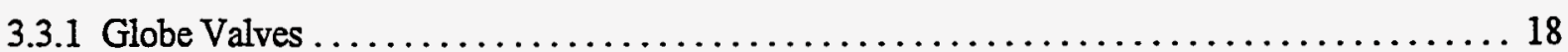

3.3.2 Check Valves $\ldots \ldots \ldots \ldots \ldots \ldots \ldots \ldots \ldots \ldots \ldots \ldots \ldots \ldots \ldots \ldots \ldots \ldots \ldots \ldots \ldots, 18$

3.3.3 Gate Valves .................................................. 22

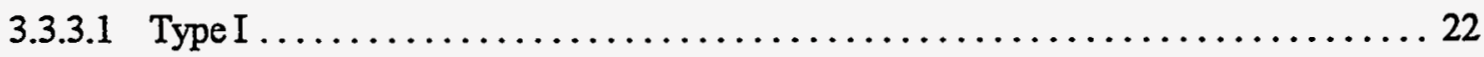

3.3.3.2 Type II $\ldots \ldots \ldots \ldots \ldots \ldots \ldots \ldots \ldots \ldots \ldots \ldots \ldots \ldots \ldots \ldots \ldots \ldots \ldots \ldots \ldots \ldots \ldots \ldots, 24$

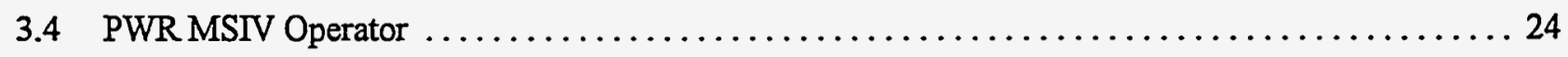

3.4.1 Globe Valves $\ldots \ldots \ldots \ldots \ldots \ldots \ldots \ldots \ldots \ldots \ldots \ldots \ldots \ldots \ldots \ldots \ldots \ldots \ldots \ldots \ldots \ldots \ldots \ldots \ldots \ldots, 24$

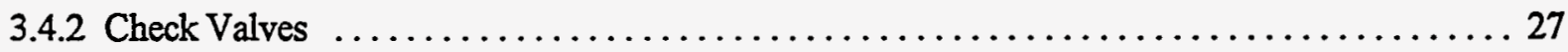

3.4 .3 Gate Valves ............................................... 27

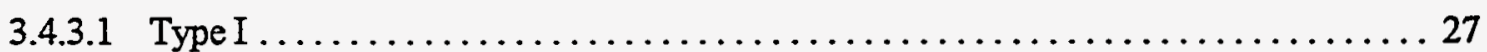

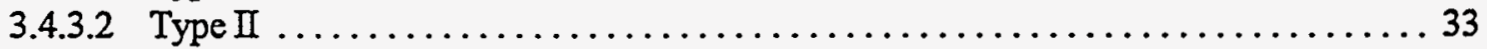

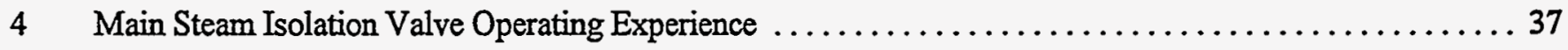

4.1 MSIV Failure Mode Distribution : BWR ..................................... 39

4.2 Cross Correlation of Valve Failure Modes and Valve Failure Areas : BWR ................ 39

4.2.1 Valve Seat Leakage ............................................... 39

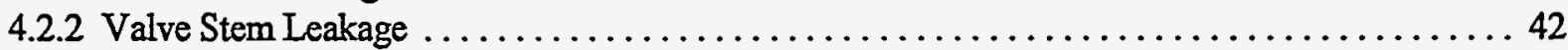

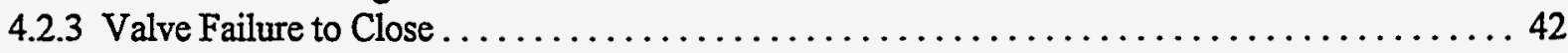

4.2 .4 Valve Failure to Open $\ldots \ldots \ldots \ldots \ldots \ldots \ldots \ldots \ldots \ldots \ldots \ldots \ldots \ldots \ldots \ldots \ldots \ldots, 44$

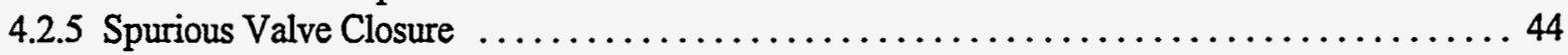

4.3 Major Valve Failure Mechanisms : BWR ................................ 44

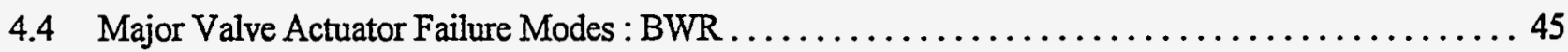

4.5 MSIV Failure Consequences on Plant Operations : BWR $\ldots \ldots \ldots \ldots \ldots \ldots \ldots \ldots \ldots \ldots \ldots$

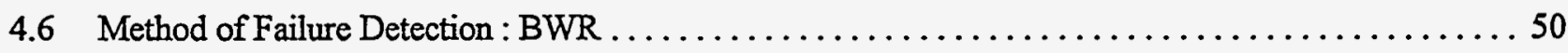

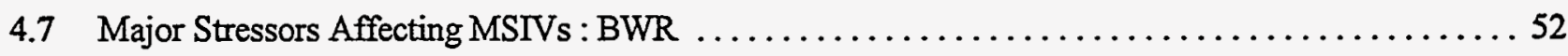

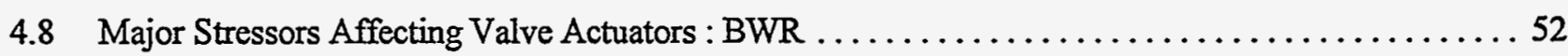




\section{Contents}

Page

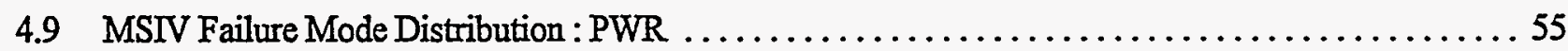

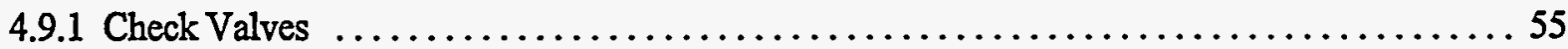

4.9 .2 Globe Valves .................................................... 55

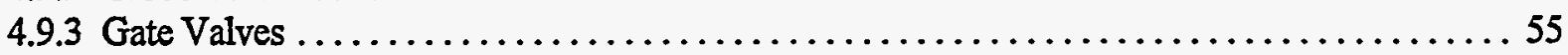

4.10 Cross Correlation of Valve Failure Modes and Valve Failure Areas : PWR ............ 55

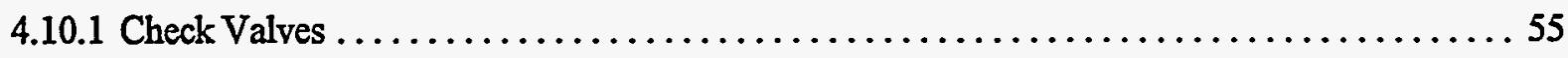

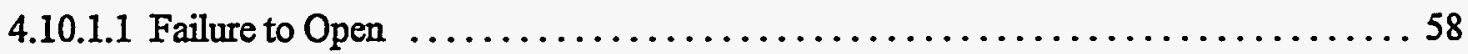

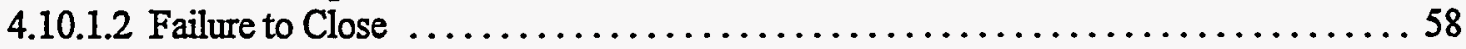

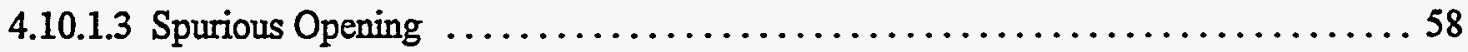

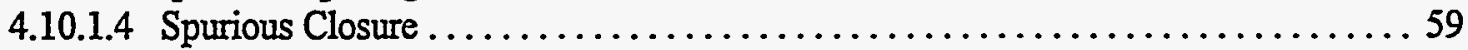

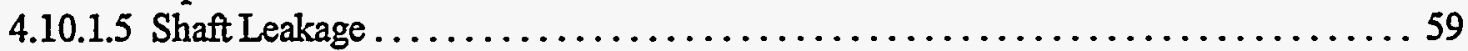

4.10.1.6 Body-to-Bonnet Leakage . ............................ 59

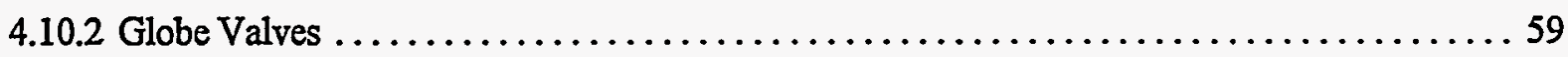

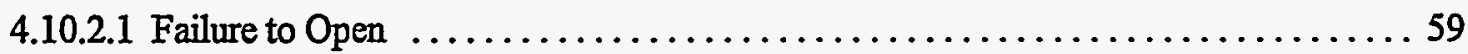

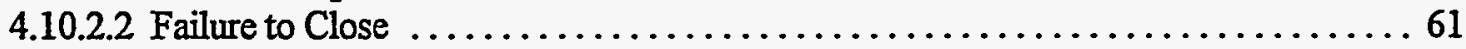

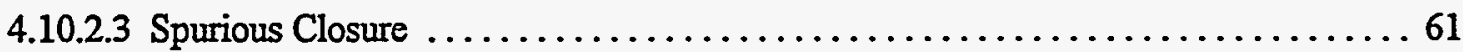

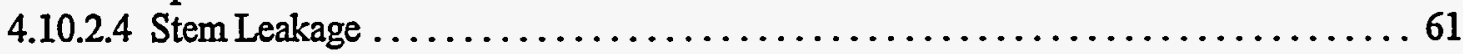

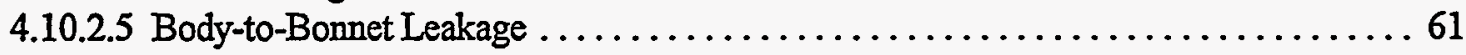

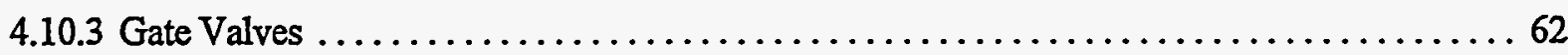

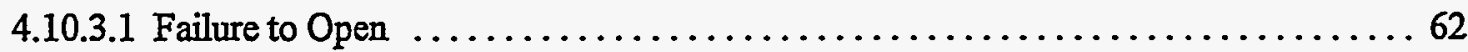

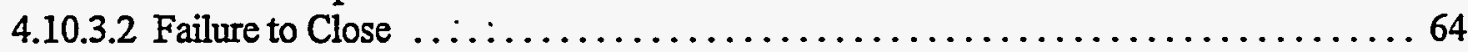

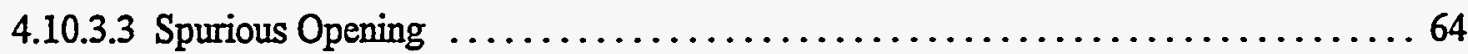

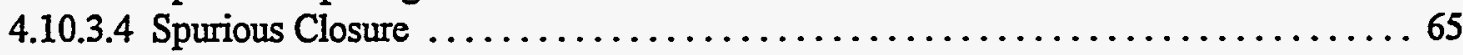

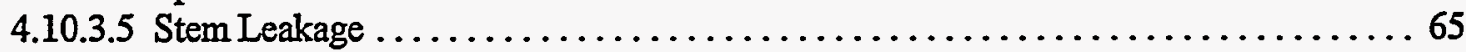

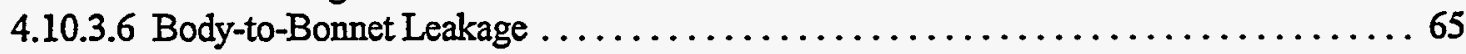

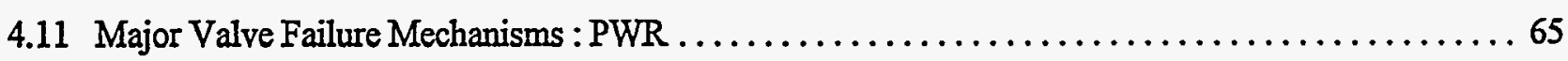

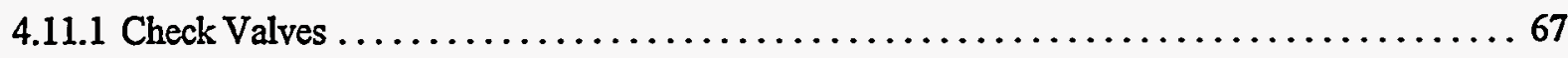

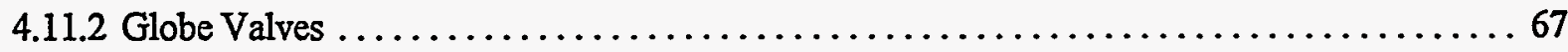

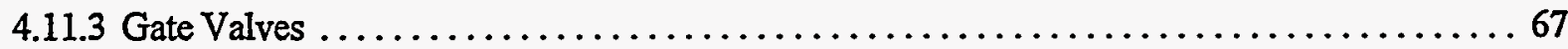

4.12 Major Valve Actuator Failure Modes : PWR $\ldots \ldots \ldots \ldots \ldots \ldots \ldots \ldots \ldots \ldots \ldots \ldots \ldots \ldots \ldots \ldots \ldots \ldots$

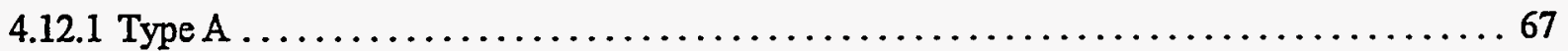

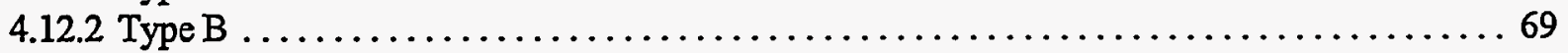

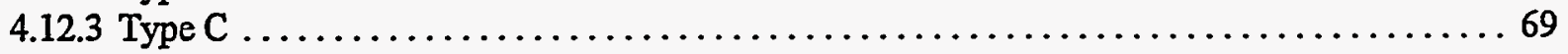




\section{Contents}

Page

4.13 MSIV Failure Consequences on Plant Operations : PWR .................... 70

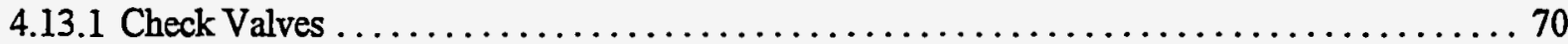

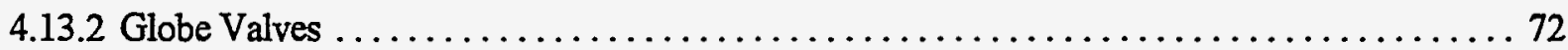

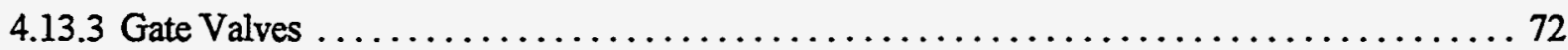

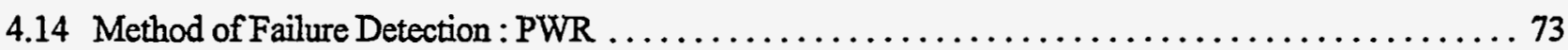

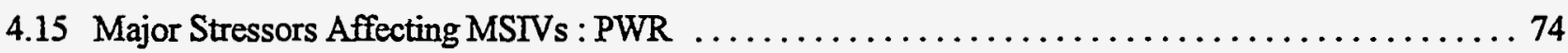

4.16 Major Stressors Affecting Valve Actuators : PWR $\ldots \ldots \ldots \ldots \ldots \ldots \ldots \ldots \ldots \ldots \ldots \ldots$

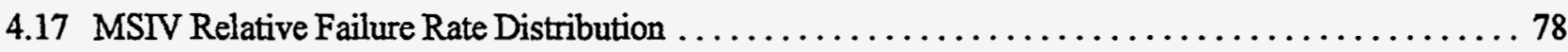

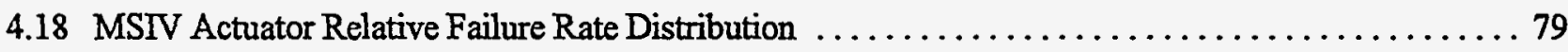

5 Main Steam Isolation Valve Surveillance Requirements $\ldots \ldots \ldots \ldots \ldots \ldots \ldots \ldots \ldots \ldots \ldots \ldots$

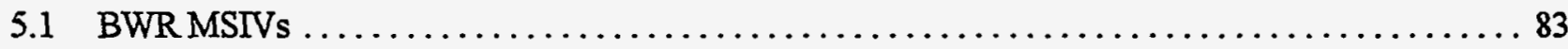

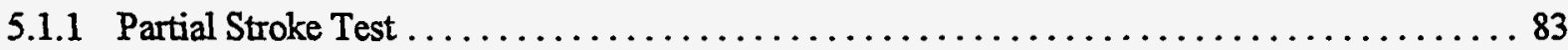

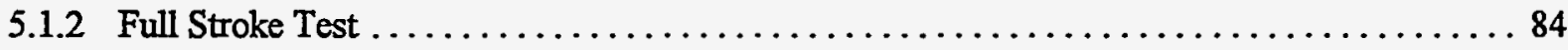

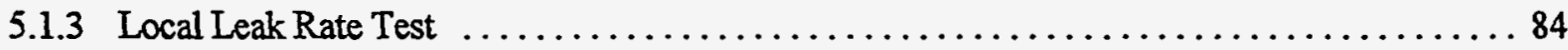

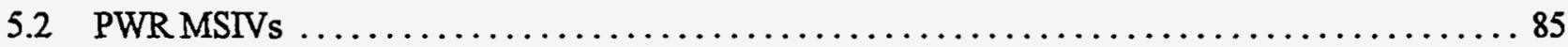

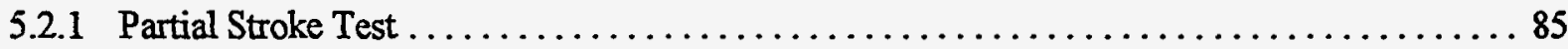

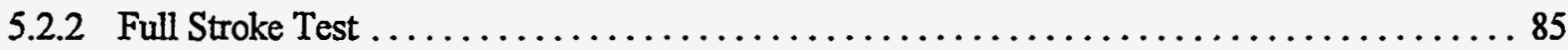

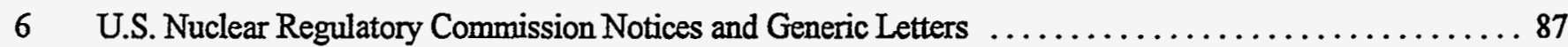

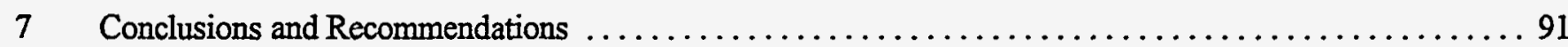

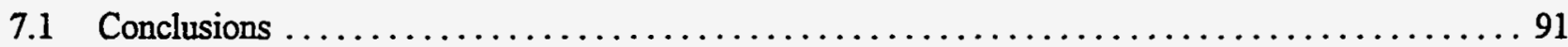

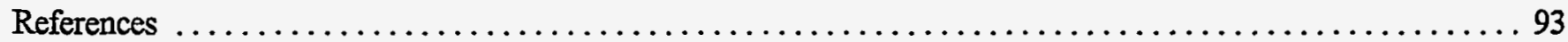




\section{Figures}

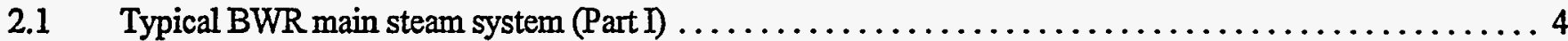

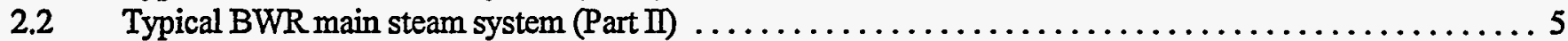

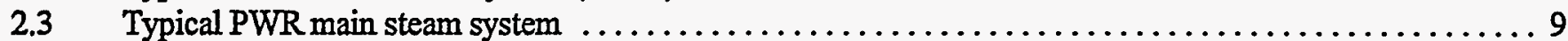

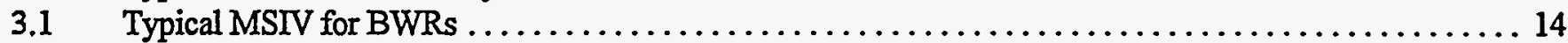

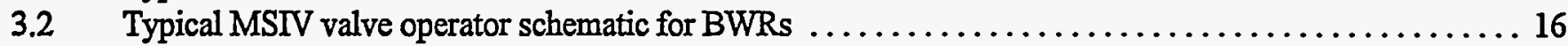

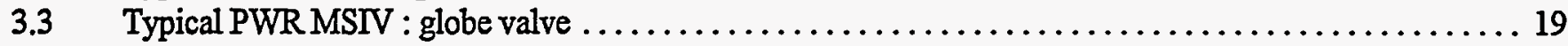

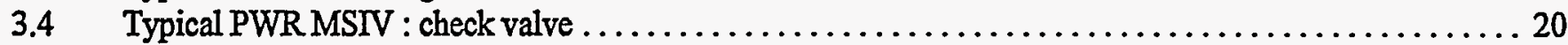

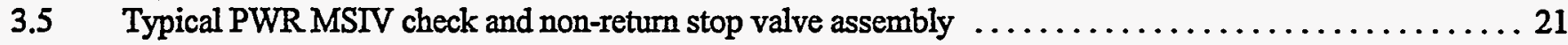

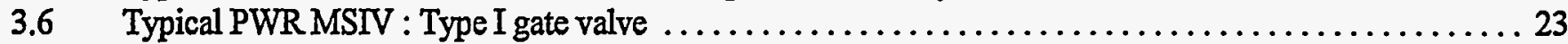

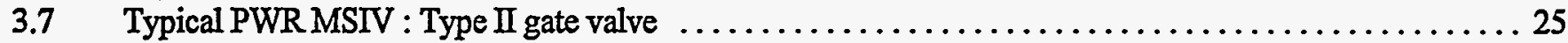

3.8 Typical PWR valve operator schematic for MSIVs using globe and check valves $\ldots \ldots \ldots \ldots \ldots \ldots 26$

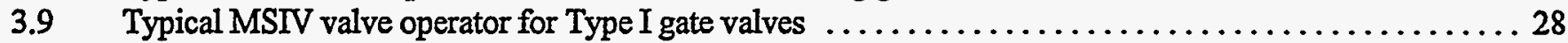

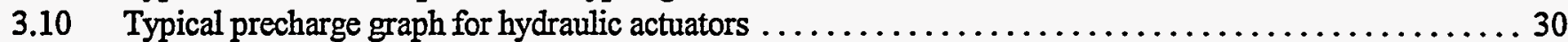

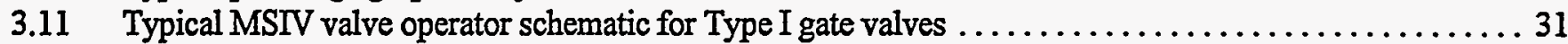

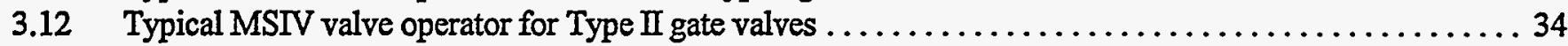

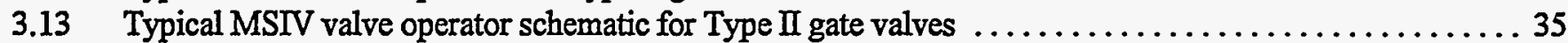

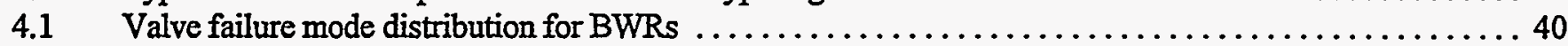

4.2 Cross correlation of MSIV failure mode and failure area for BWRs $\ldots \ldots \ldots \ldots \ldots \ldots \ldots \ldots \ldots \ldots \ldots$

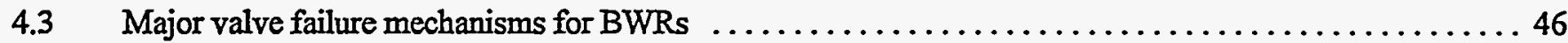

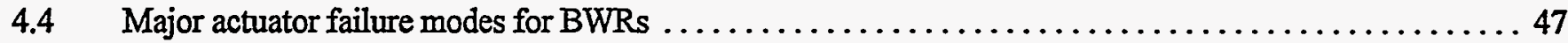

4.5 Distribution of MSIV failure consequences on plant operations : BWR $\ldots \ldots \ldots \ldots \ldots \ldots \ldots \ldots$

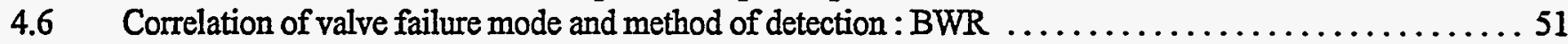

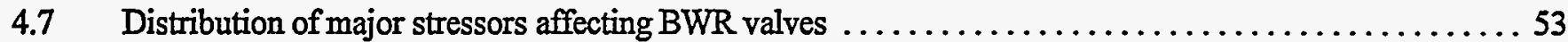

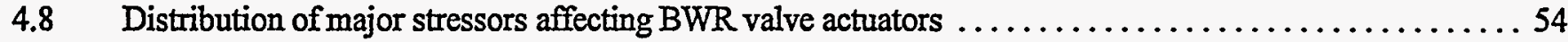

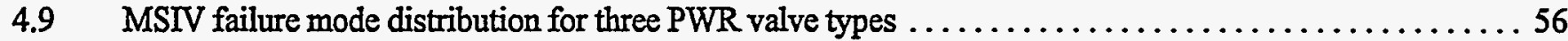

4.10A Correlation of check valve failure modes and failure area $:$ PWR $\ldots \ldots \ldots \ldots \ldots \ldots \ldots \ldots \ldots \ldots \ldots \ldots$

4.10B Correlation of globe valve failure modes and failure area $:$ PWR $\ldots \ldots \ldots \ldots \ldots \ldots \ldots \ldots \ldots \ldots \ldots$

4.10C Correlation of gate valve failure modes and failure area $:$ PWR $\ldots \ldots \ldots \ldots \ldots \ldots \ldots \ldots \ldots \ldots \ldots \ldots$

4.11 Distribution of MSIV failure mechanisms for three PWR valve types $\ldots \ldots \ldots \ldots \ldots \ldots \ldots \ldots \ldots \ldots 6$

4.12 Failure mode distribution for three major valve actuator types $: P W R \ldots \ldots \ldots \ldots \ldots \ldots \ldots \ldots \ldots 6$

4.13 Distribution of MSIV failure consequences on plant operations : $P W R \ldots \ldots \ldots \ldots \ldots \ldots \ldots \ldots \ldots$

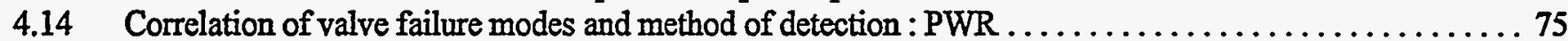

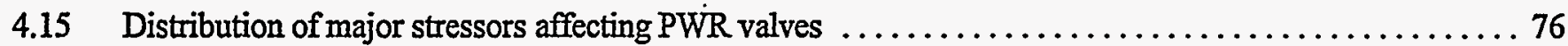

4.16 Distribution of major stressors affecting PWR valve actuators $\ldots \ldots \ldots \ldots \ldots \ldots \ldots \ldots \ldots \ldots \ldots 77$

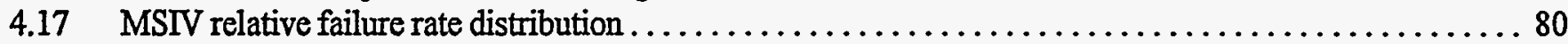

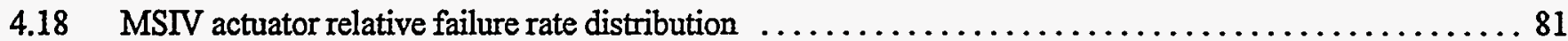




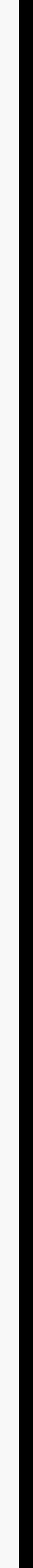




\section{Acknowledgments}

The author thanks the following Oak Ridge National Laboratory staff, without whom the study could not have been completed: Donald A. Casada and Daniel G. O'Connor, for technical guidance and recommendations; Nathan L. Wood for meticulous review of the initial characterizations; Daryl F. Cox, for data acquisition support; Judy C. Neely and Cindy H. Johnson, for graphics; Ronald $H$. Thornton, for general information on main steam isolation valve (MSIV) surveillance testing; and Debbie S. Queener, for research and summarization of U.S. Nuclear Regulatory Commission notices, letters, and bulletins associated with MSIVs. 


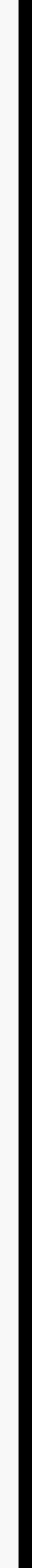




\section{Acronyms and Initialisms}

$\begin{array}{ll}\text { ADS } & \text { Automatic Depressurization System } \\ \text { AO } & \text { air operator } \\ \text { ASME } & \text { American Society of Mechanical Engineers } \\ \text { ATWS } & \text { Anticipated Transient Without Scram } \\ \text { BWR } & \text { boiling-water reactor } \\ \text { CIV } & \text { combined intermediate valve } \\ \text { CSV } & \text { code safety valve } \\ \text { CV } & \text { control valve } \\ \text { D/W } & \text { demineralized water } \\ \text { DBA } & \text { Design Basis Accident } \\ \text { dc } & \text { direct current } \\ \text { DD } & \text { double disc } \\ \text { ESF } & \text { engineered safety feature } \\ \text { ESFAS } & \text { Engineered Safety Feature Actuation System } \\ \text { EHC } & \text { electro-hydraulic control } \\ \text { FE } & \text { flow element } \\ \text { FVC } & \text { fast valve closure } \\ \text { FWCS } & \text { Feedwater Control System } \\ \text { ISI } & \text { Inservice Inspection (Plan) } \\ \text { LCO } & \text { Limiting Condition of Operation } \\ \text { LLR } & \text { Local Leak Rate (Test) } \\ \text { LT } & \text { level transmitter } \\ \text { MA } & \text { manual auto } \\ \text { MO } & \text { motor operator } \\ \text { MSIV } & \text { main steam isolation valve } \\ \text { NPRDS } & \text { Nuclear Plant Reliability Data System } \\ \text { NRC } & \text { U.S. Nuclear Regulatory Commission } \\ \text { NSSS } & \text { Nuclear Steam Supply System } \\ \text { NSSSS } & \text { Nuclear Steam Supply Shutoff System } \\ \text { ORNL } & \text { Oak Ridge National Laboratory } \\ \text { PCV } & \text { Pressure control valve } \\ \text { PST } & \text { Partial Stroke Test } \\ \text { PT } & \text { pressure transmitter } \\ \text { PORV } & \text { power-operated relief valve } \\ \text { PWR } & \text { pressurized-water reactor } \\ \text { RCIC } & \text { reactor core isolation cooling } \\ \text { RCS } & \text { Reactor Coolant System } \\ \text { RFPT } & \text { reactor feed pump turbine } \\ \text { RHR } & \text { Residual Heat Removal (System) } \\ \text { SG } & \text { steam generator } \\ \text { SI } & \text { safety injection } \\ \text { SJAE } & \text { steam jet air ejector } \\ \text { SRV } & \text { safety relief valve } \\ \text { STS } & \text { Standard Technical Specification } \\ \text { SV } & \text { stop valve } \\ \text { TS } & \text { Technical Specification } \\ \text { T } & \text { average temperature } \\ & \end{array}$




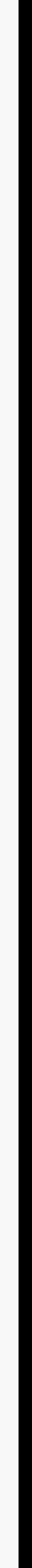




\section{Introduction}

Under the sponsorship of the U.S. Nuclear Regulatory Commission's (NRC's) Nuclear Plant Aging Research Program, Oak Ridge National Laboratory staff have conducted a review of historical main steam isolation valve (MSIV) failure data for both boiling-water reactors (BWRs) and pressurized-water reactors (PWRs). Failure records from the Nuclear Plant Reliability Data System database were reviewed and characterized. This report evaluates agerelated degradation associated with MSIVs by focusing on MSIV failure modes, actuator failure modes, consequences of failure on plant operations, method of failure detection, and major stressors affecting both valves and valve operators.

Because this study covers MSIVs used on both BWRs and PWRs, Section 2 gives a brief description of a typical main steam system for both reactor types. This information provides the reader with an overall perspective of how the MSIVs function within the main steam system.

Section 3 provides a general description of the various types of valves used for MSIV applications. BWRs use globe valves exclusively, whereas PWRs employ check valves, globe valves, and gate valves. In addition to the different type of valves, Section 3 also describes the four basic types of valve actuators. This information is necessary for understanding of the various failure mechanisms affecting each valve and valve operator.

Section 4 describes the MSIV operating experience for both BWRs and PWRs. Covered are MSIV failure modes, valve actuator failure modes, MSIV failure consequences on plant operations, method of failure detection, major stressors affecting MSIVs, major stressors affecting valve actuators, MSIV relative failure rates, and valve actuator relative failure rates.

Section 5 provides a general description of MSIV surveillance requirements. Section 6 lists pertinent NRC notices and generic letters. Many of the technical problems discussed in these documents are closely correlated with the MSIV operating experience described in Section 4. And Section 7 summarizes conclusions based on MSIV operating experience and provides recommendations. All age-related terminology used within this document was chosen for consistency with published data. ${ }^{1}$ 



\section{Main Steam System General Description}

Brief descriptions of typical main steam systems for boiling-water reactors (BWRs) and pressurized-water reactors (PWRs) are presented in this section. This information provides the reader with an overall perspective of how the main steam isolation valves (MSIVs) function within the main steam systems. All relevant design information was obtained from previously published documents. ${ }^{2-12}$

\subsection{Boiling Water Reactor}

The main steam system for a BWR is designed to direct and control steam flow from the reactor vessel to the main turbine and other loads and to provide over-pressure protection for the Reactor Coolant System (RCS).

As shown in Figures 2.1 and 2.2, four steam lines originating from the reactor vessel penetrate the drywell and containment via guard pipes to the auxiliary building. The guard pipes, which are an integral part of containment, are designed to vent high-energy steam to containment in the event of a pipe break between the inboard and outboard MSIVs. This design feature is intended to prevent steam blowdown within the reactor shield building. Whether a plant (BWR or PWR) has guard pipes depends on when it was built and the plant's particular pipe break rules. Within the auxiliary building the main steam lines are routed through the steam tunnel to a pressure-equalizing header in the turbine building. The steam tunnel provides radiation shielding and protects safety-related equipment located in the auxiliary building from the effects of a potential pipe break. From the pressure-equalizing header steam is then routed to the main turbine and a number of auxiliary support systems. Each steam line has an inboard and outboard MSIV. The inboard MSIVs are located in the drywell; the outboard MSIVs, in the steam tunnel. The safety-related portion of the main steam system extends from the reactor vessel to the outboard MSIVs.

Penetrations in the " $\mathrm{A}$ " main steam line are used to provide continuous venting of the reactor vessel head during reactor operation and to provide steam supply to the Reactor Core Isolation Cooling (RCIC) System and the Residual Heat Removal (RHR) Systems. Continuous venting to the main condenser is necessary to remove noncondensible gases, including free hydrogen and oxygen generated by the radiolytic decomposition of water, from the reactor vessel head.

A drain network for collecting low-point drains at various locations throughout the main steam system is provided. This drain network is used not only to drain condensate from the main steam lines but may also be used to equalize pressure around closed MSIVs to facilitate valve opening.

The main steam system contains three components that are engineered safety features (ESFs): the MSIVs, the main steam line flow restrictors, and the safety/relief valves. Brief descriptions of these components and others are given in the following subsections.

\subsubsection{Major Components}

Brief descriptions of the major components of the main steam system follow. A more detailed description of a typical MSIV is given in Section 3.1.

\subsubsection{Elbow Flow Taps}

Located in each main steam line just outside the reactor vessel is a steam flow elbow tap. The elbow taps provide steam flow signals for use by the Feedwater Control System. The flow elements (FEs) measure not only flow to the turbine but also any steam flow going through any of the SRVs. 
卆

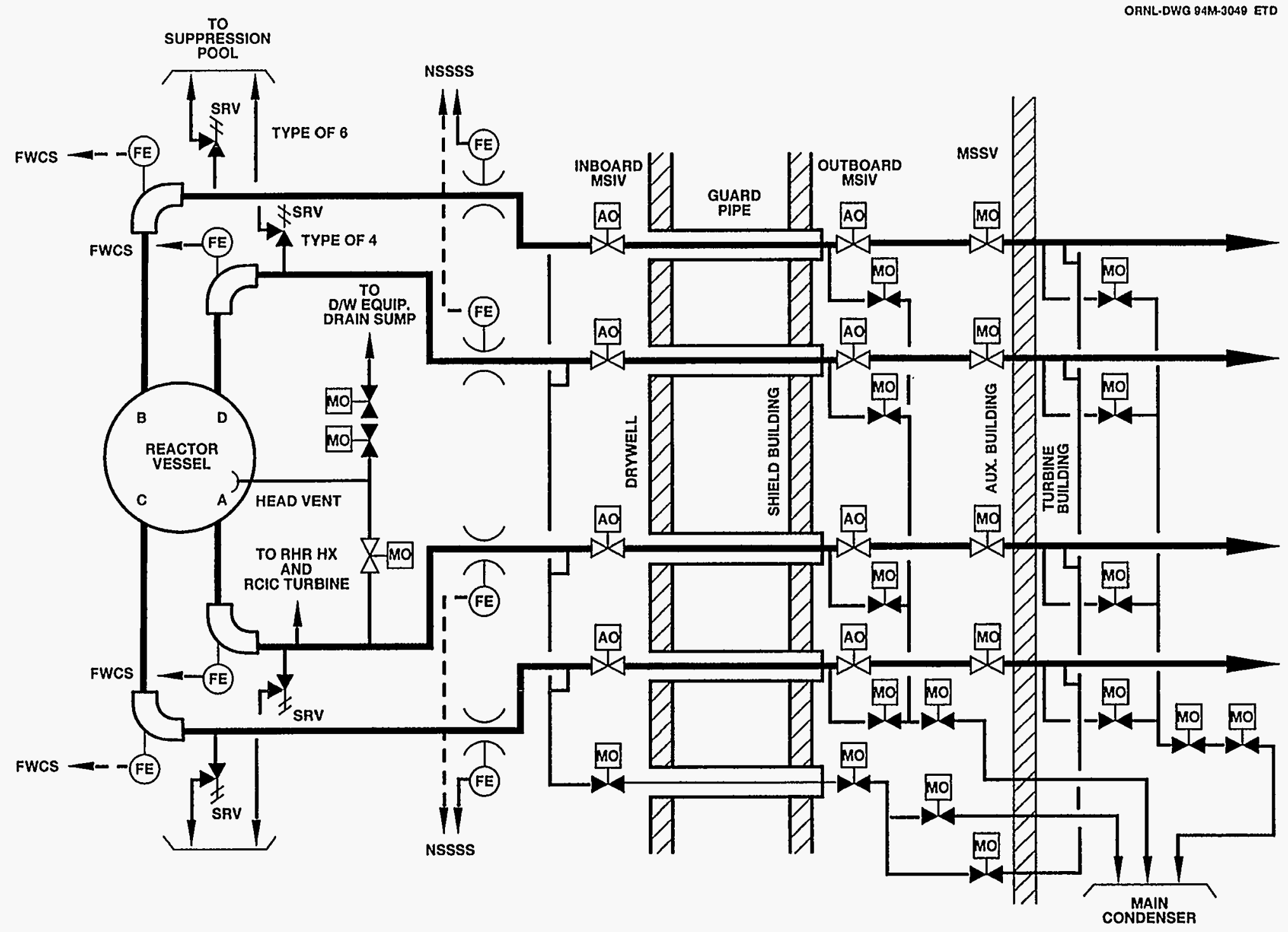

禺

Figure 2.1 Typical BWR main steam system (Part I) 


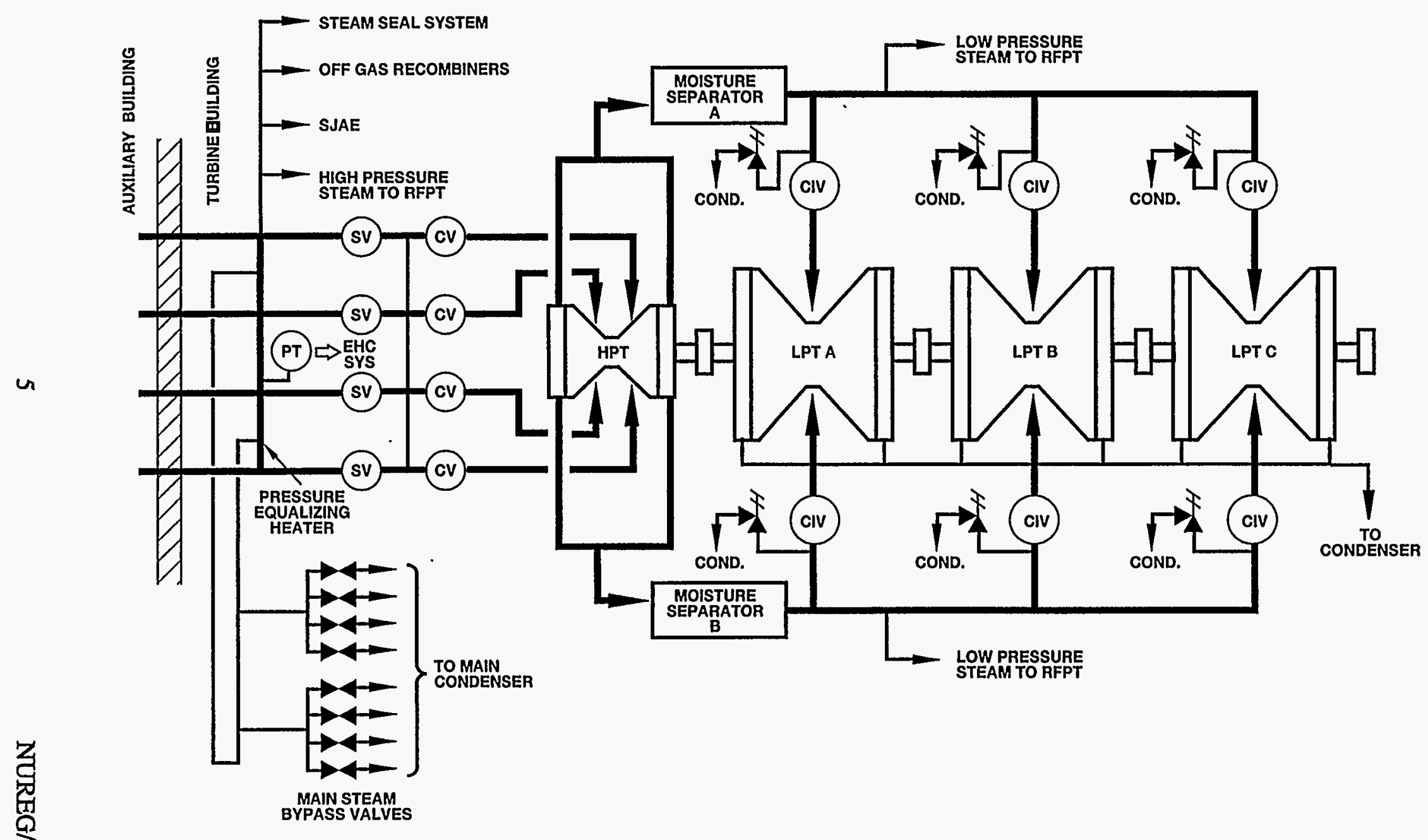

Figure 2.2 Typical BWR main steam system (Part II) 


\section{General Description}

\subsubsection{Safety/Relief Valves}

The SRVs are located on the main steam lines between the reactor vessel and the inboard MSIVs. The valves are mounted on a horizonal run of the main steam lines within the drywell; this simplifies vessel head removal and makes the SRVs readily accessible during reactor shutdowns. A typical plant has approximately nineteen SRVs, each having a capacity of 895,000 to $971,000 \mathrm{lb} / \mathrm{hr}$.

All SRVs provide over-pressure protection for the RCS by opening when required to discharge reactor steam to the suppression pool. The suppression pool condenses the steam and lowers reactor pressure. Eight of the nineteen SRVs are part of the Automatic Depressurization System (ADS). The SRVs can operate in four different modes:

- relief mode (pressure switch actuation)

- safety mode (self actuation)

- remote manual mode (control switch actuation)

- ADS mode (ADS logic actuation)

All SRVs can operate using any of the first three modes, while the last mode is provided only on SRVs that are part of the ADS.

The relief, remote manual, and ADS modes all use pneumatic actuators to open and spring force to close the SRVs. The safety mode is strictly self actuating (i.e., RCS pressure is used to open, and spring force is used to close the SRVs).

\subsubsection{Main Steam Line Flow Restrictors}

A flow restrictor is located on each main steam line inside containment to limit the loss of mass inventory from the reactor vessel in the event of a steam line break. The restrictors are located as close as possible to the reactor vessel to minimize the potential for a steam line break upstream of the restrictor.

The flow restrictors are designed to limit blowdown to less than $200 \%$ of rated steam line flow and to limit the resulting thrust forces on the main steam system piping. The flow restrictors are also used to develop steam flow signals for use in the Nuclear Steam Supply Shutoff System (NSSSS).

\subsubsection{Main Steam Bypass Valves}

The main steam bypass valves and their associated control circuits are non-safety-related. The bypass valves are used to bypass up to $35 \%$ of rated steam flow directly to the main condenser whenever a power mismatch occurs between the reactor and the main turbine. The bypass valves work in conjunction with the turbine control valves to ensure a constant reactor pressure for a given reactor power level. Operation of the bypass valves is automatically controlled by the Electro-Hydraulic Control (EHC) System.

\subsubsection{Main Steam Isolation Valves}

The MSIVs are engineered safety features designed to limit the release of radioactive materials to the environment and to minimize reactor vessel inventory loss during a Design Basis Accident. Redundant valves are located on each main steam line: one inside the drywell and one in the steam tunnel in the auxiliary building. The MSIVs are air- and spring-operated valves - air to open, air and spring to close. The MSIVs are automatically closed by the NSSSS under the following conditions: 
- main steam line high radiation

- main steam tunnel high temperature

- main steam tunnel high vent duct radiation

- main steam line turbine area high temperature

- main steam line high flow

- main steam line low pressure

- main condenser low vacuum

- reactor low water level

Main steam isolation valve closure, with the reactor critical, can result in large pressure and reactor power increases. For this reason the reactor is scrammed whenever the MSIVs are closed. To minimize the pressure/power increases, and at the same time limit the release of radioactive materials to the environment, the valves are designed to close in 3 to 5 seconds.

To ensure that $10 \mathrm{CFR} \mathrm{Pt.} 100$ limits for off-site dose limits will not be exceeded in the event of a design basis accident, the MSIVs are leak-tested during each refueling outage to verify that the local leak rate for each valve does not exceed the limits specified by the plant's technical specifications.

Detailed descriptions of the MSIV and valve operator are given in Subsection 3.1.

\subsubsection{Main Turbine Stop and Control Valves}

Four turbine stop valves (SVs) are located in the main steam piping just upstream of the turbine control valves (CVs). The SVs provide rapid closure upon detection of potentially unsafe turbine conditions, and the CVs regulate the steam flow to meet the load demand as determined by the EHC. During plant operations the CVs also provide the control mechanism for rolling, synchronizing, and loading the turbo-generator. The hydraulically operated turbine SVs and CVs can be tripped closed within 0.1 and 0.2 seconds respectively. Because of the large pressure and neutron flux spikes created by SV and CV fast closure, the reactor is automatically scrammed if either valve closes with reactor power above the capacity of the bypass.

\subsubsection{Main Turbine}

The main turbine is an $1800 \mathrm{rpm}$, tandem compound machine consisting of one high-pressure turbine and three lowpressure turbines. The steam enters the middle of the high-pressure section and works its way toward each end, dissipating its energy to the turbine blades which are attached to a common shaft. Steam exiting the high-pressure turbine passes through moisture separators where entrained moisture, which could damage the turbine blades, is removed prior to entering the low-pressure turbines.

Prior to entering the low-pressure turbines, the steam passes through the low-pressure turbine SVs and CVs, called combined intermediate valves (CIVs). The CIVs are actually two valves in one housing. The CVs provide throttling to prevent turbine overspeed caused by rapid reduction in generator load. Designed to be fully open or fully closed, and the SVs provide a rapid means of isolating the low-pressure turbines from their steam supply when necessary.

At different stages on the low-pressure turbine are taps for extracting steam. This steam is used to preheat the feedwater going back to the reactor vessel. The low-pressure turbine exhaust is directed to the condenser where it is condensed and deaerated and then collected in a hotwell to be pumped by the Condensate and Feedwater System to the reactor vessel. 


\subsubsection{Auxiliary Steam Loads}

The main steam system supplies steam to a number of auxiliary loads including the following:

- steam jet air ejectors

- Gland Seal System

- Off-Gas System

- reactor feed pump turbines

- the RCIC System

- the RHR System

\subsection{Pressurized Water Reactor}

The main steam system for a PWR is designed to direct and control steam flow from the steam generators (SG) to the main turbine and other auxiliary loads. The system is designed to provide over-pressure protection for the SGs and to ensure that a heat sink (atmosphere or condenser) is available to the RCS.

As shown in Figure 2.3, dry saturated steam exits the SGs through individual main steam lines. The steam lines penetrate containment via mechanical penetrations and are routed through the valve vault to a pressure-equalizing header in the turbine building. From the pressure-equalizing header, steam is routed to the main turbine and a number of auxiliary support systems. The steam lines are sized to limit the pressure difference between SGs to a maximum of 10 psid which maintains system balance and ensures uniform heat removal from the RCS.

The valve vault houses the SG power-operated relief valves (PORVs), the code safety valves (CSVs), the MSIVs, the MSIV bypass valves, and for some plants, the main steam line nonreturn check valves. As with the steam tunnel in the BWR design, the valve vault provides equipment protection from the effects of a potential pipe break for equipment located in the auxiliary buildings.

The safety-related portions of the main steam system extend from the SGs to the MSIVs and include the main steam isolation check valves if installed. As is the case with the BWR design, the main steam systems for PWRs also contain engineered safety features: the MSIV, the main steam line flow restrictors, the SG PORVs, the SG CSVs, and for some plants, the main steam line nonreturn check valves. Brief descriptions of these components and others follow.

\subsubsection{Major Components}

Brief descriptions of the major components of the main steam system for PWRs are given in the following subsections. More detailed descriptions of MSIVs for PWRs are given in Subsection 3.2.

\subsubsection{Main Steam Line Flow Restrictors}

A flow restrictor is located in each main steam line inside containment to limit flow in the event of a steam line break. Limiting the steam flow rate minimizes the core cooldown rate which reduces the reactivity excursion and the probability of fuel damage. The restrictor will also limit the resulting thrust forces on the main steam lines. The restrictors are located as close as possible to the SGs to minimize the potential for a steam line break upstream of the restrictor. On later designs the restrictor is incorporated in the outlet nozzle of the SG. In both designs the differential pressure developed across the restrictor is utilized as an indication of steam flow for use by the feedwater control and the Reactor Protection System. 
General Description

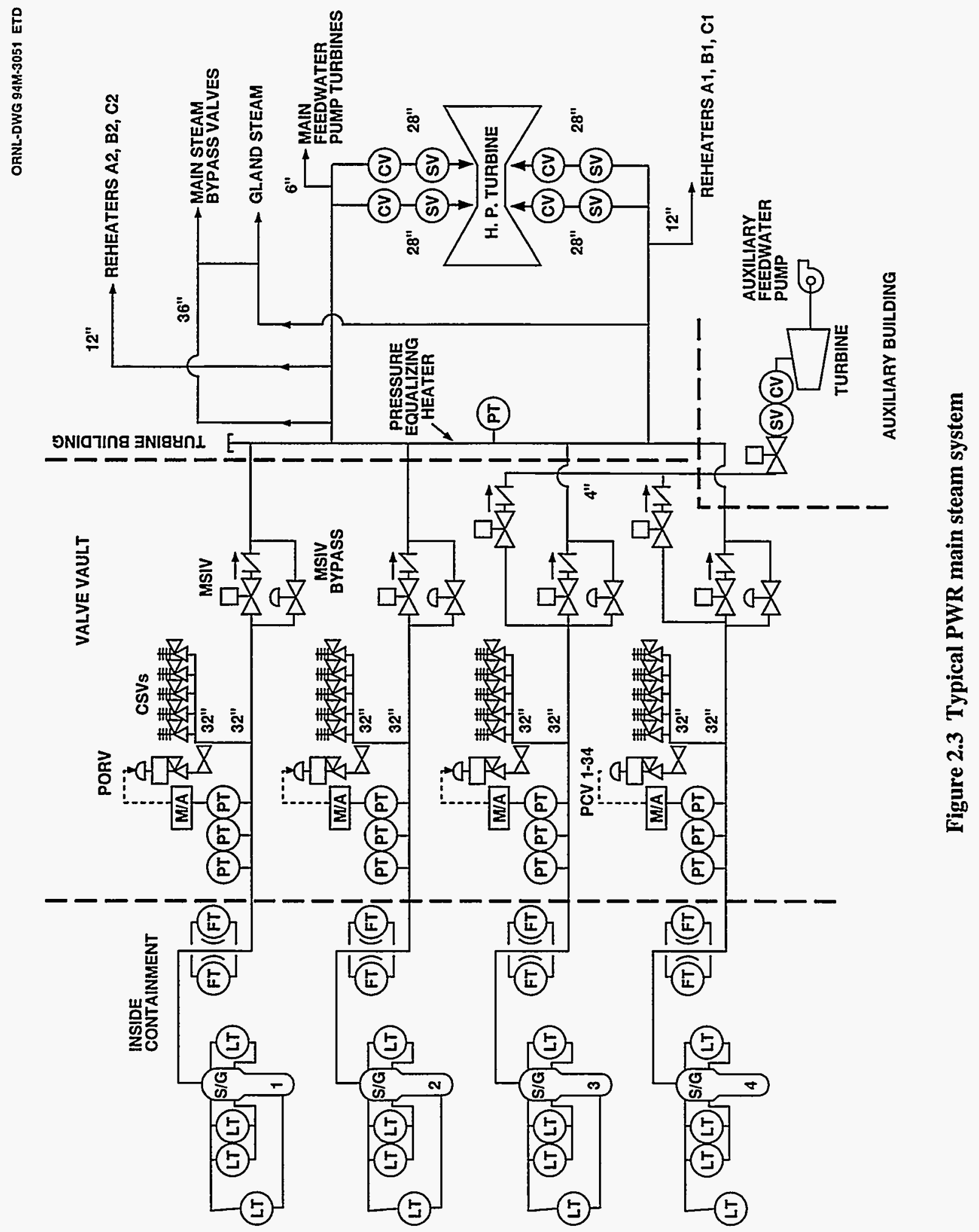




\section{General Description}

\subsubsection{Steam Generator Code Safety Valves}

Each SG is supplied with five CSVs located upstream of the MSIVs to provide over-pressure protection. The five valves have a combined flow capacity of $3.917 \times 10^{6} \mathrm{lb} / \mathrm{hr}$, or $110 \%$ of design steam flow for that generator. The pressure set point of each of the five CSVs is set at different set points to limit the perturbation to the main steam system on increasing steam pressure transient. Accident analysis for a steam system valve failure is predicated on a maximum steam flow rate. Typically, this flow rate is 890,000 to $950,000 \mathrm{lb} / \mathrm{hr}$ at $1085 \mathrm{psig}$. In this case five valves are used instead of one on each steam line to ensure that the accident design flow rate is not exceeded in the event that one valve sticks fully open.

\subsubsection{Power-Operated Relief Valves}

Provisions must be made for removal of heat from the Nuclear Steam Supply System (NSSS) during periods when the main heat sink (i.e., condenser) is not available. To meet this requirement, a PORV is installed on each steam line upstream of the MSIVs. The PORVs are designed to regulate SG pressure at the no-load condition following a plant trip coincident with loss of condenser. Both the steam dump valves and the PORVs prevent operation of the SG CSVs during normal operating transients.

The minimum total relieving capacity of the PORVs must be $10 \%$ of the total steam flow used for plant design at noload steam pressure. The maximum flow rate through any one valve must not exceed the flow rate assumed in the accident analysis.

The SG PORVs are essential for mitigating SG tube rupture events. The PORVs are used during RCS cooldown and depressurization to minimize reactor coolant leakage to the ruptured SG by balancing RCS and SG pressure.

\subsubsection{Main Steam Isolation Valves}

The MSIVs are engineered safety features designed to limit the consequences of a steam line break. In the event of a steam line break inside containment, the MSIVs must close within 5 seconds to isolate the reverse steam flow from the intact $S G$ to limit containment pressure below its design limits. The reverse steam flow is the result of the intact $S G$ 's feeding the steam line break through the pressure-equalizing header located in the turbine building. The containment is designed to accommodate only one SG blowdown.

The MSIVs are automatically closed by the Engineered Safety Feature Actuation System (ESFAS). For many plants the ESFAS signals used to generate main steam isolation signals are:

- high steam line flow coincident with low average RCS temperature $\left(T_{\text {ave }}\right)$ or low steam header pressure

- high containment pressure

For other plants the ESFAS signals are:

- high negative steam header pressure rate

- low steam header pressure

- high containment pressure

Detailed descriptions of the various MSIVs and valve operators used in PWRs are given in Subsection 3.2. 


\subsubsection{Main Steam Line Nonreturn Check Valves}

Main steam line nonreturn check valves are used on some PWRs to prevent reverse flow in the event of a main steam line break upstream of the MSIV (see Subsection 2.2.1.6).

\subsubsection{Main Steam Isolation Bypass Valves}

These air-operated valves are used to decrease the pressure differential across the MSIVs and nonreturn check valves during main steam line warm-up to allow opening of the MSIVs.

\subsubsection{Main Steam Bypass Valves}

The main steam bypass valves for PWRs perform the same basic function as those performed by BWRs (i.e., the bypass valves dump steam to the main condenser whenever a power mismatch occurs between the reactor and the main turbine).

\subsubsection{Main Turbine Stop and Control Valves}

The main turbine SVs and CVs for PWRs perform the same basic functions as those used on BWRs. The SVs provide rapid closure upon detection of potentially unsafe turbine conditions; the CVs regulate steam flow to meet the load demand as controlled by the EHC System. A turbine trip during normal operations results in a large power mismatch between the reactor and the main turbine. To avoid unnecessary RCS thermal stresses and challenges to other ESFs, the reactor is automatically scrammed if reactor power is above the capacity of the bypass valves.

\subsubsection{Main Turbine}

The main turbine for PWRs is essentially the same as those used for BWRs (see Subsection 2.2.1.8).

\subsubsection{Auxiliary Steam Loads}

As with BWRs, the main steam systems for PWRs supply steam flow to a number of auxiliary loads including the following:

- auxiliary feedwater pump turbines

- main feedwater pump turbines

- the Gland Seal Steam System

- moisture separator reheaters 


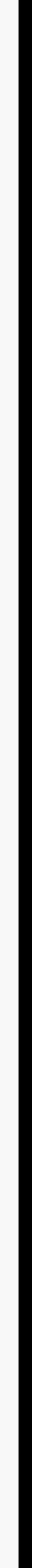




\section{Main Steam Isolation Valve and Valve Operator Descriptions}

General descriptions of typical main steam isolation valves (MSIVs) and valve operators for both boiling-water reactors (BWRs) and pressurized-water reactors (PWRs) are given. All relevant design information was obtained from previously published documents. ${ }^{13-16}$

\subsection{BWR MSIV}

A typical MSIV is depicted in Figure 3.1. For most BWR applications the valve is a Y-pattern, 26-inch globe valve connected to matching 26 -inch, schedule 80 pipe. The valve is designed for saturated steam flow of approximately $3.51 \times 10^{6} \mathrm{lb} / \mathrm{hr}$ at $1000 \mathrm{psig}$ with a moisture content of approximately $0.23 \%$, an oxygen content of $30 \mathrm{ppm}$, and a hydrogen content of $4 \mathrm{ppm}$.

The main disc or poppet is attached to the lower end of the stem and moves in guides at a 45-degree angle from the inlet pipe. Normal steam flow tends to close the valve, and higher inlet pressure tends to hold the valve closed. The bottom end of the valve stem is used to open and close a small pressure-balancing port in the center of the poppet. When the valve stem lifts, the assembly acts as a pilot valve to relieve the pressure differential on the poppet; this reduces the valve operator force required to open the valve. The valve stroke for a 26 -inch valve has an approximately 10-inch stem travel; the main disc travels 9 inches, and the last 1 inch closes the pilot valve. A helical spring between the stem and the poppet keeps the pilot valve open when the main poppet is off its seat, but failure of the spring will not prevent closure of the valve. The valve operator can open the poppet with a maximum of $200 \mathrm{psi}$ differential pressure across the isolation valve in a direction tending to hold the valve closed.

The diameter of the poppet seat is approximately the same as the inside diameter of the pipe, and the 45-degree angle permits lining of the inlet and outlet passage to minimize pressure drop during normal steam flow and to avoid blockage by debris. The pressure drop at rated flow is $6 \mathrm{psi}$ or less. The valve stem penetrates the valve bonnet through a stuffing box with replaceable packing. The valve backseats in the fully open position to minimize leakage through the stem packing. The bonnet has provisions for seal welding if required.

Four large yoke rods are screwed and pinned into the valve bonnet to support the valve operator and to contain the helical springs which provide the motive force for valve closure. The springs are attached to the upper and lower spring seats. The lower spring seat is designed to slide up and down the yoke rods. As the valve is open, the lower spring seat rises and compresses the springs between the upper and lower spring seats. Yoke rod guides are provided as part of the valve seismic qualification to minimize lateral movement of the lower spring seat. The guides are brass bolts that screw into the sides of the lower spring seat. The bolts are aligned to the center line of the holes on the lower spring seat through which the yoke rods pass. Four guides prevent deflection of the lower spring seat along the axis of the main steam line, and two guides prevent deflection along the axis perpendicular to the main steam line. In addition to the yoke rod guides, spring guides are also provided to prevent scoring the yoke rods during normal operation and to prevent binding if a spring breaks.

If a main steam line break occurs downstream of the MSIV, the steam flow will quickly increase to no more than $200 \%$ of rated flow due to the effect of the flow restrictor located upstream of the valve. Note that because the flow is choked by the venturi, the valves can be stroked to the $25 \%$ opening position during full power operations with little or no effect on the flow rate. For this reason, no system perturbation should be evident whenever the valves are stroked $10 \%$ closed during surveillance testing. ${ }^{17}$ 
Operator Descriptions

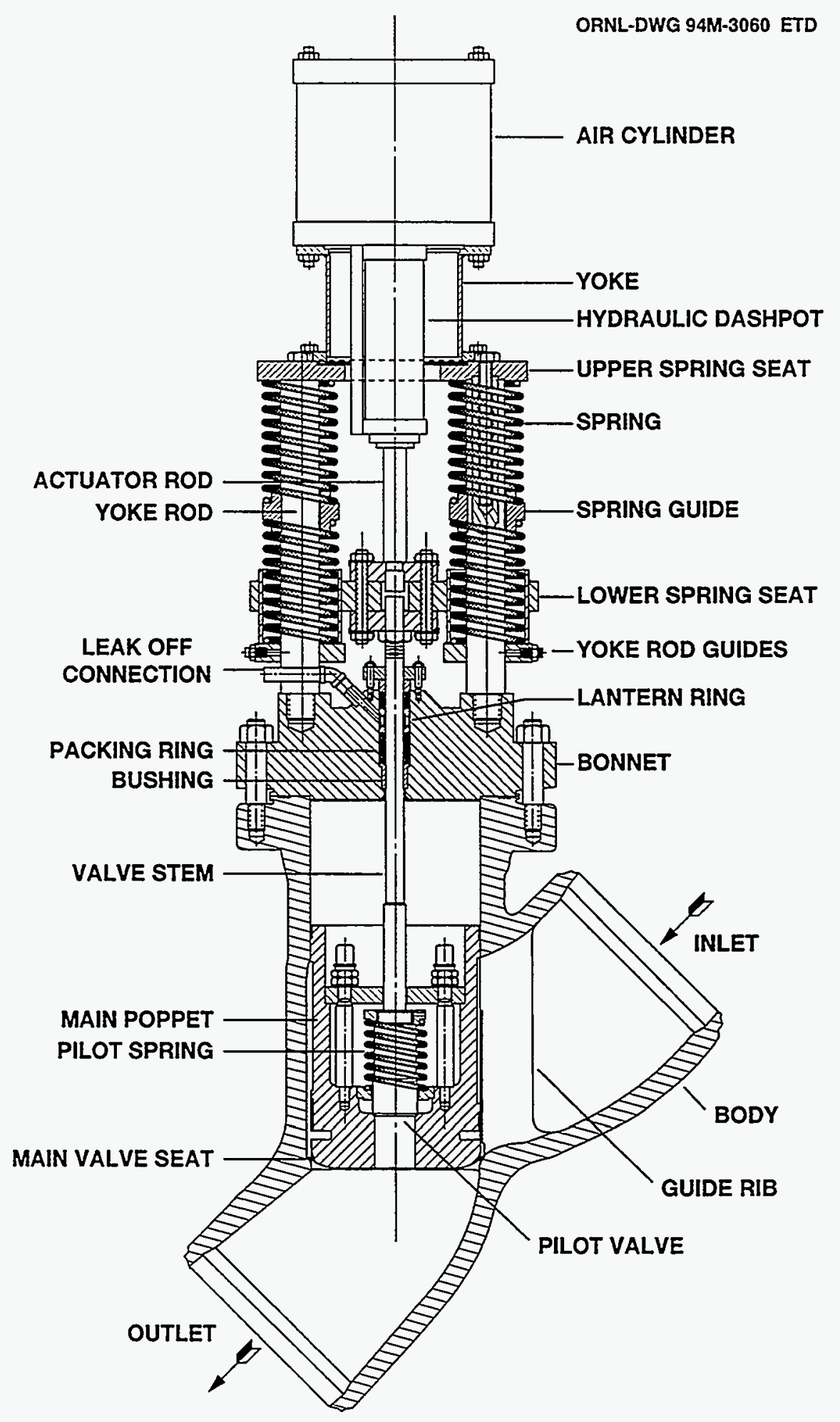

Figure 3.1 Typical MSIV for BWRs 


\subsection{BWR MSIV Operator}

A typical MSIV valve operator schematic for BWR application is shown in Figure 3.2. The valve operator or actuator employs four systems: electrical, pneumatic, mechanical, and hydraulic. The electrical system converts the main control room electrical signals to pneumatic signals which are then used to control the air-operated pilot valves. The air-operated pilot valves control the plant air supply to the operating cylinder (mechanical system) which opens and closes the MSIV. If required, the energy stored in the compressed valve springs when the valve was first opened is used to provide the motive force to initiate fast valve closure. The self-contained hydraulic system is used to control the valve opening and closing speed.

The electrical system consists of solenoid coils, limit switches, terminal blocks, wiring, and junction boxes. The pneumatic system consists of air-operated pilot valves, check valves, flow control valves (i.e., throttling valves), and accumulator. The mechanical system consists of the air-operating cylinder, piston, and valve spring. The hydraulic system consists of the hydraulic cylinder, piston, flow control valves, check valves, and accumulator.

The limit switches provide valve full open, $90 \%$ open, and full close indication. The limit switches are actuated by the motion of the spring seat member. The $90 \%$ open limit switches are also used to initiate reactor scram if more than one MSIV closes.

Under normal operating conditions, the valve operators are designed to operate under the following conditions:

- a temperature of $150^{\circ} \mathrm{F} \max$

- radiation of $25 \mathrm{R} / \mathrm{hr}$

- humidity of $100 \%$

\subsubsection{Electrical and Pneumatic System Components}

The plant air supply to the operating cylinder is controlled by a 4-way pilot valve (\#1) located in the pneumatic control system. Depending on its position, the 4-way pilot valve applies air pressure to either the top or bottom end of the air operating cylinder. This 4-way pilot valve is controlled by a 3 -way normally energized dual solenoid valve (\#4).

To open the MSIV, either or both of the coils on the three-way solenoid valve are energized; this feeds air pressure to the piston of the four-way pilot valve (\#1), causing it to shift its position. The 4-way pilot valve then feeds a much larger supply of air to the underside of the air-operating cylinder and at the same time exhausts air from the top end of the cylinder, causing the MSIV to open. Should either one of the coils on the 3-way solenoid valve de-energize, the air pressure will still be maintained on the piston of the 4-way pilot valve (\#1), keeping the MSIV in the open position.

To close the MSIV, both coils of the 3-way solenoid valve are de-energized; this removes the air pressure form the piston on the 4-way pilot valve (\#1), causing it to shift its position. The 4-way pilot valve then feeds air pressure to the top side of the operating cylinder and at the same time exhaust the air from the bottom side of the cylinder, causing the MSIV to close. Both air and spring are used to close the MSIV. The air is supplied from the plant air supply system (nonsafety related) and from the air accumulator (safety related). A check valve is used to isolate the air accumulator from the plant air supply system. The isolation is necessary to prevent depressurizing the air accumulator if the normal air supply is lost. 


\begin{tabular}{|l|}
\multicolumn{1}{|c|}{ LEGEND } \\
1. MAIN PILOT VALVE \\
2. EXERCISE PILOT VALVE \\
3. DUMP VALVE \\
4. MAIN SOLENOID VALVE \\
5. EXERCISE SOLENOID VALVE \\
6. CLOSING SPEED CONTROL VALVE \\
7. OPENING SPEED CONTROL VALVE \\
8. HYDRAULIC ACCUMULATOR \\
9. AIR METERING VALVE \\
\hline
\end{tabular}

$\vec{a}$
EXERCISER CONTROL SHOWN DE-ENERGIZED 115 VOLTS, $60 \mathrm{~Hz}$, A.C.

MAIN CONTROL "A" SHOWN ENERGIZED 115 VOLTS, $60 \mathrm{~Hz}$, A.C.

MAIN CONTROL. "B" SHOWN ENERGIZED 115 VOLTS, $60 \mathrm{~Hz}$, A.C.

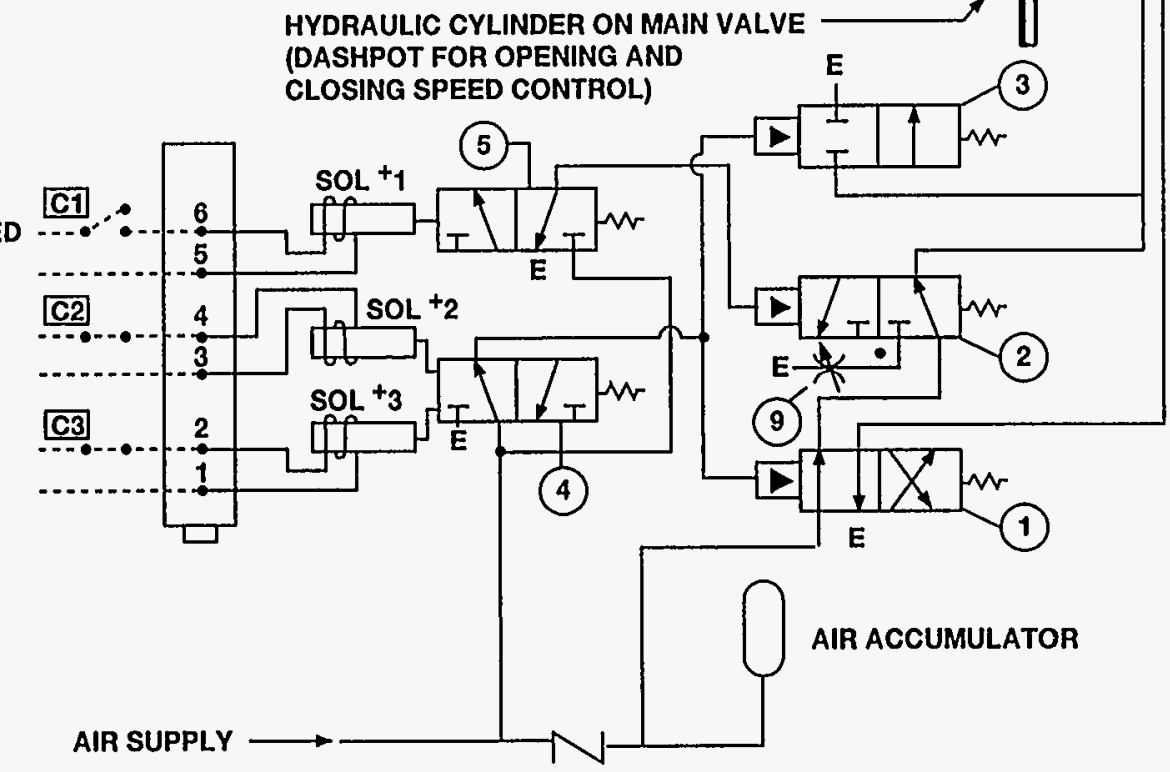

Figure 3.2 Typical MSIV valve operator schematic for BWRs 
In the event of loss of plant air supply, the air pressure applied to the piston of the 4-way pilot valve (\#1) would exhaust out through the 3-way solenoid valve (\#4) to the plant air supply line. The 4-way pilot operated valve would then shift its position and exhaust the air pressure from the underside of the operating cylinder. The force generated by the closing spring and the air stored in the accumulator will close the MSIV.

To exercise the MSIV, a 3-way solenoid valve (\#5) is energized which feeds air pressure to the piston on the 3-way pilot-exercising valve (\#2), causing it to shift its position. The air supply fed from the main 4-way pilot valve (\#1) to the underside of the operating cylinder is blocked, and the air in the cylinder is then exhausted to atmosphere through the 3-way pilot-exercising valve (\#5). When the air pressure on the underside of the air-operating cylinder decays to a point where its force can no longer overcome the force generated by the closing springs, the MSIV will start to close. A small metering valve (\#9) installed in the exhaust port of the 3-way pilot exercising valve is used to adjust the rate of valve closure. The valve closing time from $100 \%$ open to fully closed position in the exercise mode is 45 to 60 seconds. When the 3-way solenoid valve (\#5) is de-energized, it exhausts the air pressure from the piston of the pilot exercising valve, causing it to shift its position. The exhaust port of the pilot exercising valve is now blocked, and the supply port is open. This action causes the air from the main 4-way pilot valve to be fed to the underside of the operating cylinder, and the MSIV returns to its full open position.

A 2-way pilot valve (\#3), or dump valve, is installed in a tee in the air line between the underside of the operating cylinder and the normally open 3-way pilot exercising valve. This dump valve serves as an additional air exhaust valve in the pneumatic control system. This dump valve is controlled by the same dual solenoid valve (\#4) that controls the main 4-way pilot valve (\#1). When the dual solenoid valve (\#4) is energized, air pressure is fed to the piston on the dump valve (\#3), causing it to shift its position. This action causes dump valve exhaust port to close which then prevents the air pressure in the line to the underside of the air-operating cylinder from exhausting to atmosphere.

When both of the dual coils of the main 3-way solenoid valve (\#4) are de-energized, the air pressure is exhausted from the piston on the dump valve (\#3), causing it to shift its position. The air from the underside of the operating cylinder is then exhausted to atmosphere through the open dump valve (\#3), as well as through the main 4-way pilot operated valve (\#1), causing the MSIV to close.

\subsubsection{Hydraulic System Components}

As shown in Figure 3.2, the hydraulic speed control system controls the MSIV closing and opening speed by regulating the amount of hydraulic fluid flow from one side of the hydraulic cylinder piston to the other. The flow rate is manually adjusted using flow control valves and check valves.

The adjustable flow control valve (\#6) is sized so that the time to fully stroke the operator is less than 5 seconds when only spring force is applied. The range of closing speed adjustment ( 3 to 10 seconds) is accomplished with not less than two full revolutions of the adjustment spindle. The closing flow control valve (\#6) is equipped with a minimum flow position and a positive locking device.

Flow control valve (\#7) is sized so that the time to fully stroke the actuator open is set at a rate of $1 \pm 0.5$ inch per second.

The accumulator is included to accommodate the increase in fluid level due to the volumetric expansion caused by the increase in ambient temperature from that existing during filling and sealing of the hydraulic system to that existing during accident conditions. 


\subsection{PWR MSIV}

For PWR application three basic types of valves are used for main steam isolation: globe, check, and gate.

\subsubsection{Globe Valves}

The globe valves described in Subsection 3.1 for BWRs are basically the same as those found on many PWRs. However, these valves are not designed to isolate reverse steam flow. For these particular globe valves a nonreturn stop valve must be located downstream of the MSIV to prevent reverse steam flow in the event of an accidental pressure reduction in any SG or a pipe break upstream of the MSIV. To overcome this problem, several PWRs have installed bidirectional globe valves that are capable of isolating reverse steam flow. A drawing of a typical bidirectional globe valve with its operator is shown in Figure 3.3.

The ability to isolate steam flow in either direction is accomplished by a small pilot assembly located in the center of the main disk. During reverse flow conditions the small pilot assembly opens to equalize pressure above and below the main disk. With the main disk pressure balanced, the valve actuator has sufficient force to keep the valve closed for at least $1 \mathrm{hr}$ against full reverse steam pressure. This design feature allows the MSIV the capability to hold reverse pressure until a plant cooldown to below $300^{\circ} \mathrm{F}$ can be accomplished.

Note that the yoke rods for the valve shown in Figure 3.3 are not encased by the valve springs. The valve springs are mounted on stanchions located between the fixed upper spring seat and the moveable lower spring seat. The lower spring seat is designed to slide up and down the yoke rods. Stanchion guides are used to prevent deflection of the lower spring seat.

\subsubsection{Check Valves}

A drawing of a typical check valve used for MSIV application is shown in Figure 3.4. The check valves are of the swing-disk-type which use a pneumatic operator for normal valve opening and closing and valve springs for fast closure. The major valve components are the valve body, the cover, the disc, the disc arm, the shaft, the packing gland, and disc back stops welded to the valve body. As can be seen from Figure 3.4, the swing-disk-type check valves are installed backwards. This means that the valve operator must open the valve against steam flow but is assisted by steam flow during closure. This arrangement also allows steam pressure to assist in tightly seating the valve. A 4-inch diameter hydraulic dashpot is provided to control valve closing speed. The dashpot is rated at 5000 psi. The dashpot regulates the rate of valve closure by controlling the rate of hydraulic fluid flow through the bypass holes drilled into the dashpot piston. The pneumatic operators for these valves are very similar to those used on globe valves (see Subsection 3.4.1). The MSIVs are designed to close within 5 seconds upon receipt of an automatic closure signal.

Located downstream of each MSTV is a nonreturn stop valve whose function and design are like a conventional swing check valve. The non-return stop valves are used to prevent reverse steam flow in case of an accidental pressure reduction in any SG or a pipe break upstream of the MSIV. For a pipe break upstream of the MSIV, the affected SG will continue to blowdown. However, the nonreturn valve in the affected steam line will help limit the severity of the event by preventing blowdown from the other intact SG. A complete assembly of a typical MSIV and nonreturn stop valve is shown in Figure 3.5. 


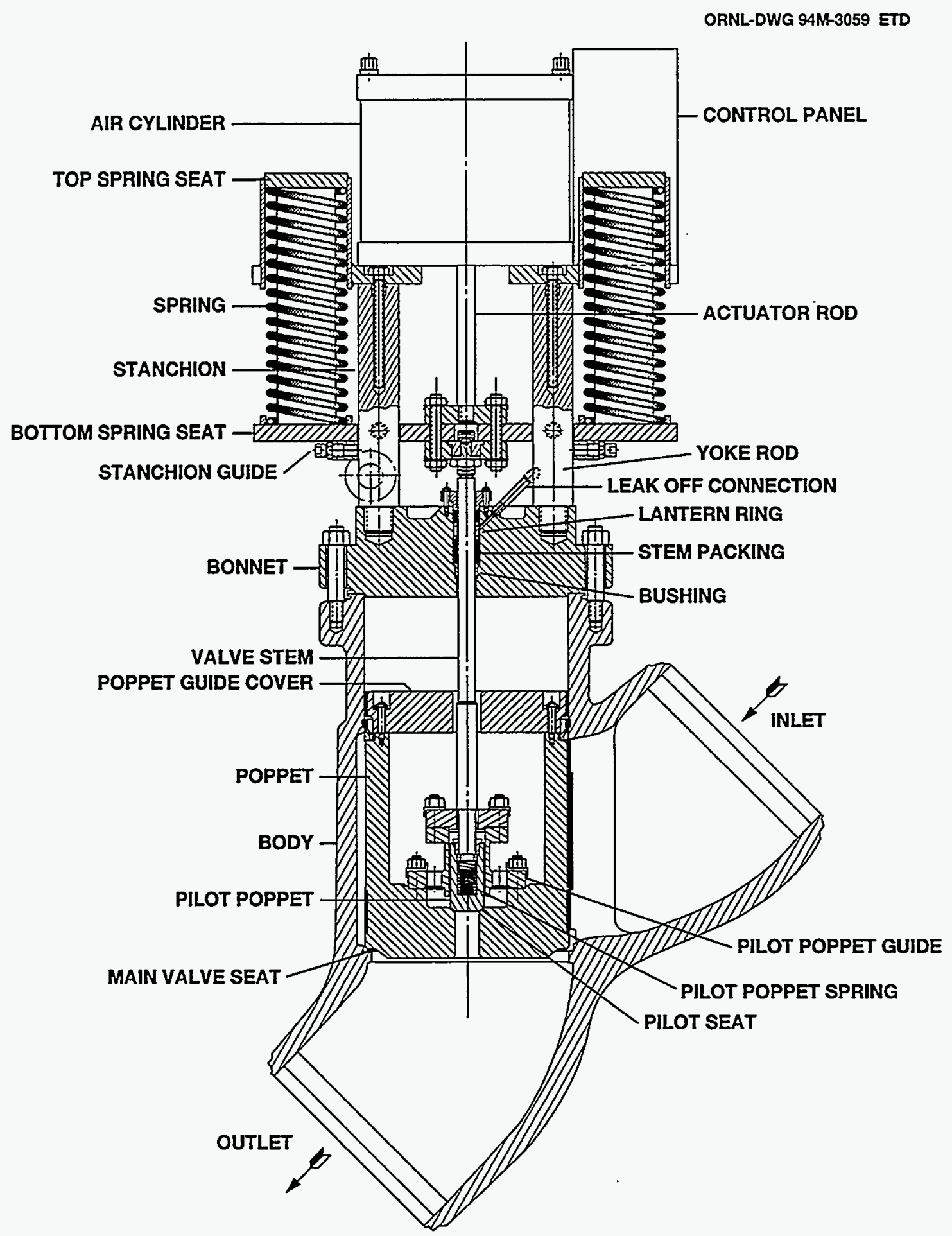

Figure 3.3 Typical PWR MSIV: globe valve 
Operator Descriptions

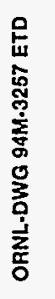
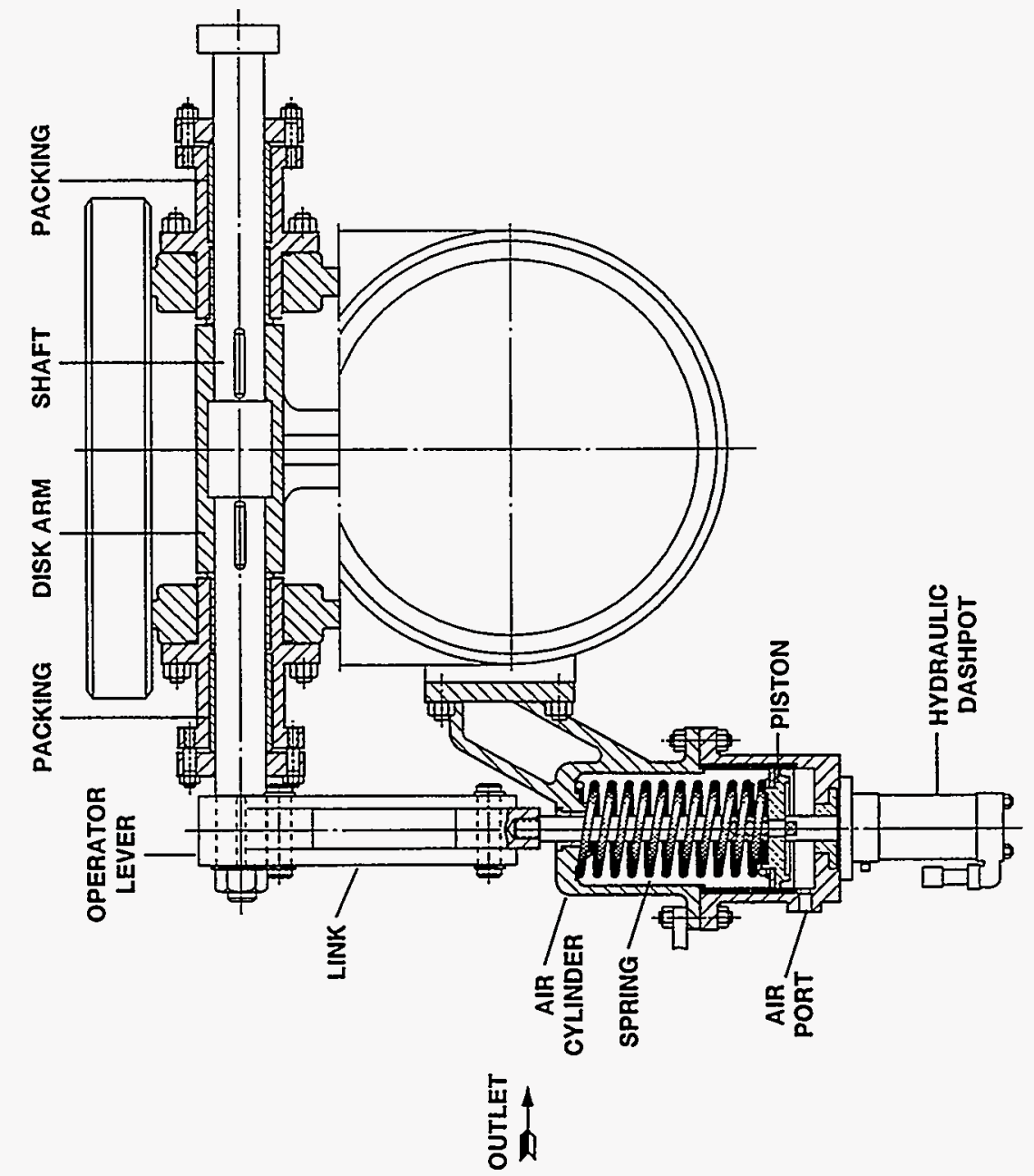

 


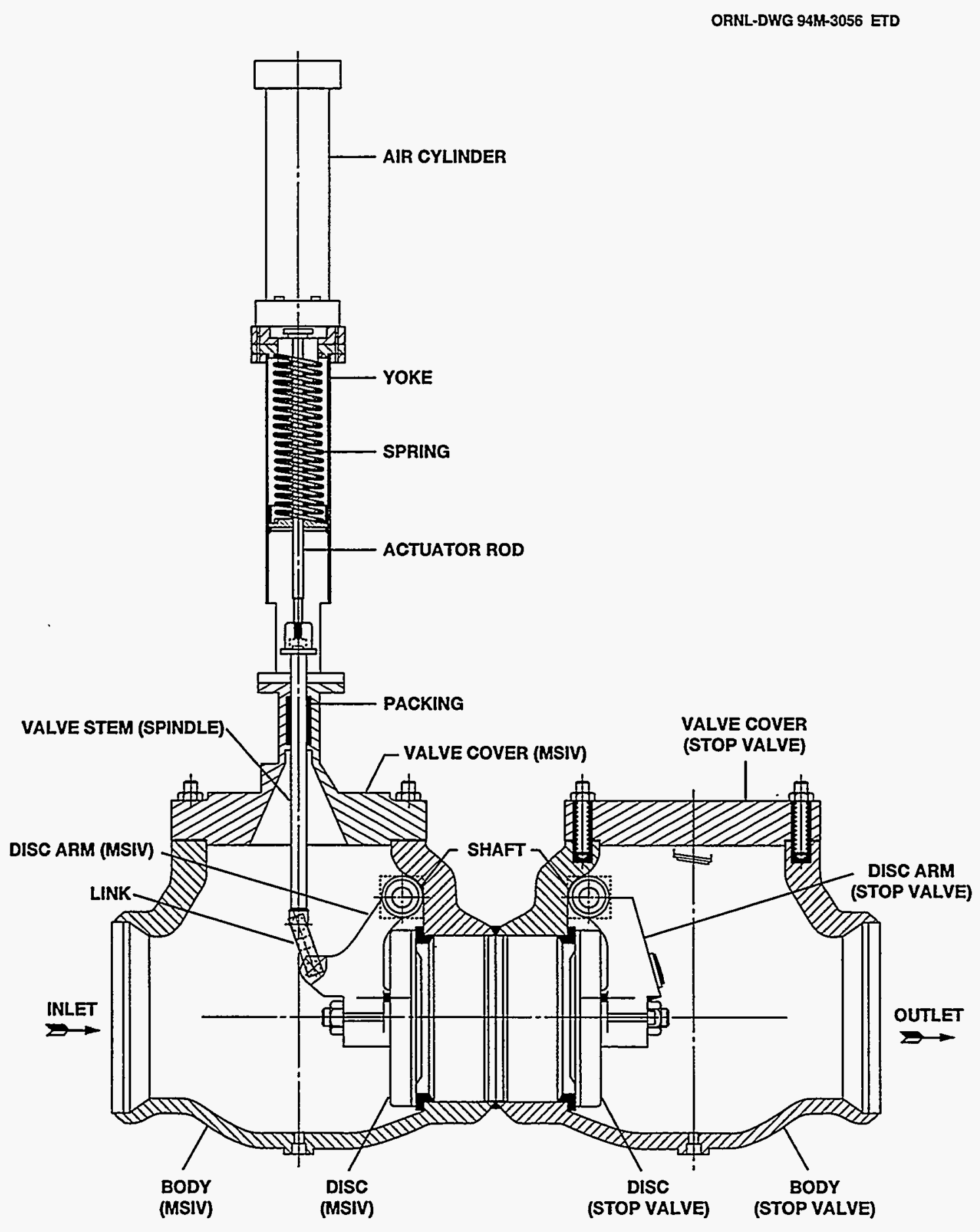

Figure 3.5 Typical PWR MSIV check and nonreturn stop valve assembly 


\section{Operator Descriptions}

\subsubsection{Gate Valves}

Basically, two types of gate valves are used for main steam isolation on PWRs, these are described in the following subsections.

\subsubsection{Type I}

A drawing of a typical Type I gate valve used for MSIV application is shown in Figure 3.6. This valve is a double disc (DD) gate valve with a hydraulic actuator. The body and bonnet are the pressure boundary components of the valve. The major valve internals consist of the upstream disc, the downstream disc, the disc retainer, the upper wedge, the lower wedge, and seat rings. The valve-to-actuator connections consist of the yoke and stem.

The seat rings and discs have hard-faced (i.e., stellite) seating surfaces. This provides a high-load, wear-resistant material that will enhance leak-tight shutoff after many operational cycles. The upper and lower wedges also have stellite hard-faced mating areas for extended life of their wear surfaces.

To close the DD gate, actuator thrust is exerted on the valve stem, pushing the valve internals between the seats of the valve. As the internals approach the fully closed position, the lower wedge contacts the bridge of the valve body, stopping the lower wedge motion. With the lower wedge stopped, the upper wedge is forced toward the seat to push the discs into the seat (refer to Figure 3.6). The valve-wedging action will seal the valve discs to the seats with low differential pressure (100 psig or less). At higher pressures the downstream disc will be sealed to the seat by the steam pressure acting on the back side of the disc, creating a sealing force.

To open the DD gate, actuator thrust is exerted on the valve stem, pulling the valve internals out from between the valve seats. When the stem first starts to move, the wedges contract and then the valve internals are pulled out from between the seats. The valve is fully opened when the discs' lower edges are in contact with the upper edge of the seats.

Rapid closure of the DD gate valve will not damage the valve internals, including the seating surfaces. As described earlier, the lower wedge impacts the valve body bridge, not the seats, during closure. This contact absorbs most of the impact forces and thereby prevents seat damage.

Isolation is assumed by several valve design features: disc rotation, simple seating surfaces design, and wedgepressure activated sealing. As the discs approach full closure, the discs rotate to provide a different seating position on each closing cycle, provide equal seating surface wear, and minimize the possibility that small seat imperfections will escalate into major leakage problems.

The seating surfaces of the seat rings and discs are simple flat planes that can be easily lapped should a leak occur. Using a portable lapping machine, the seat rings can be lapped in the body. The discs can be removed from the body and lapped on a large lapmaster.

Sealing of the seating surfaces (i.e., discs-seats) is accomplished by forcing the disc onto the seat. This force is provided by actuator thrust acting through the wedges and by steam line pressure acting on the back side of the disc. At low differential pressures the actuator thrust is the predominate sealing force, but at differential pressures above $100 \mathrm{psig}$, the steam line pressure is the predominate sealing force. Therefore, the DD gate valve is a good choice for isolation at low pressures as well as at higher pressures. 
Operator Descriptions

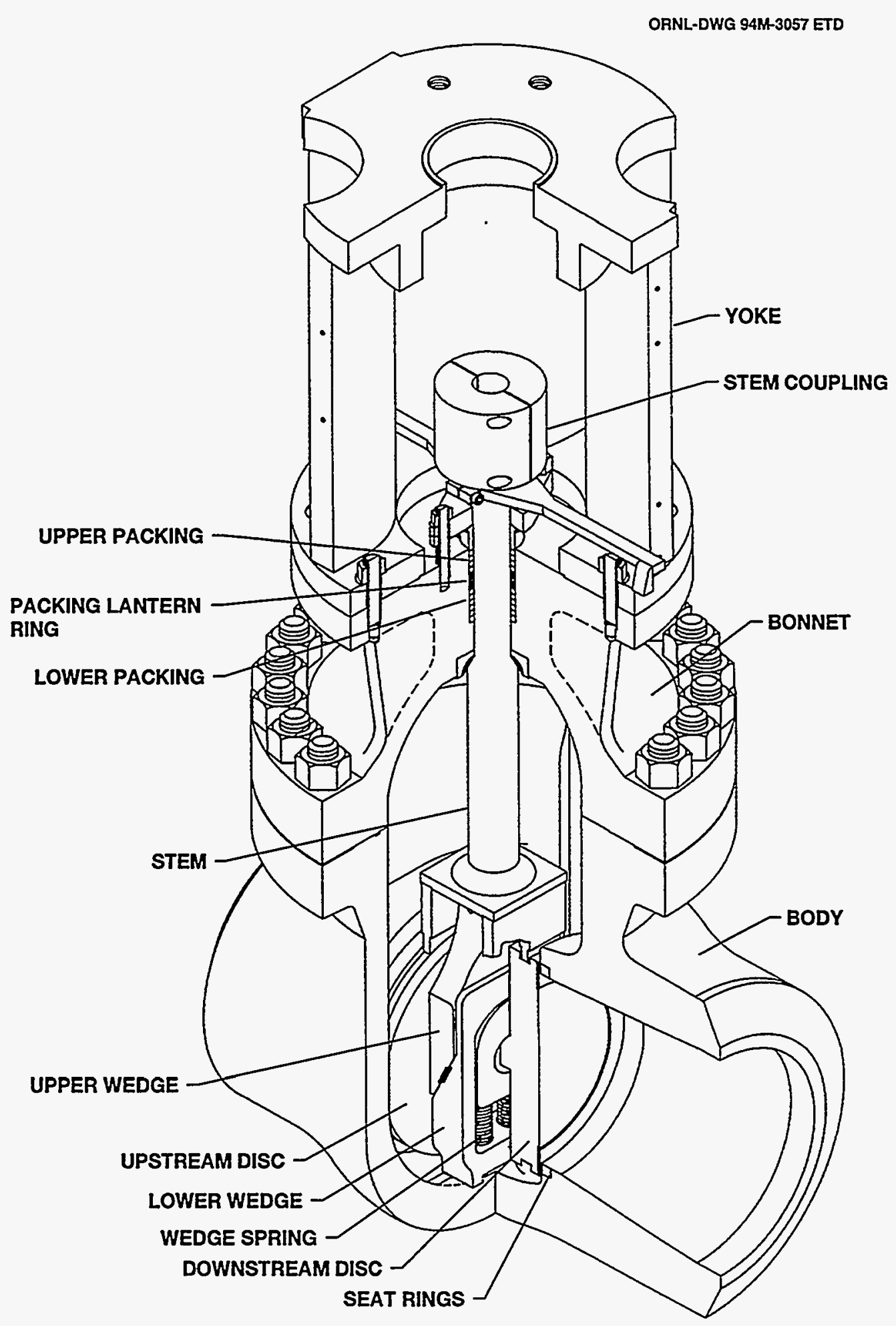

Figure 3.6 Typical PWR MSIV: Type I gate valve 


\section{Operator Descriptions}

\subsubsection{Type II}

A drawing of a typical Type II gate valve used for MSIV application is shown in Figure 3.7. This valve is a bidirectional, wedge-type gate valve with the valve body welded into the steam line. The valve body is a straightthrough T-pattern with the stem and upper works vertically upright above the flow line. The valve's flow passage is sealed by closing the gate into the seat rings, which are welded to the valve body. The gate halves are tapered to match the angle of the seat rings. The gate halves are guided throughout the stroke by tongues on the gate sides that fit into grooves in the valve body. A spacer ring is placed between the gate halves to maintain flexibility during valve stroke. The gate is positioned (open or closed) by the stem, which is captured between the gate halves. The stem passes through the bonnet by way of the packing chamber, which is sealed against leakage by the junk ring, packing rings, and lantern rings. Any leakage in the lower set of packing is carried off by the leak-off connection. The bodyto-bonnet joint is sealed against leakage by a pressure seal gasket. As the differential pressure across the disk increases, the seating load also increases, providing a tight seal throughout the entire range of operating differential pressures. Because the disks are completely independent of each other and because the design is essentially symmetrical, positive sealing can be maintained in either direction. This design feature eliminates the necessity of installing a check valve downstream of the MSIV to stop reverse flow.

\subsection{PWR MSIV Operator}

Typical valve operators found on globe and check valves used for MSIV application on PWRs are described in Subsection 3.4.1 and 3.4.2. For gate valves there are two general types of valve operators. These valve operators are significantly different in that the primary mechanism for fast closure is not the mechanical energy stored in springs but rather the energy stored in hydraulic or pneumatic fluids. The design characteristics of these valve operators are described in Subsections 3.4.3.1 and 3.4.3.2.

\subsubsection{Globe Valves}

A typical valve operator for globe valves using air to open and springs to close is shown in Figure 3.3. This valve operator is similar to the ones used on BWRs. However, there are differences. For this particular valve operator the pneumatic system, not a hydraulic system, is used to control the valve opening and closing speed.

To increase system availability, redundant electrical and pneumatic control systems are provided. The electrical systems use solenoid valves to convert electrical control signals to pneumatic signals. The pneumatic systems employ air-operated pilot valves to regulate the plant air supply to and from the air cylinder. The air cylinder's main function is to convert the plant air supply pressure to mechanical force needed to slowly open and close the MSIV. The valve springs provide the motive force for fast valve closure.

A typical control diagram for this particular valve operator is shown in Figure 3.8. To retract the actuator rod and compress the spring coils, the inlet supply valves ( $A$ and $B)$ must be open, and the dump valves $(D, E, H$, and $J)$ must be closed. The open inlet supply valves (A and $B$ ) allow air flow to be supplied to the operating cylinder, while the closed dump valves maintain system pressure by blocking flow through the exhaust header.

To close the valve, either of the inlet supply valves ( $A$ or $B$ ) are closed to shut off the air supply, and either of the pair of dump valves in channel $A$ or $B$ are open to allow the air from the operating cylinder to exhaust through the airmetering valves $(P$ and $N)$ and the pressure relief valves $(K$ and $M)$. The pressure relief valves $(K$ and $M)$ are designed to dump air quickly from the cylinder until the pressure drops to approximately $30 \mathrm{psig}$ before closing and reverting air flow completely to the metering valves. The valve adjustments to the pressure relief valves and the metering valves determine the rate of valve closure. 


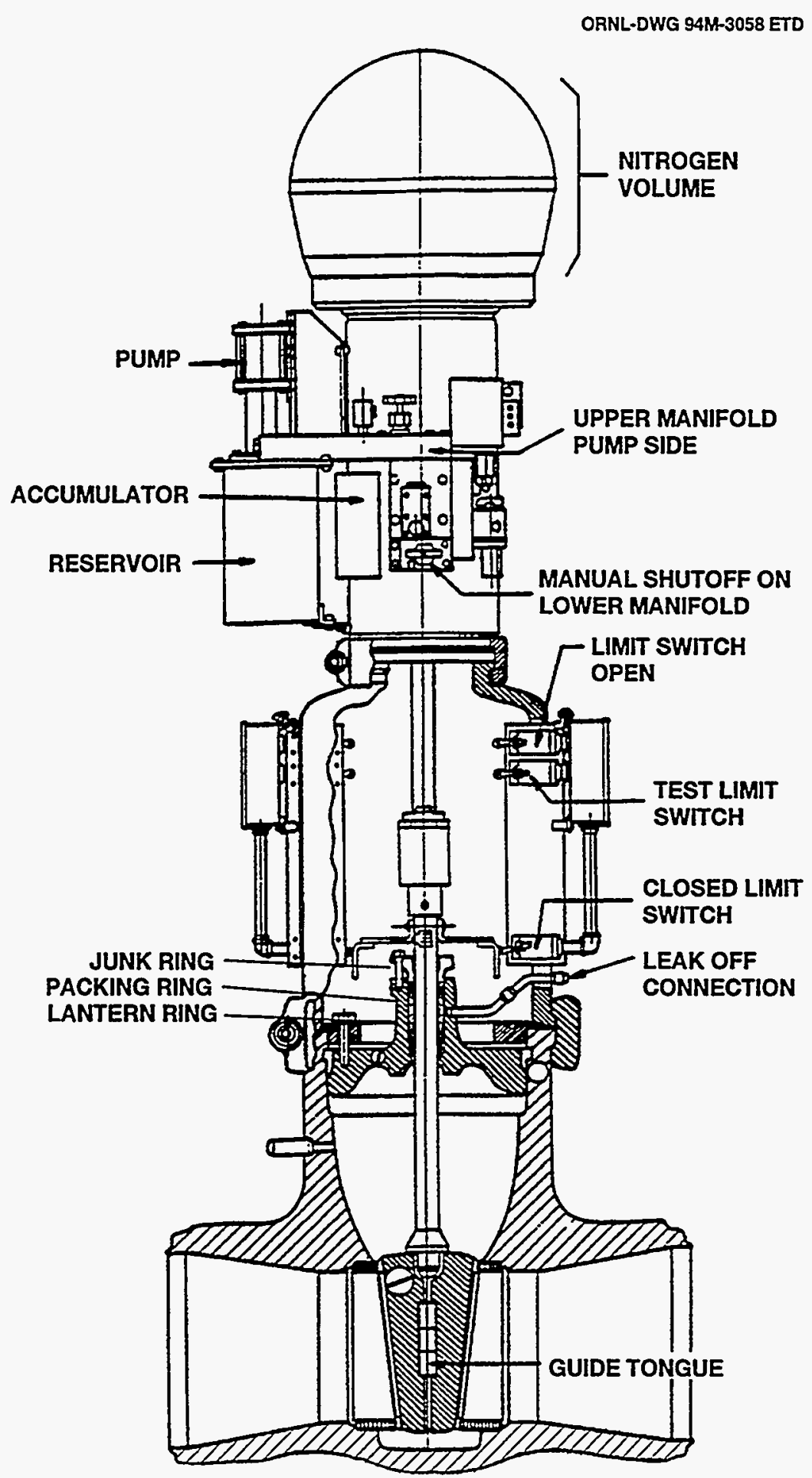

Figure 3.7 Typical PWR MSIV: Type II gate valve 


\begin{tabular}{l} 
LEGEND \\
1. SUPPLY VALVES \\
2. DUMP VALVES \\
3. BLOCK VALVES \\
4. EXERCISE SPEED CONTROL VALVES \\
5. RELIEF VALVES \\
6. MSIV SPEED CONTROL VALVES \\
7. AIR CYLINDER \\
\hline
\end{tabular}

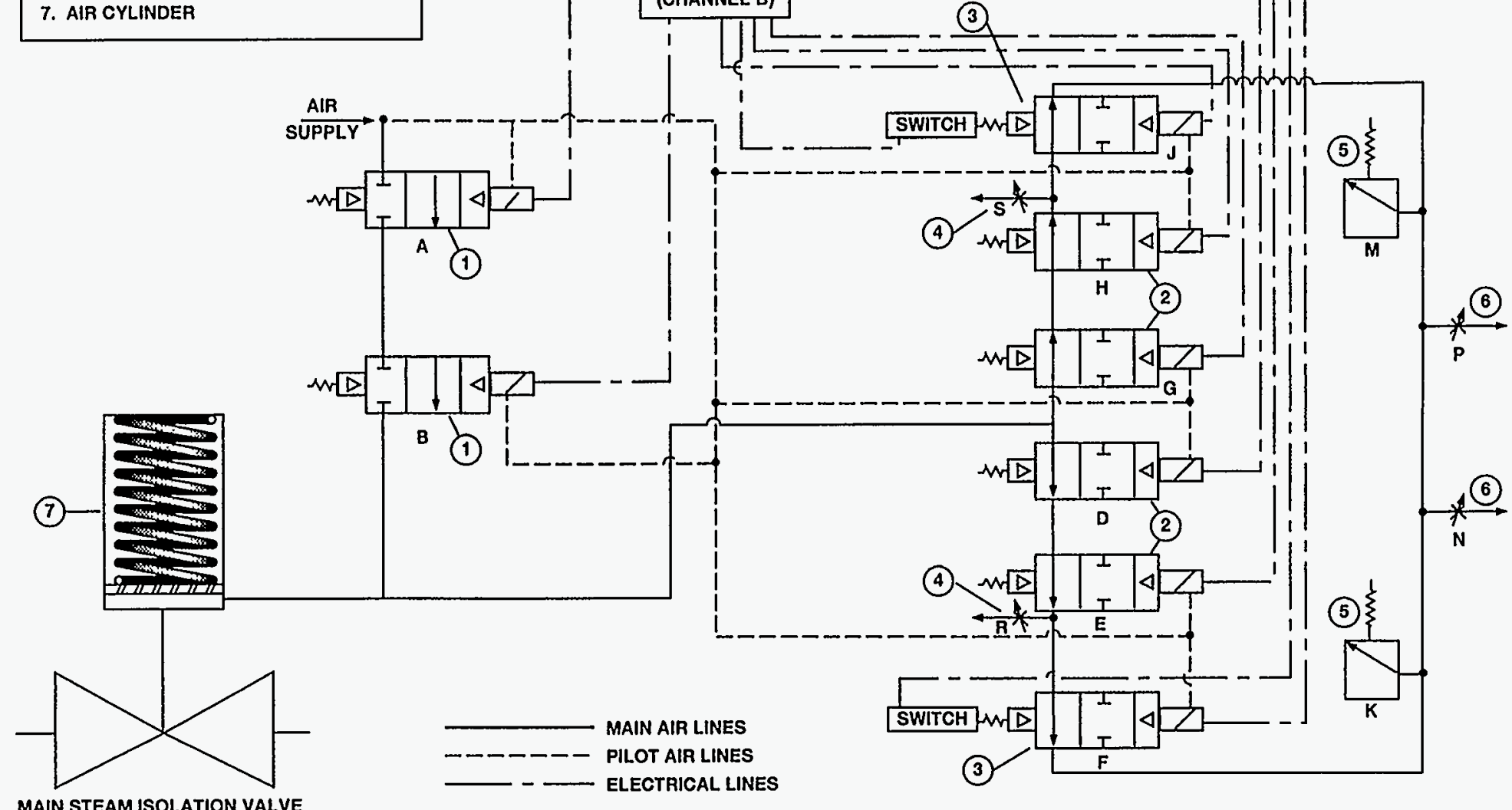

Figure 3.8 Typical PWR valve operator schematic for MSIVs using globe and check valves 
To exercise the MSIV and to test the dump valves in each channel for satisfactory operation, the valve operator is equipped with a normally de-energized block valve ( $F$ and $J$ ) in each control channel.

To stroke the valve in the exercise mode, the block valve ( $F$ or $J$ ) in either channel is first energized to block air flow to the exhaust header. The dump valves in that channel are then de-energized to slowly exhaust the air from the operating cylinder through the fine relief valve ( $R$ or $S$ ). When the MSIV is approximately $90 \%$ open, the dump valves are energized to block the exhaust flow, and the block valve is de-energized to allow the pilot-operated valve to return to its normally open position. When these conditions are met, the MSIV will slowly return to the full open position. If at any time during the exercise mode an automatic closure signal is generated, the redundant channel will override the exercise mode and initiate fast valve closure.

\subsubsection{Check Valves}

A typical valve operator for check valves using air to open and springs to close is shown in Figure 3.4. This valve operator is similar to the ones described in Subsection 3.4.1, since in both designs, air pressure is applied to a piston within the air cylinder which forces the actuator or piston rod to retract and compress the spring coils. The torque generated by the piston and mechanical linkage is transmitted to the operating lever which then causes the main disc to rotate off its seat. The back stops located within the valve body limit the valve opening stroke and prevent the main disk from jamming into the valve body. To close the valve, air is removed from the underside of the piston at a flow rate determined by air-metering valves. For fast closure the air is dumped from the air cylinder, and the spring force, along with steam flow, forces the main disc to swing closed at high velocity. To avoid disc and seat damage, a hydraulic dashpot is used to control the closing speed as the main disc approaches the valve seat. The dashpot is not actually active until the main disc approaches the last one-third of valve stroke.

In addition to the hydraulic dashpot, a rupture disc is also provided to prevent damage to the air cylinder during fast closure. During fast closure under high-steam-flow conditions, the disc and piston will travel at high velocity compressing the air in the air cylinder. If under these operating conditions the air exhaust from the valve operator becomes restricted for any reason, a large pressure increase will occur in the air cylinder. To protect the air cylinder from potential over pressurization, a rupture disc is normally provided.

The electrical and pneumatic controls that regulate the flow of air in and out of the air cylinder for normal valve opening, closing, fast closure, and for valve exercising during normal plant operations are basically the same as those that were described in Subsection 3.4.1 for globe valves.

\subsubsection{Gate Valves}

The valve operators for Type I and II gate valves are discussed in Subsection 3.4.3.1 and 3.4.3.2 respectively. The valve operator for Type I gate valves use hydraulics both to open and close the valves, whereas the valve operators for Type II gate valves use hydraulics to open and pneumatics to close.

\subsubsection{Type I}

A typical valve operator for Type I gate valves is shown in Figure 3.9. The valve operator is assembled using three control systems: electrical, pneumatic, and hydraulic. The electrical control system converts the main control room electrical signals to pneumatic signals which are then used to control the hydraulic system. The hydraulic system controls the hydraulic cylinder which opens and closes the MSIV. No springs assist with fast valve closure. 


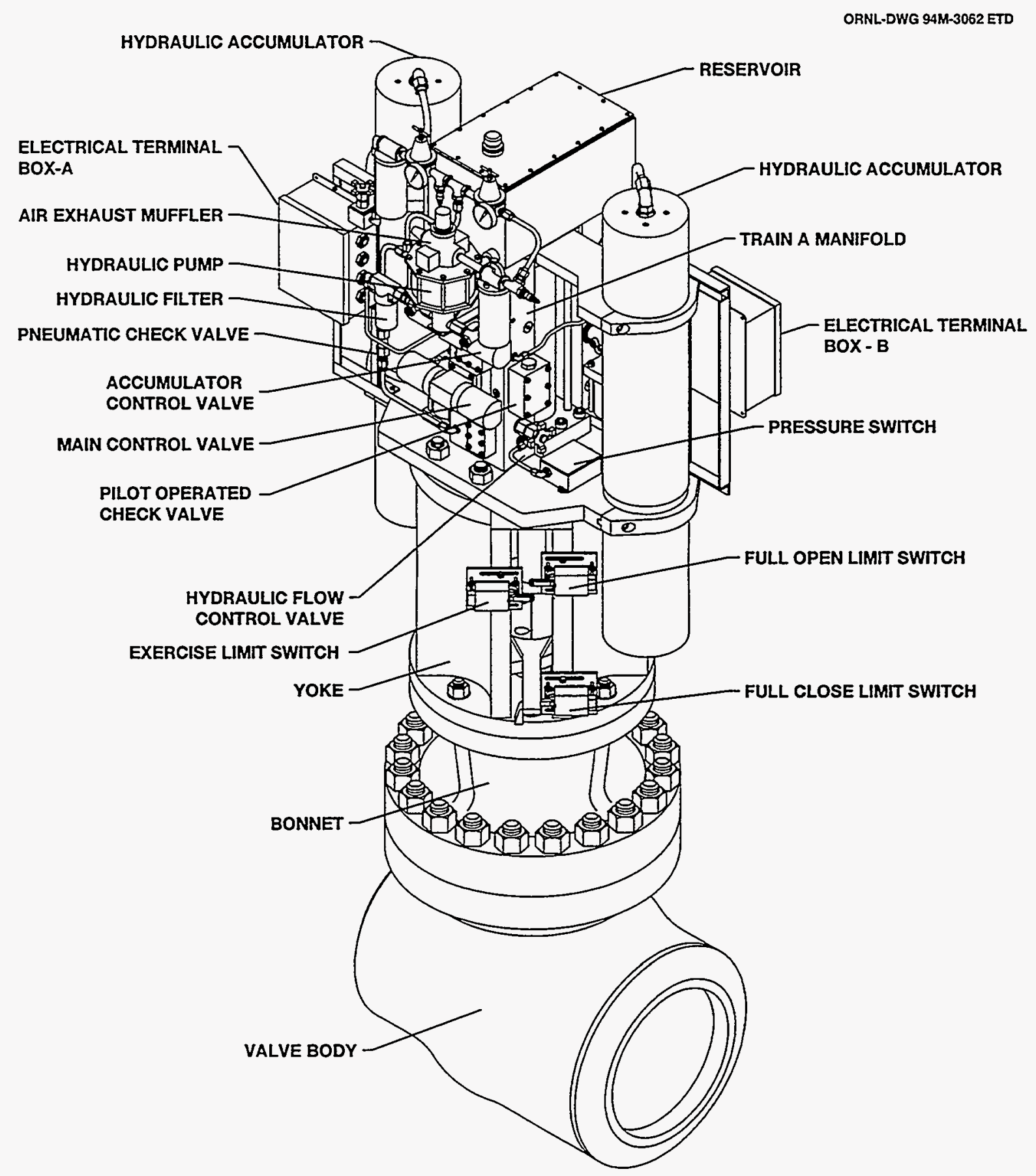

Figure 3.9 Typical MSIV valve operator for Type I gate valves 
The major components within the electrical system are solenoid coils, limit switches, terminal blocks, wiring, and junction boxes. The electrical equipment is environmentally qualified to operate under accident conditions. Loss of electrical power will result in MSIV closure.

The major components within the pneumatic control system are check valves, solenoid valves, air reservoir, lubricator, relief valve, pressure regulator, filter, shutoff valve, pressure switch, pressure transducer, accumulator precharge valve, and air exhaust muffler.

The air pressure regulator and relief valve is installed in the pneumatic control system to control plant air supply pressure. The two check valves in the "T" connection downstream of the first relief valve are used in conjunction with the air reservoir to maintain air pressure if a leak occurs upstream of the check valves or if plant air supply is lost. The lubricator is used to add lubricant to the air-driven motor on the hydraulic pump to extend the life of the motor. The air exhaust muffler is used to limit the noise generated by the air motor. Note that for this actuator, air pressure must be available to close the MSIVs.

The major components within the hydraulic control system are flow control valves, check valves, hydraulic cylinder, accumulator, hydraulic pump, filter, pressure switch, relief valve, orifices, and fluid reservoir.

As can be seen from Figure 3.11, the hydraulic system is pressurized by the air-driven hydraulic pump to approximately $5000 \mathrm{psi}$. The hydraulic pump discharge pressure is directly related to the regulated plant air supply pressure. The nominal hydraulic-to-air-pressure ratio is 60 to 1 . The two check valves located in the "T" connection downstream of the hydraulic pump are used in conjunction with the hydraulic accumulators to maintain system pressure if the hydraulic pump fails or if a leak develops upstream of the check valves.

The hydraulic accumulators are also used to perform fast valve closure. To perform this function, a predetermined amount of hydraulic fluid pressurized by nitrogen gas is stored in the accumulators. A piston is used to separate the nitrogen gas from the hydraulic fluid. During blowdown the nitrogen gas expands from its initial state to its final state, and the hydraulic fluid pressure decreases from its initial pressure of $5000 \mathrm{psi}$ to the pressure needed to fully close the MSIV. This closure pressure is the precharge pressure which is verified during post maintenance testing. Because the accumulator volume is fixed, the precharge pressure is sensitive to the nitrogen gas temperature, which is a function of the ambient temperature. A typical Nitrogen Precharge Pressure vs. Temperature curve is shown in Figure 3.10. After the nitrogen precharge pressure and temperature have been verified, the accumulators are charged by the hydraulic pump to approximately $5000 \mathrm{psi}$. If the accumulator's precharge pressure is too high, the accumulator hydraulic charge will not store enough high-pressure fluid to effect MSIV fast closure. The MSIV will partially close in the fast mode, run out of accumulator-supplied hydraulic fluid, and assuming air supply is available to the nonsafety related hydraulic pump, finish its closure function using pump-supplied fluid. The MSIV will close but will require more than 5 seconds. The same process could also occur if the accumulators were charged at high ambient temperature. The volume of high-pressure fluid stored in the accumulator may not be adequate to fully fast close the MSIV. Of course, if the accumulator is not charged to the correct pressure or if a hydraulic or nitrogen gas leak occurs, the rate the hydraulic fluid is discharged from the accumulator may be insufficient to satisfy the fast valve closure requirements. For these reason low-accumulator pressure alarms are provided in the main control room.

As can be seen from Figure 3.11, the actuator has two control channels, A and B. Either one can be used for normal valve opening and closing and to initiate fast valve closure if required. A description of channel " $\mathrm{A}$ " is given. 
Operator Descriptions

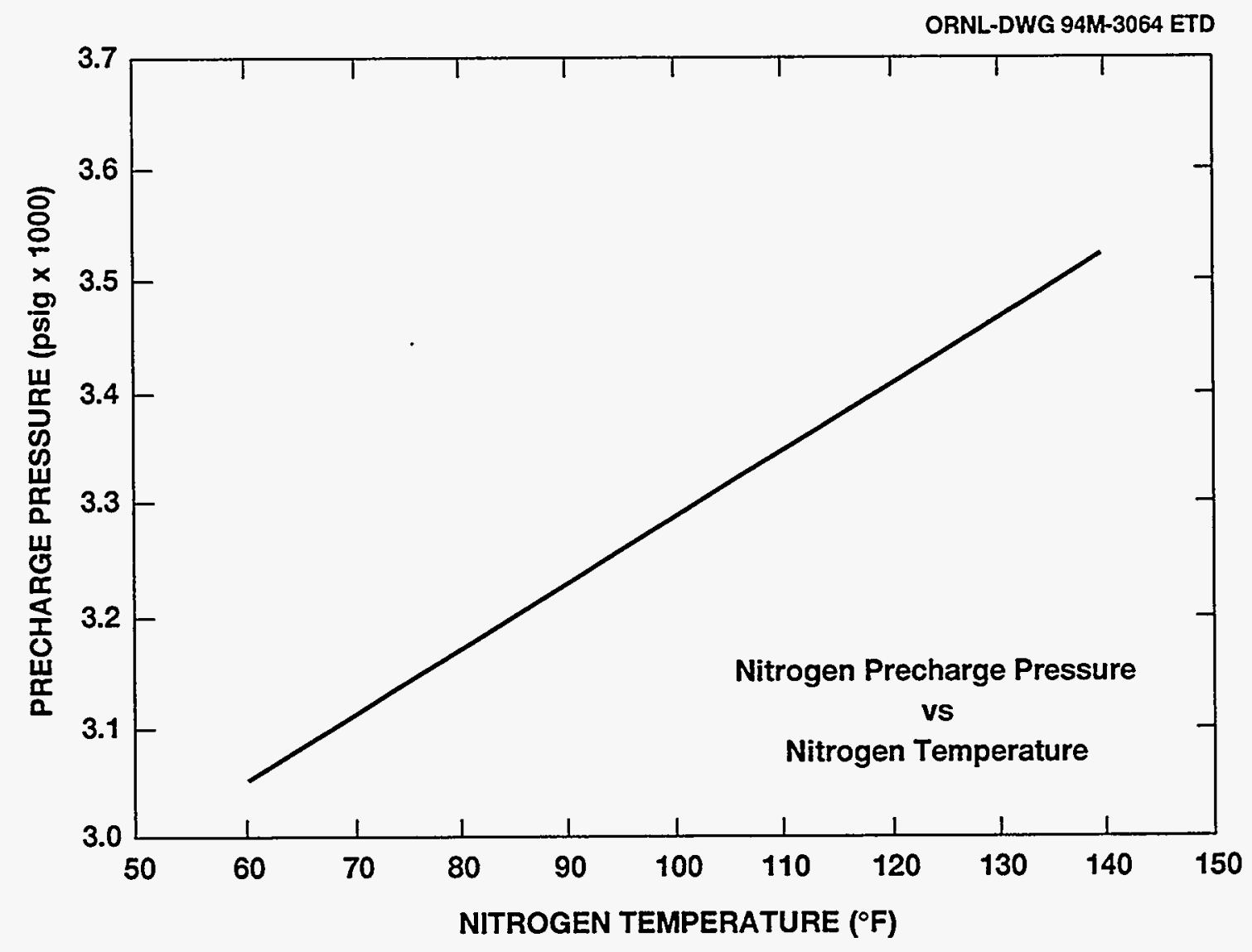

Figure 3.10 Typical precharge graph for hydraulic actuators 


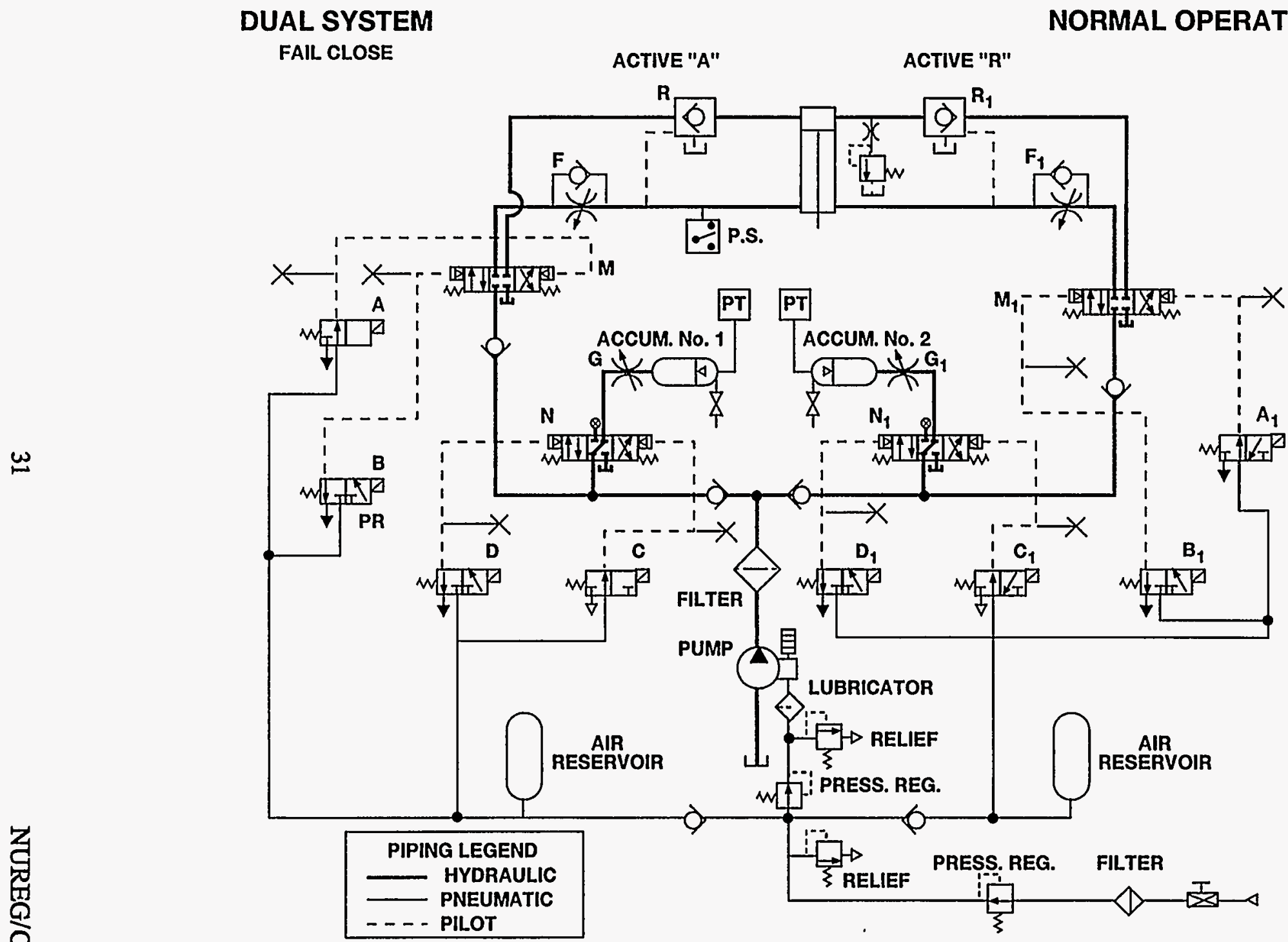

Figure 3.11 Typical MSIV valve operator schematic for Type I gate valves 


\section{Operator Descriptions}

To open the MSIV, the following control sequence is used:

- Solenoid valve " $C$ " is energized to allow pilot air pressure to close accumulator dump valve "N" (valve shifts to the center position) to isolate the hydraulic accumulator.

- Solenoid valves $A$ and $B$ are energized. Solenoid valve A exhausts the air pressure from the right side of hydraulic flow control valve $M$, while solenoid valve $B$ allows pilot air to be applied to the left side of the hydraulic valve. This action causes hydraulic control valve $M$ to shift to the left (parallel arrow position); this opens the control valve allowing the hydraulic pump to direct high-pressure fluid to the lower part of the hydraulic cylinder. The fluid in the upper part of the cylinder is forced out by the piston and is drained to the oil reservoir through pilot-operated check valve $R$. Pilot-operated check valve $R$ will allow reverse flow when the hydraulic pilot signal (dashed lines) to the check valve is pressurized. The MSIV will open at a rate governed by the pump and the main steam system conditions.

When the MSIV is fully open, solenoid valve B is de-energized. This control action removes pilot air pressure from the left side of hydraulic flow control valve $M$, and the valve shifts to the close position to isolate the hydraulic cylinder from the hydraulic pump and accumulator. Solenoid valve $C$ is then de-energized, allowing pilot air to shift the accumulator dump valve to its normally open position. With the accumulator dump valve open, the hydraulic accumulator is now in the standby mode, ready to initiate fast valve closure if required.

To close the MSIV under normal operating conditions, the following control sequence is used:

- Solenoid valve $C$ is energized to allow pilot air pressure to close accumulator dump valve $N$ to isolate the hydraulic accumulator.

Solenoid valves $A$ and $B$ are de-energized. Solenoid valve $A$ allows pilot air to be applied to the right side of hydraulic flow control valve $M$, while solenoid valve $B$ exhausts the air pressure from the left side of the hydraulic valve. This action causes hydraulic control valve $M$ to shift to the right which allows the hydraulic pump to direct high-pressure fluid to the upper part of the cylinder through check valve $R$. The fluid in the lower part of the cylinder is forced out by the piston and is drained to the oil reservoir through check valve $F$ and hydraulic control valve $M$. The MSNV will close at a rate governed by the pump and the main steam system conditions.

When the MSIV is fully closed, solenoid valve $A$ is energized, centering hydraulic flow control valve $M$ which isolates the hydraulic cylinder from the hydraulic pump and accumulator. Solenoid valve " $\mathrm{C}$ " is then de-energized, allowing pilot air to shift the accumulator dump valve to its normally open position. With the accumulator dump valve open, the hydraulic accumulator is now in the standby mode, ready to initiate fast valve closure if required.

To initiate fast valve closure, the following control sequence is used:

- The hydraulic accumulator is initially in the standby mode (i.e., dump valve $\mathrm{N}$ is open).

- Solenoid valve $\mathrm{A}$ is de-energized, shifting hydraulic control valve $\mathrm{M}$ to the right (cross arrow position). This control action allows the hydraulic accumulator to direct high-pressure fluid to the upper part of the cylinder through check valve $R$. The fluid in the lower part of the cylinder is forced out by the piston and is drained to the oil reservoir through check valve $F$ and hydraulic control valve $M$. The MSIV will close at the rate governed by the setting of flow control valve $G$ and the main steam system conditions. 
When the MSIV is fully closed, solenoid valve $A$ is energized, centering hydraulic flow control valve $M$ which isolates the hydraulic cylinder from the hydraulic pump and accumulator.

To perform the accumulator precharge check, the following control sequence is used:

- Solenoid valves $C$ and $D$ are energized, shifting accumulator dump valve $N$ to the parallel arrow position. This isolates accumulator \#1 from the hydraulic pump, discharges the high-pressure fluid in the accumulator to the reservoir, and allows the nitrogen gas to expand to a known volume (i.e., the accumulator volume).

After the nitrogen gas temperature has thermalized for 10 minutes, the nitrogen pressure and temperature are compared with the applicable precharge pressure requirements for the specific power plant and adjusted accordingly.

When the precharge pressure is determined to be acceptable, accumulator \#1 is recharged by de-energizing solenoid valves $C$ and $D$. This action causes accumulator dump valve $N$ to return to its normal position, allowing the hydraulic pump to recharge the accumulator.

\subsubsection{Type II}

A typical valve operator for Type II gate valves is shown in Figure 3.12. The actuator is basically a hydraulic cylinder coupled directly to a precharged nitrogen accumulator which stores the closing energy. The precharged high-pressure nitrogen is stored in an integral, essentially hemispherical accumulator designed as a pressure vessel meeting the requirements of ASME VIII, Div. 1. The stored energy volume acts directly on the actuator piston, which has a redundant sealing system to ensure that no leakage of nitrogen occurs while the unit is in the standby mode.

The hydraulic cylinder provides a simple, reliable method for reopening the valve and for charging the nitrogen accumulator. The operating pressure of the hydraulic cylinder is $4300 \mathrm{psig}$ maximum at $110^{\circ} \mathrm{F}$. The hydraulic cylinder is connected to a dual Electro-Hydraulic Control (EHC) System to ensure system reliability.

The dual EHC System is depicted in Figure 3.13. Both systems are pressurized by a non-safety-related, air-operated hydraulic pump. The air supply to the air motor for the hydraulic pump is closely regulated because the hydraulic pressure developed by the pump is directly proportional to the air pressure. A small accumulator serves to dampen fluid vibration and to provide temperature and leakage compensation. To open the valve, high-pressure fluid enters the hydraulic cylinder and applies pressure to the bottom side of the piston. This opening, or "charging," operation is completed in 5 minutes.

Fast closure of the valve occurs when either solenoid valve $A$ or $B$ opens, releasing pilot pressure from either hydraulic dump valve $\mathrm{C}$ or $\mathrm{D}$; this allows the hydraulic fluid from the cylinder to drain to the reservoir through adjustable flow control valve $\mathrm{E}$ or $\mathrm{F}$. The normal setting of the flow control valve will allow the MSIV to close within 5 seconds or less using one control system, and will result in 2.5 to 3 seconds if both systems are used.

Normal valve closure is accomplished by first energizing exercise solenoid valve $\mathrm{G}$ or $\mathrm{H}$ which releases pilot pressure from either exercise valve I or $\mathrm{J}$. The exercise valve then places a flow orifice into the dump line. When the orifice is in position, the main dump valve is de-energized to allow hydraulic fluid to bleed from the hydraulic cylinder. During this time air supply solenoid valve $\mathrm{K}$ is de-energized, cutting off the air supply to the hydraulic pump.

In the exercise mode the same sequence of events as that described for normal valve closure occurs except that when the valve hits the limit switch indicating $90 \%$ open, the test is terminated and the valve is automatically reopened. 


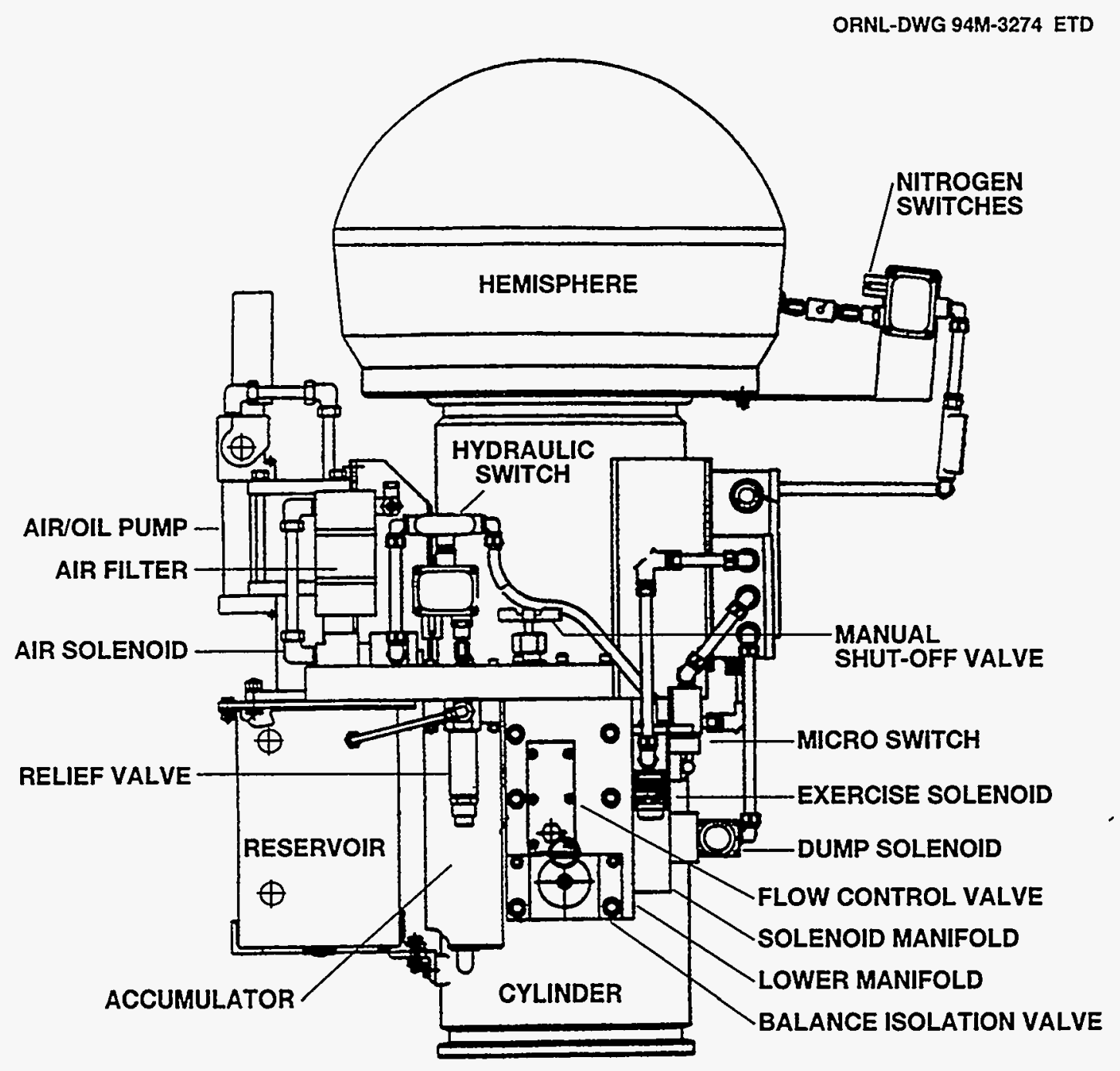

Figure 3.12 Typical MSIV valve operator for Type II gate valves 
ORNL-DWG 24M-3066 ETD

$\underline{u}$

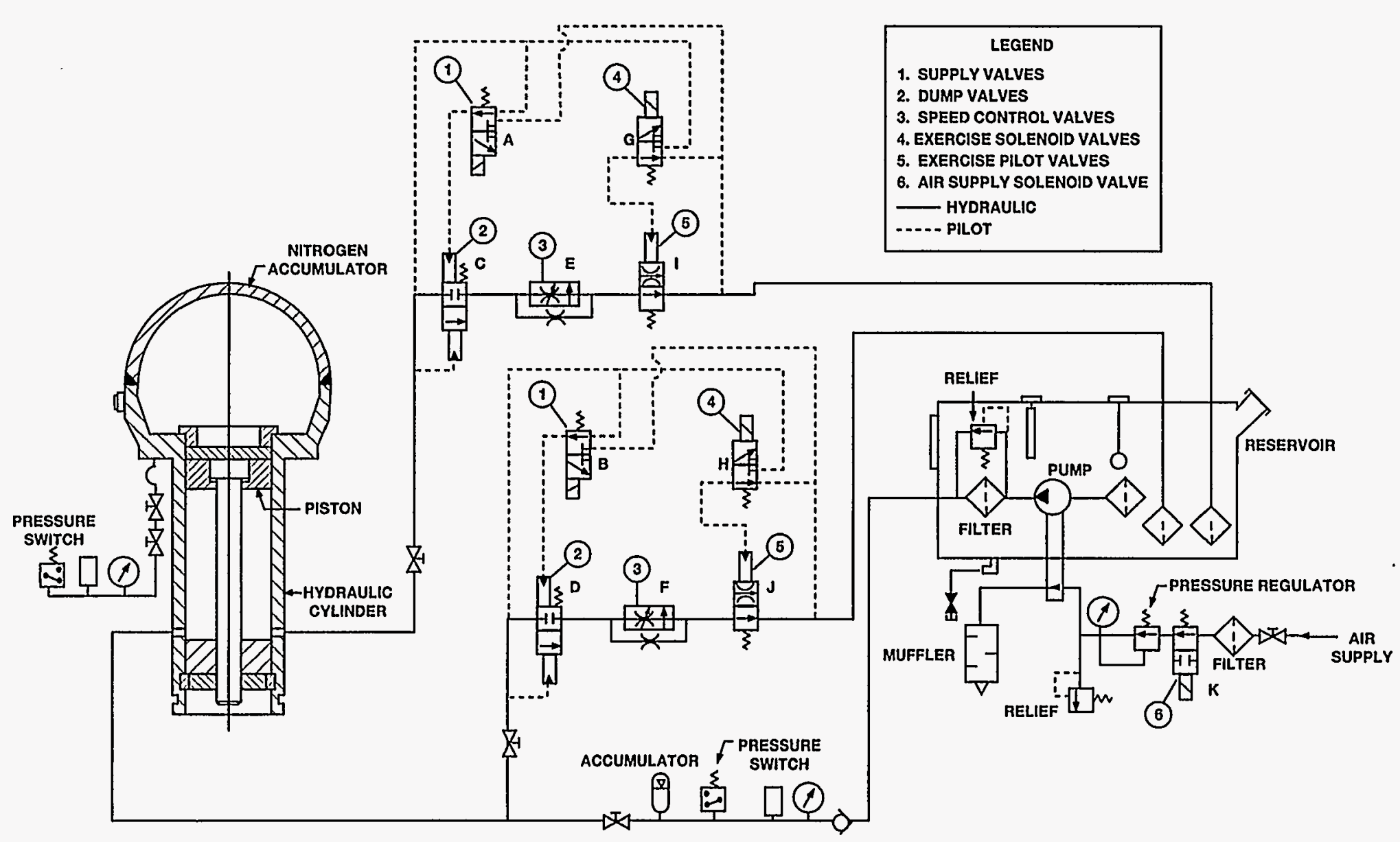

Figure 3.13 Typical MSIV valve operator schematic for Type II gate valves 


\section{Operator Descriptions}

As mentioned above, the air-driven hydraulic pump is non-safety-related. A check valve and hydraulic accumulator are provided to maintain system pressure if the pump fails. Complete loss of hydraulic pressure or electrical power will result in MSIV closure. Nitrogen accumulator pressure is continuously monitored with local low-pressure alarms and main control room MSIV trouble alarms to alert plant personnel of abnormal operating conditions. This method ensures that adequate nitrogen pressure is available at all times to close the MSIVs. 


\section{Main Steam Isolation Valve Operating Experience}

The Main Steam Isolation Valve (MSIV) operating experience for valves manufactured by Atwood \& Morrill Company, Anchor/Darling Valve Company, Rockwell International Corporation, and Schutte \& Koerting were obtained from the Nuclear Plant Reliability Data System (NPRDS) database. The total number of failure records for the four manufacturers was 840 , of which 422 were associated with boiling water reactors (BWRs) and 418 were associated with pressurized-water reactors (PWRs). The data for these four manufacturers covered 80 operating units (i.e., approximately $72 \%$ of all operating units in the United States). The database contained all MSIV failure records that occurred between January 1, 1984, and January 1, 1993.

Several of the characterization parameters of interest are inherent in the NPRDS database. Those parameters chosen for consideration in this study which are specifically inherent in the NPRDS data include:

- unit identification

- plant type

- Nuclear Steam Supply System (NSSS)

- valve manufacturer

- valve type

- valve operator type

- description of failure narrative

- cause of failure narrative

- corrective action narrative

In addition to considering these inherent parameters, several additional parameters were developed during the failure data review based on the narrative descriptions of the event. Previous Oak Ridge National Laboratory studies have found that more reliable, consistent characterizations are developed from narrative description rather than NPRDS coding. These parameters include:

- valve failure mode

- actuator failure mode

- consequences of failure on plant operations

- method of failure detection

- major stressors

Failure mode is defined as the manner or state in which a system, structural or component, fails. ${ }^{1}$ Based on this definition, valve failure modes were classified according to seven categories:

- valve failed to open

- valve failed to close

- spurious valve closure

- spurious valve open

- valve stem or shaft leakage

- body-to-bonnet leakage

- valve seat leakage

If the above failure modes were due to mechanical damage associated with the valve, the appropriate mechanical damage was then classified as one of the following: 


\section{Operating Experience}

- valve stem binding

- disc/poppet/actuator separated from valve stem

- actuator/disc misaligned with valve stem

- bowed valve stem

- disc jammed in valve body

- internal binding

In the same manner, actuator failure modes were classified as:

- electrical failures

- pneumatic failures

- hydraulic failures

- mechanical failures

The electrical failures were categorized as:

- failed solenoid valves

- failed limit switches

- failed relay/fuse/switch

The pneumatic and hydraulic failures were categorized as:

- failed check valves

- failed control valves (including pressure-regulating relief valves, etc.)

- fitting failures

- air motor failure (pneumatic)

- pump failure (hydraulic)

- seal failures

The mechanical failures were categorized as either spring failure or miscellaneous.

Note that a single failure record may contain several failure modes that are associated with the valve and/or actuator. Therefore, the total number of failure modes in this report exceeds the total number of failure records.

The failure consequences on plant operations due to the above failure modes were categorized as:

- failed local leak rate (LLR) test

- failed fast valve closure (FVC) test

- failed partial stroke test

- lost fast valve closure capability

- reactor trip

- degraded MSIV train/channel

Degraded MSIV train/channel was related to the following failure modes:

- valve failed to open

- spurious valve closure with no reactor trip

- spurious valve open with no reactor trip 
- valve stem leakage

- electrical, pneumatic, hydraulic, or mechanical actuator failures with no loss of fast valve closure capability or reactor trip

Note also that several failure modes may be associated with a given failure consequence. However, only one failure consequence is defined for each failure record. Therefore, the total number of failure consequences is the same as the number of failure records.

The various methods of failure detection were categorized as:

- surveillance testing

- failed on demand

- routine observations

- routine maintenance

The parameters used to describe the major stressors affecting both MSIVs and valve operators follow; this list includes both normal and error-induced stressors previously defined and published: ${ }^{1}$

- vibration

- stress corrosion

- high humidity

- congealing

- high ambient temperature

- low ambient temperature

- scale buildup

- normal aging due to mechanical and thermal cycling

- maintenance error

- friction

- design error

- metal fatigue

- thermal creep

- unknown

\subsection{MSIV Failure Mode Distribution : BWR}

The MSIV failure mode distribution for BWRs is shown in Figure 4.1. The total number of failures for all major failure modes identified in Figure 4.1 was determined from the NPRDS database to be 344 . Nearly three-fourths of these failures were related to valve seat leakage. The second highest number of failures was associated with valve stem leakage (13\%), followed by valve failed to close $(6 \%)$, valve failed to open (4\%), and spurious valve closure $(2 \%)$.

\subsection{Cross Correlation of Valve Failure Modes and Valve Failure Areas : BWR}

For each valve failure mode, Figure 4.2 depicts the fraction of failures due to valve problems and those due to actuator problems. Brief descriptions of each valve failure mode and failure area are given in the following subsections.

\subsubsection{Valve Seat Leakage}

Valve seat leakage is the result of improper seating of the valve disc or main poppet. Figure 4.2 shows that approximately $82 \%$ of all valve seat leakage is due to problems with the valve and that approximately $18 \%$ can be attributed to the actuator. Seat leakage due to valve problems was attributed to internal binding, bowed valve stem, normal valve seat wear, maintenance error, thermal creep, and scale buildup. Internal binding was attributed to excessive clearance between poppet and guide rib, causing the poppet to cock in the valve body, which then prevented the main poppet from seating. The excessive clearance was due to improper maintenance, design errors, and wear of 


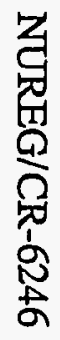

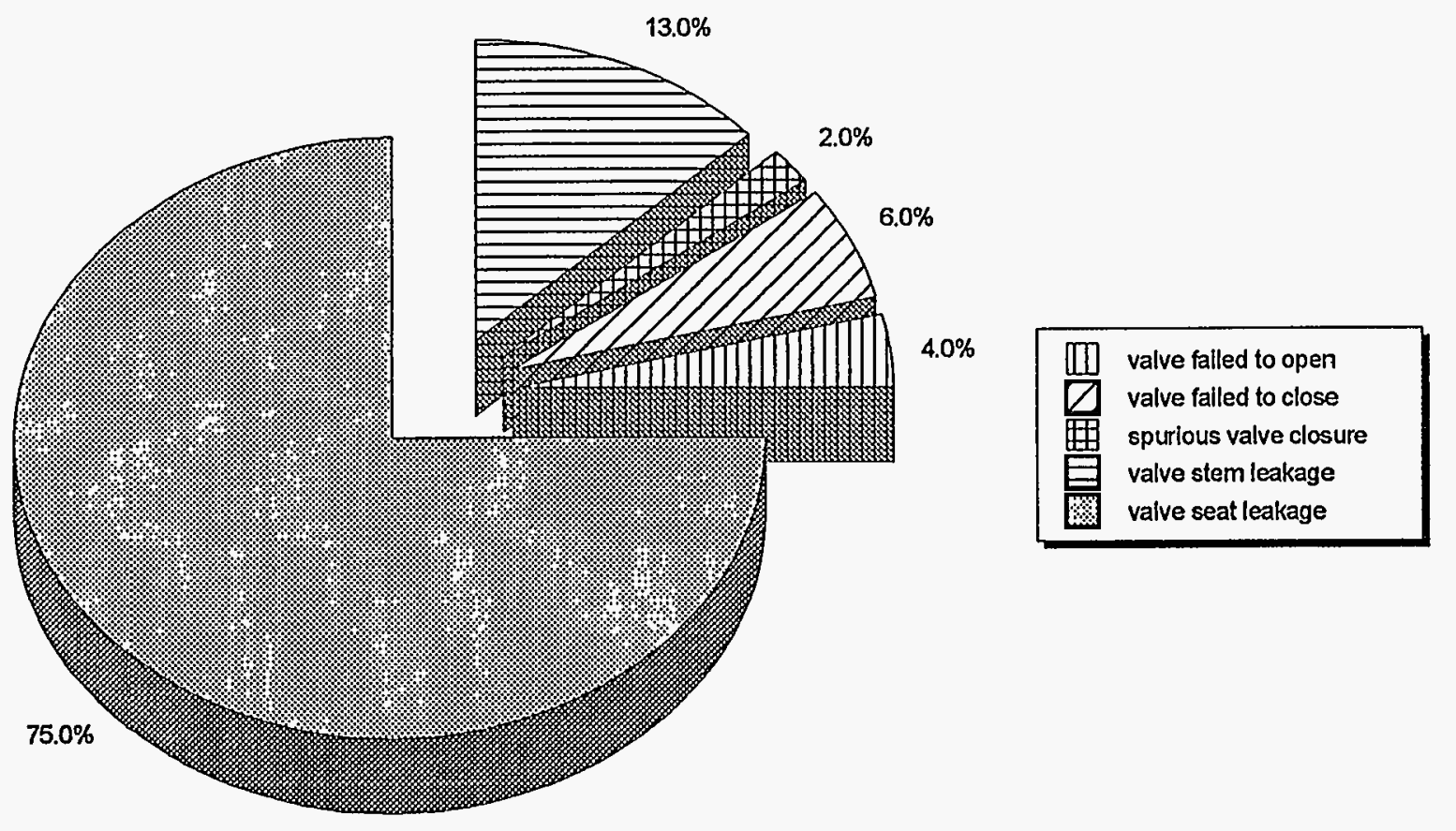

Figure 4.1 MSIV failure mode distribution for BWRs 


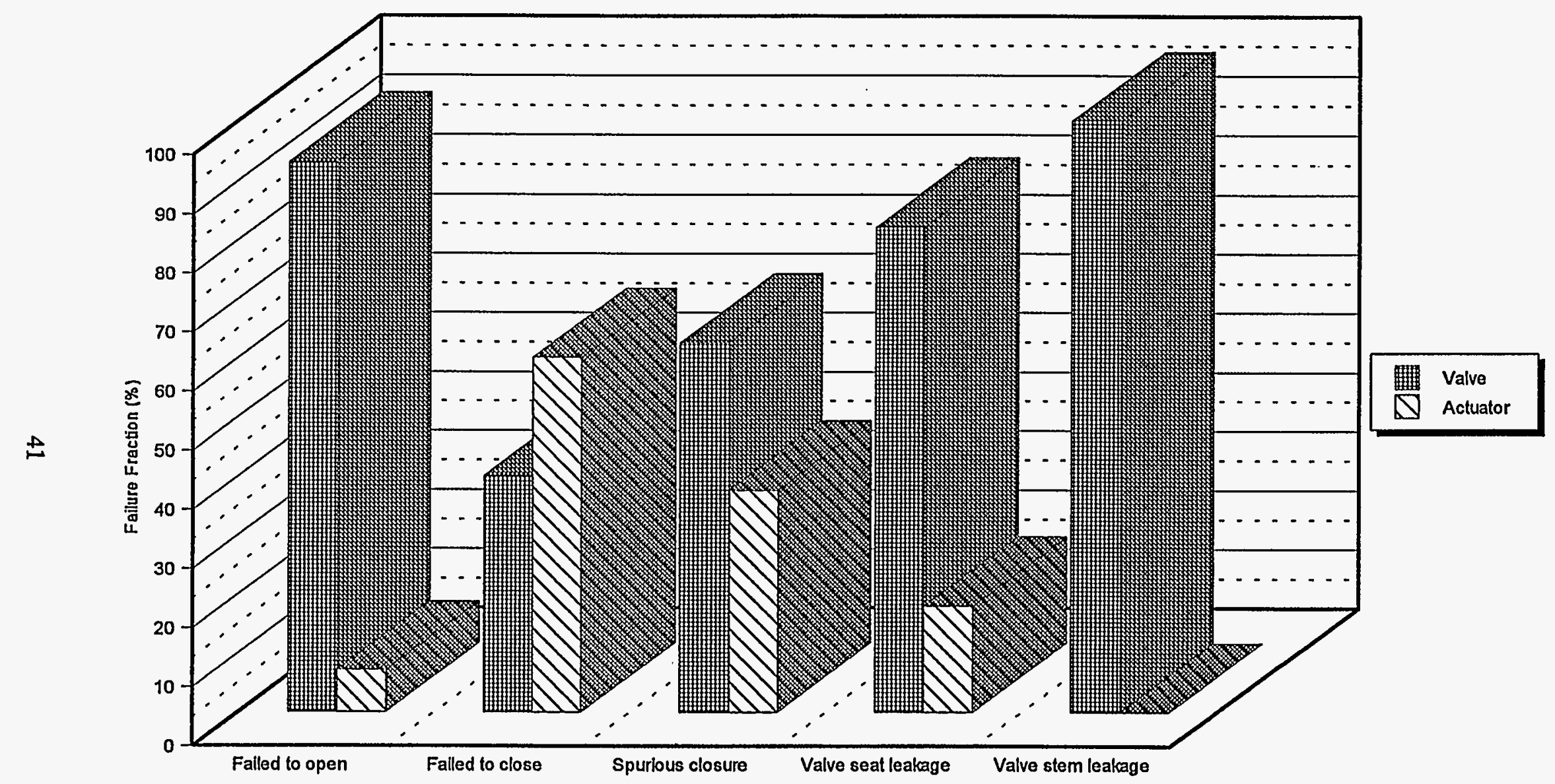

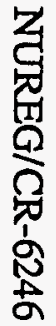

Figure 4.2 Cross correlation of MSIV failure mode and failure area for BWRs 


\section{Operating Experience}

the guide ribs caused by flow-induced vibration. Seat leakage associated with the actuator was attributed to misalignment of the valve stem and the operator stem. The misalignment was attributed to excessive torquing of the yoke rod guides; this caused misalignment of the bottom spring seat such that it forced the attached valve stem off its proper line of travel (see Figure 3.1). This then caused the valve stem to bind on the valve packing, preventing the valve from seating properly. To compound the problem with valve seat leakage, most MSIVs are rolled over nearly 90 degrees from the vertical position. This orientation allows the weight of the actuator to place binding stresses on the yoke rod guides. The combined mechanical and thermal stresses on the yoke rod guides then cause misalignment of the bottom spring seat, causing the valve not to seat properly. These conditions may explain why so many LLR tests failed the acceptance criteria by a large margin (see Subsection 4.5).

\subsubsection{Valve Stem Leakage}

Valve stem leakage is predominately associated with the valve and is due to dry and brittle packing caused by heat and normal wear. The problem is controlled by replacing the valve packing on a regular basis. Valve stem leakage is a concern for the following reasons:

- excessive leakage during plant shutdown could result in potential overcooling of the Reactor Coolant System

- excessive leakage may exceed drywell pressure limits if not corrected

- excessive leakage can generate higher than normal levels of radiation in the drywell

- excessive leakage may cause the valve operator to fail if continuously sprayed with high-energy fluid

\subsubsection{Valve Failure to Close}

As shown in Figure $4.2,60 \%$ of all valve fail-to-close events were associated with the actuator and $40 \%$ were associated with the valve. The actuator problems had multiple failure modes (i.e., electrical, pneumatic, hydraulic, and mechanical). A detailed description of these failure modes is given in Subsection 4.4. In addition to these failure modes, the MSIVs also failed to close at one plant because of inadequate design [see the U.S. Nuclear Regulatory Commission (NRC) Information Notice IN85-84]. Under normal operating conditions, the MSIVs will stroke closed when air is directed by the valve actuator to the top of the air cylinder piston while air is vented from the bottom of the piston (see Figure 3.2). Closure is then assisted by spring forces, by steam flow in the steam lines, and by gravity. Operating air for the MSIVs is stored in air accumulators mounted on the valve assembly with nonsafety-related plant instrument air as backup. Assuming a loss of plant instrument air, the air stored in the safety -related accumulators should be sufficient to close the MSIVs without assistance from steam flow. At this particular plant, however, the accumulators were not capable of closing the valves under low-steam-flow conditions without assistance from plant instrument air. This problem was not recognized during surveillance testing because the plant's MSIV surveillance testing did not call for securing the instrument air supply to the MSIV control system as required by Section XI of the ASME Boiler and Pressure Vessel Code. This code requires that failed-safe valves be tested by observing the operation of the valves upon loss of actuator power (i.e., instrument air and electrical power). Proper implementation of the Code requirements would have detected the actuator design problems much earlier.

As a consequence of this event, General Electric GE Service Information Letter SIL-477 identifies the following concern. If a recirculation line break were to occur during low-power operation, a significant increase may occur in containment pressure. In addition to high containment pressure, there may also be insufficient steam flow to assist with valve closure. For MSIVs located inside containment, the increased containment pressure will affect valve closure by exerting an opening force on the valve actuators. The opening force is due to containment pressure applied to the bottom of the actuator piston via the dump valve (see Figure 3.2). Under such circumstances the MSIV springs alone will not close the MSIV unless the spring force can overcome the combined forces of the opening force caused by containment pressure and the resistive force caused by valve stem packing friction. To determine whether the 
spring force is adequate to close an MSIV, it is necessary to estimate the MSIV's existing spring force, valve stem packing friction force, and the valve opening force that would be exerted by containment pressure in the postulated Design Basis Accident (DBA). A force balance calculation prepared from these estimates will indicate whether some additional air pressure is required to close the MSIVs.

The MSIV manufacturer can furnish estimates of valve stem packing friction force. Such estimates are reliable only for MSIVs maintained according to the manufacturer's recommendations. However, modifications may have been made in packing chamber maintenance, packing material, or gland flange torque relative to the manufacture's recommendations. After such modifications are made, significant uncertainty is introduced regarding the amount of friction force at the valve stem. This uncertainty can be addressed through periodic testing of the closing capability of the MSIV without air assistance. This approach will confirm that the spring force is greater then the friction force, and the minimum air assistance force then becomes that which is necessary to ensure that the accumulator pressure can overcome the containment back pressure. To implement these requirements, General Electric recommended that each plant implement the following:

(1) Review packing chamber maintenance practices to ensure that the valve stem is not subjected to friction forces high enough to prevent valve closure.

(2) During each refueling outage after MSIV leak rate testing or whenever the packing chamber is adjusted, perform a "springs-only" full stroke test to confirm that valve stem packing friction does not prevent the MSIVs from closing.

(3) Perform a force balance calculation of DBA containment pressurization to determine the MSIV pneumatic force needed to close the MSIVs and to keep them closed during the postulated DBA. Based on this calculation, establish a safety-related, low-air-pressure accumulator alarm set point. Modify plant operating procedures to require isolation of the affected MSIV on low air pressure. If the low-air-pressure alarm set point is higher than the normal operational minimum expected accumulator pressure during a DBA, consider implementing one or more of the following alternatives:

- increase air accumulator pressure

- reduce air leakage from the accumulator and supply lines

- increase size of accumulator

(4) Test each MSIV's actuator and accumulator for leak tightness during each refueling outage. The permissible leak rate must be limited to the rate that will prevent the air accumulator pressure from falling to the alarm set point before reactor vessel water level drops to initiate MSIV closure during the postulated DBA.

(5) Modify the applicable licensing basis document so that it is consistent with the plant's actual MSIV closure capability following the postulated DBA.

In summary, NRC Information notice IN85-84 and General Electric Service Information Letter SIL-477 reveals that the following significant problems can occur: inadequate designed air accumulators, programmatic failure to implement ASME code requirements in the MSIV Surveillance Testing Program, and the fact that for some plants, two independent energy sources (i.e., spring and stored air) must both be available to close the valves in the event of a DBA. These documents also provided insights on how DBAs may affect MSIV closure capabilities (i.e., high containment pressure exerting an opening force on the valve actuators). 


\section{Operating Experience}

The failures associated with the valves were related to valve stem binding, separation of disc from valve stem, and internal binding. The valve stem binding was the result of packing-induced friction and binding of the yoke rod guides. The packing-induced friction was attributed to hardening of the valve packing due to heat, inadequate lubrication, and over-torqued packing glands. Binding of the yoke rod guides was attributed to maintenance errors as discussed in Subsection 4.2.1 and thermal cycling. During plant startup the valve bonnet will expand slightly, forcing the yoke rods to move laterally from the valve centerline and, in turn, reducing the clearance between the yoke rod guides and the yoke rods. If this clearance is lost, the lower spring seat will bind on the yoke rods (see Figure 3.1). The binding will cause either the valve stem to bind on the valve packing or the main poppet to bind against the guide ribs as the valve attempts to stroke closed. To help eliminate this problem, the yoke rod guide bushings were readjusted at rated temperature and pressure, and the yoke rods were lubricated. The cause of the disc separation from the valve stem was unknown, but flow-induced vibration may have contributed to the separation. Internal binding was attributed to excessive clearance between poppet and guide rib, causing the poppet to cock in the valve body due to friction. Thermal cycling may have also contributed to internal binding. During plant heatup and cooldown different thermal expansion coefficients between the valve body and poppet will cause the valve to bind if internal clearance is not properly set.

\subsubsection{Valve Failure to Open}

As shown in Figure 4.2 , over $90 \%$ of all valve failure-to-open events were associated with the valve, and less than $10 \%$ were associated with the actuator. The valve failures were mainly due to separation of the pilot poppet assembly from the valve stem, a result of maintenance and design errors. The pilot assembly is used to equalize the pressure above and below the main poppet. If the pilot assembly fails to equalize pressure, and if main steam pressure is greater than approximately $320 \mathrm{psig}$, the actuator will not have sufficient force to open the valve. The valve failure to open due to actuator problems was associated with improper lubrication of the air-operated pilot valves.

\subsubsection{Spurious Valve Closure}

As shown in Figure 4.2 , approximately $63 \%$ of all spurious valve closure events were due to valve problems, and $37 \%$ were due to actuator problems. The valve failures were due to separation of the pilot poppet assembly from the valve stem, sheared valve stems, and failure of a retaining pin. The pilot valve assembly failed because of maintenance and design errors. As discussed in Subsection 3.2, the pilot assembly lifts and supports the main poppet. If it separates from the valve stem, the main poppet will fall into the valve body. The sheared valve stem was attributed in one case to excessive vibration caused by steam flowing through the valve while the valve was not fully back-seated. In other incidents the sheared valve stem was due to high-cycle fatigue caused by excessive wear between the poppet pads and guide ribs. Failure of the retaining pin was attributed to flow-induced vibration that allowed the disc to unthread from the stem and drop into the valve body. The root cause was attributed to design error. The actuator failures were due to failed solenoid valves which dump the air from the air cylinders. The exact cause of failure of the solenoid valves was unknown, but normal aging is suspected because the solenoid valves are normally energized. The combined effects of self heating due to current flow, high ambient temperature, and high humidity will eventually cause the solenoid valves to fail.

\subsection{Major Valve Failure Mechanisms : BWR}

A global distribution of the major valve failure mechanisms for BWRs is shown in Figure 4.3. Failure mechanisms are physical processes that result in failure. ${ }^{1}$ These failure mechanisms were characterized as:

- actuator/disc misaligned with valve stem

- valve stem binding 
- internal binding

- bowed valve stem

- disc/actuator separated from valve stem

- worn valve packing

The total number of failure mechanisms was determined from the NPRDS database to be 135 . The failure mechanisms related to actuator/disc misalignment with the valve stem are associated predominately with valve seat leakage. Valve stem binding, internal binding, and bowed valve stem failure mechanisms are associated with valve seat leakage and failure to close (see Subsections 4.2.1 and 4.2.3). The failure mechanisms related to separation of the disc/actuator from the valve stem are associated with spurious valve closure. The worn valve packing failure mechanisms are associated with valve stem leakage.

\subsection{Major Valve Actuator Failure Modes : BWR}

A global distribution of the major actuator failure modes for BWRs is shown in Figure 4.4. The total number of actuator failure modes was determined from the NPRDS database to be 86 . Note that many of the actuator problems had multiple failure modes (i.e., electrical, pneumatic, hydraulic, or mechanical).

Fifty percent of the failure modes were related to electrical problems. Of these electrical failures, approximately $73 \%$ were related to solenoid valves, and $27 \%$ were related to limit switches. The major stressors affecting these components were associated with normal aging due to mechanical and thermal cycling and maintenance error. Many solenoid valves failed because of improper use of lubricants.

The second most prevalent failure mode, hydraulic failures, represented $31 \%$ of the total. Most of the hydraulic failures were related to problems with the speed control valves, pipe fittings, seals, and hydraulic fluid. The speed control valve would develop small leaks and, over a period of time, cause the valve set point to drift. Small leaks in the dashpot piping and fittings would also occur. The hydraulic fluid itself would deteriorate over time because of heat and congealing. Heat affects the hydraulic fluid viscosity, and congealing, which occurs when air comes in contact with hydraulic fluid at high temperature, causes progressive plugging of the flow control valves. Oil leaks affect the valve closing speed because the leak reduces the fluid inventory. The lower the fluid inventory, the faster the valve will close.

Pneumatic failures represented $15 \%$ of the total failures. Most of the pneumatic failures were related to air leaks due to worn out pilot valves, solenoid valves, failed pipe fittings, and seals. The majority of the failures were attributed to normal aging; however, a few failures were attributed to improper lubrication caused by maintenance error.

Mechanical damage, representing $4 \%$ of the total failures, was mostly related to broken valve springs which were attributed to inadequate heat treatment.

\subsection{MSIV Failure Consequences on Plant Operations : BWR}

A global distribution of the consequences of all BWR failures affecting plant operations is given in Figure 4.5. The total number of failure consequences was determined from the NPRDS database to be 422 , which is the total number of BWR failure records reported in Section 4. 


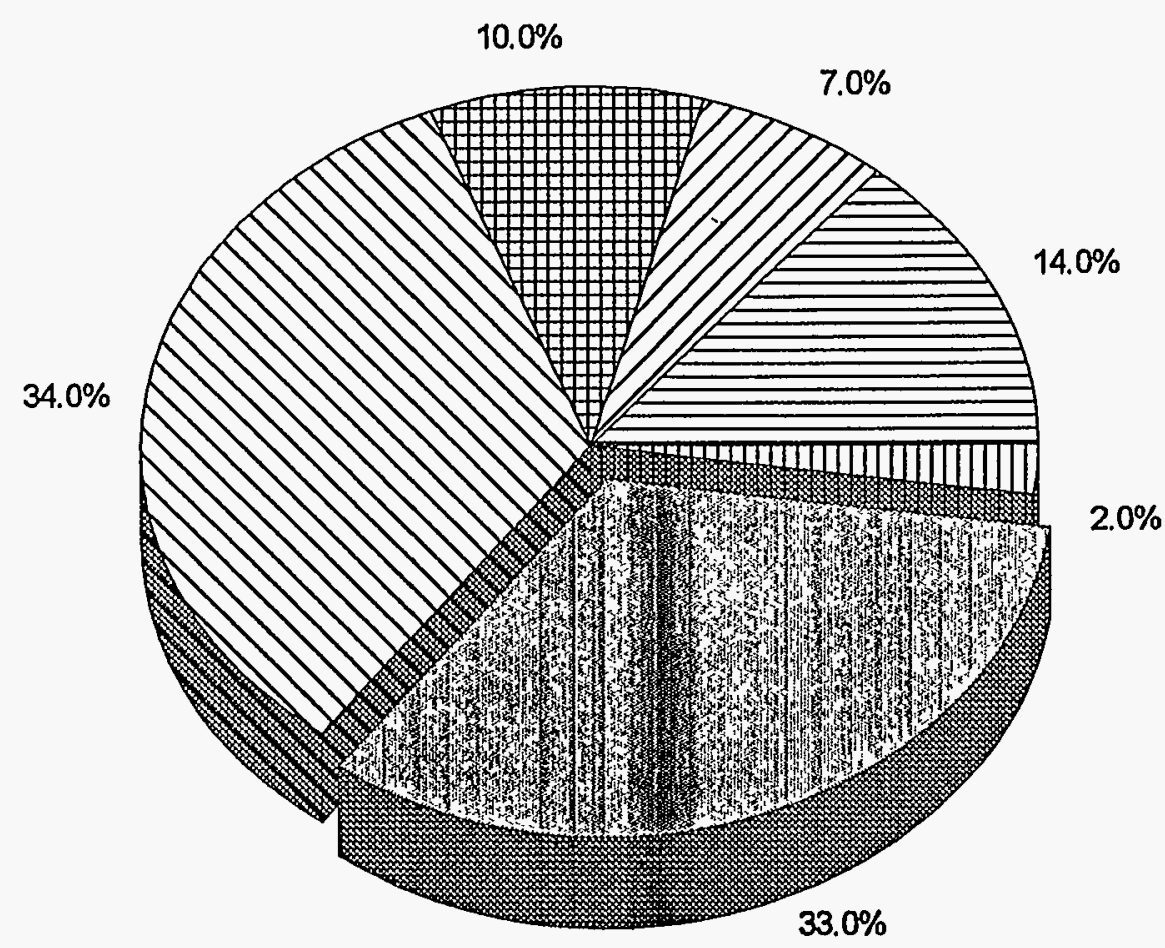

disc separated from valve stem
valve stem binding
internal binding
actuator/disc misaligned with valve stem
wom valve packing
bowed valve stem



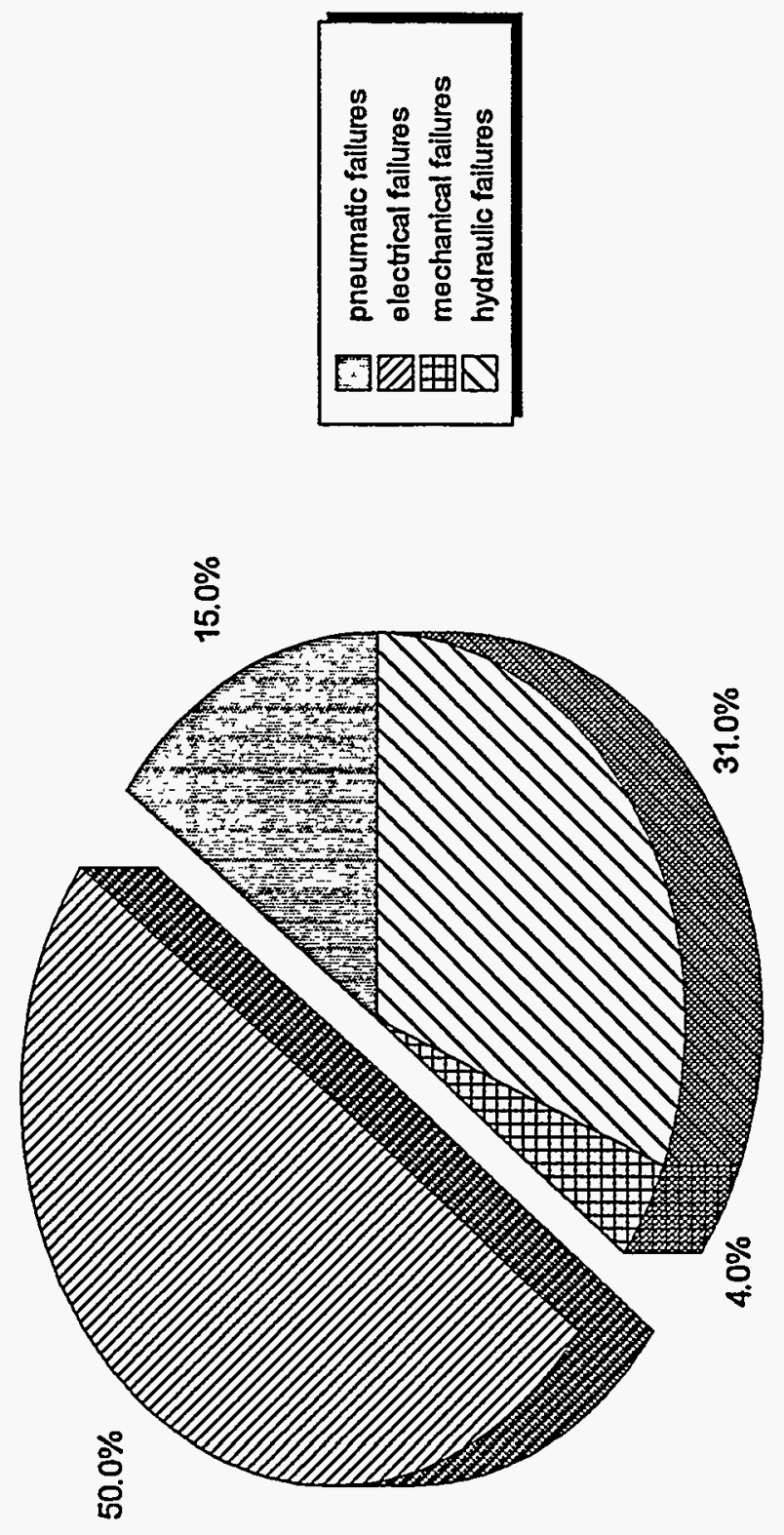

 


\section{Operating Experience}

As can be seen from the chart, $61 \%$ of all failure consequences were in the category of "Failed Local Leak Rate (LLR) Test." Possible reasons for the high failure rate are discussed in Subsection 4.2.1. It is conservatively estimated that $16 \%$ of these events resulted in the "Loss of Containment Integrity." This estimate was based on the number of failure narratives stating that containment integrity was compromised or lost. Because LLR tests are performed during plant shutdown, the amount of leakage that may have existed under postulated accident conditions is indeterminant. Because of this indeterminant condition, the degree to which $10 \mathrm{CFR}$ Pt. 100 limits for design basis accidents was approached for the affected units is unknown.

The second most prevalent failure consequence affecting plant operation was in the category of "Degraded MSIV Train/Channel" which represented $22 \%$ of the total. The MSIV degradations described in Section 4 normally manifest themselves in the form of loss of channel redundancy, adverse local environmental conditions due to steam leakage (i.e., high temperature, radiation, and humidity), and decreased plant availability if the incident required plant shutdown for repairs.

The third most prevalent failure consequence affecting plant operation was in the category of "Failed Fast Valve Closure Test" which represented $10 \%$ of the total. These consequences were the direct result of MSIVs' not closing within the plant's technical specification limits. Normally, the valve stroke time requirements for closure are 3 to 5 seconds. In most cases the failure to meet Technical Specification (TS) requirements were due to problems with the valve's hydraulic speed control circuit. The hydraulic failures were discussed in Subsection 4.4. The other reasons for failure were failed solenoid valves, leaky or faulty pilot valves, broken valve springs, internal binding, and valve stem binding.

The fourth most prevalent failure consequence affecting plant operation was in the category of "Loss of Fast Valve Closure Capability" which represented 5\% of the total. These consequences were a direct result of the MSIV failureto-close events discussed in Subsection 4.2.3, where $60 \%$ of the failures were due to actuator problems (i.e., electrical, pneumatic, hydraulic, and mechanical) and the remaining $40 \%$ were due to valve problems (i.e., valve stem binding, disc separated from valve stem, and internal binding).

The last two groups of failure consequences affecting plant operations were in the category of "Failed Partial Stroke Test" and "Reactor Trip."

The "Failed Partial Stroke Test," representing 1\% of the total, was related to limit switches out-of-adjustment and faulty solenoid valves. The faulty limit switches were attributed to vibration, lack of preventive maintenance, and possible design deficiency. For many plants the limit switches not only provide status indication but also are used to initiate reactor scram if more than one MSIV is less then $90 \%$ open. Therefore, MSIV partial stroke testing not only verifies valve operability; it also verifies that the valve's input signals to the reactor protection system are functioning properly. The faulty solenoid valves prevented the MSIVs from being exercised, and failures were attributed to normal aging.

Valve and valve actuator failures both contributed to "Reactor Trip" incidents, which represented $1 \%$ of the total. The valve failures occurred when the main disc (poppet) separated from the valve stem and fell into the valve body. The blocked steam line created a pressure spike, which then caused the reactor to scram on high neutron flux. The reasons for the spurious valve closure events are discussed in Subsection 4.2.5.

In another incident a reactor scram was due to a faulty pressure regulator in the valve operator air supply line. The pressure regulator failed in the closed position, allowing too much air to enter the air cylinder when the MSIV was first opened. The MSIV consequently opened too fast, causing reactor pressure to decrease and the reactor vessel 


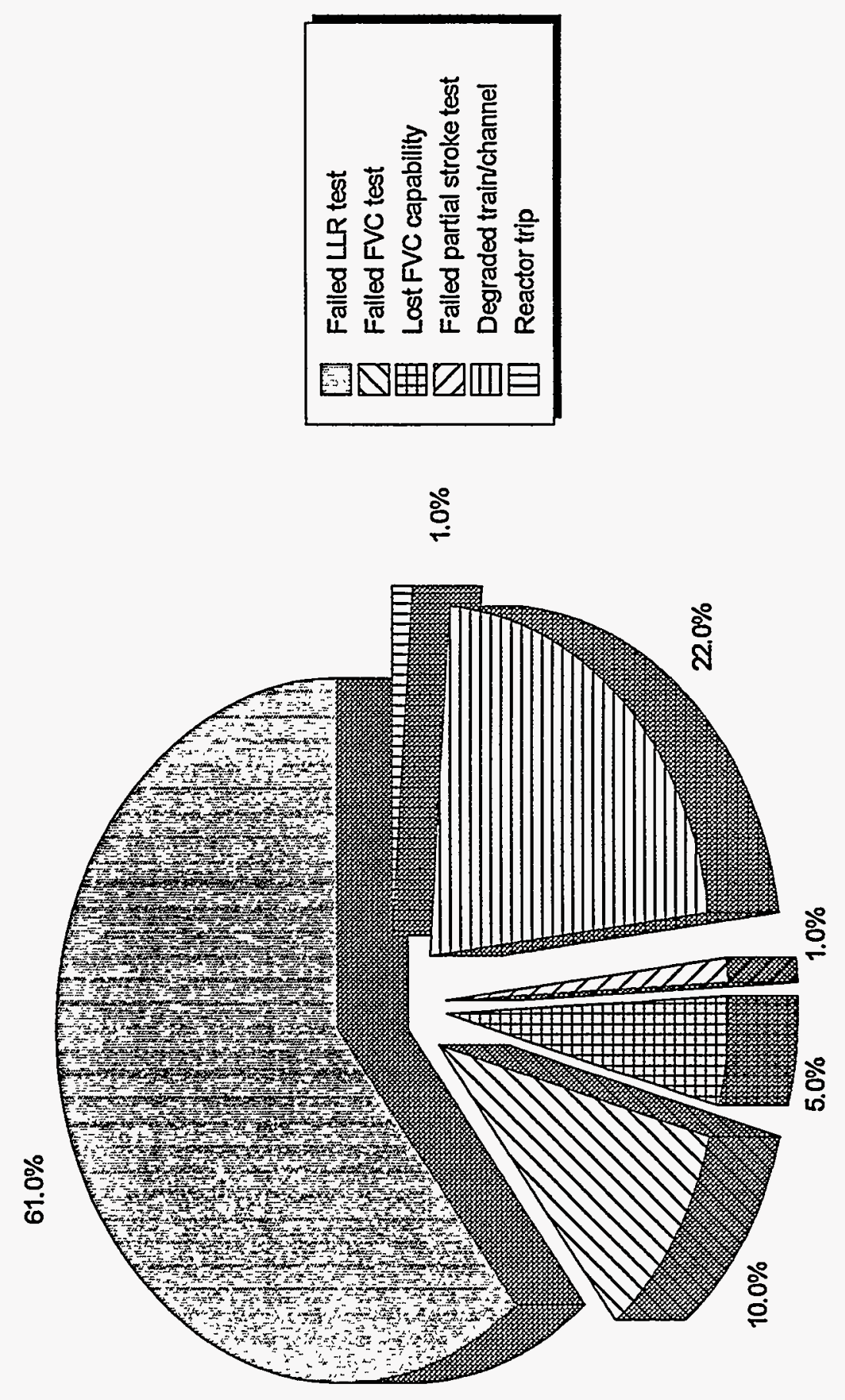

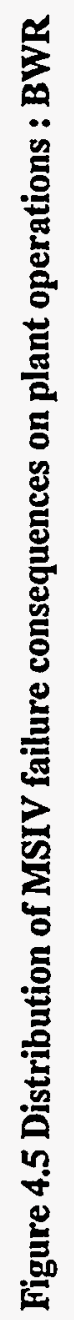




\section{Operating Experience}

level to swell. The resulting high reactor vessel level generated a Group 1 Isolation signal. The reasons the relief valve failed were unknown.

\subsection{Method of Failure Detection : BWR}

Figure 4.6 shows the cross correlation of major valve failure modes and their method of detection.

For the "failed-to-open" event, $7 \%$ of the failures were detected by surveillance testing and $93 \%$ failed on demand. The majority of the failure-to-open events were due to separation of the pilot poppet assembly from the valve stem. The separation actually occurred when the plant was at full power. However, the failure to open was not discovered until after the reactor scrammed and the subsequent attempts by the operator to reopen the MSIVs.

For the "failed-to-close" event, $60 \%$ of the failures were detected by surveillance testing and $40 \%$ failed on demand. The reasons surveillance testing did not detect a higher percentage of "failed-to-close" events can be attributed to inadequate surveillance testing. For example, NRC Information Notice IN94-08 determined that for one BWR facility, the valve failed to close because of excessive wear of the guide ribs, resulting in mechanical binding of the valve poppet. This failure mechanism (i.e., internal binding) is consistent with the findings of this report. Surveillance testing (i.e., partial stroke testing) failed to detect this condition because the test did not consider limit switch tolerance and the design characteristics of the pilot valve assembly. In this situation the limit switch tolerance was greater than the pilot valve travel and, therefore, gave a false indication that the valve poppet was $90 \%$ close. In reality the valve poppet never moved. In another instance described in IN85-84 and Subsection 4.2.3, the safetyrelated air accumulators at one plant were not capable of closing the MSIVs under low steam flow conditions concurrent with loss of plant instrument air. This problem was not recognized during surveillance testing because the test did not call for securing the non-safety-related instrument air supply from the MSIV control system as required by Section XI of the ASME Boiler and Pressure Vessel Code. Proper implementation of the Code requirements would have detected the actuator design problems much earlier.

For the "spurious valve closure" event, $25 \%$ of the failures were detected by surveillance testing and $75 \%$ were detected by routine observation. Spurious valve closure during surveillance testing was usually the result of personnel error or equipment malfunction. In one event the MSIV closed during surveillance testing of the main steam line high-radiation instrumentation which should not have occurred because of channel redundancy. In another event the main poppet on one MSIV separated from its valve stem during performance of the Fast Valve Closure Test. The valve failure was attributed to internal binding. These incidents illustrate that spurious events can occur during surveillance testing.

All other "spurious valve closure" events were detected by reactor trips. The spurious valve closure events normally cause the reactor to scram on high neutron flux or low reactor vessel level due to shrinkage.

For the "valve stem leakage" event, $43 \%$ of the failures were detected by surveillance testing and $57 \%$ were detected by routine observation. Hydrostatic and LLR testing were the primary method by which valve stem leakage events were detected by surveillance testing. All other valve stem leakage events were detected by routine observations such as plant walkdowns.

Valve seat leakage events were detected primarily by LLR testing.

As can be seen from Figure 4.6, $93 \%$ of the valve "failed-to-open" events and $40 \%$ of the valve "failed-to-close" events were detected by "failed on demand." These high percentages indicate that the current MSIV monitoring, inspection, and maintenance programs and post-trip analysis may be inadequate. 
Operating Experience

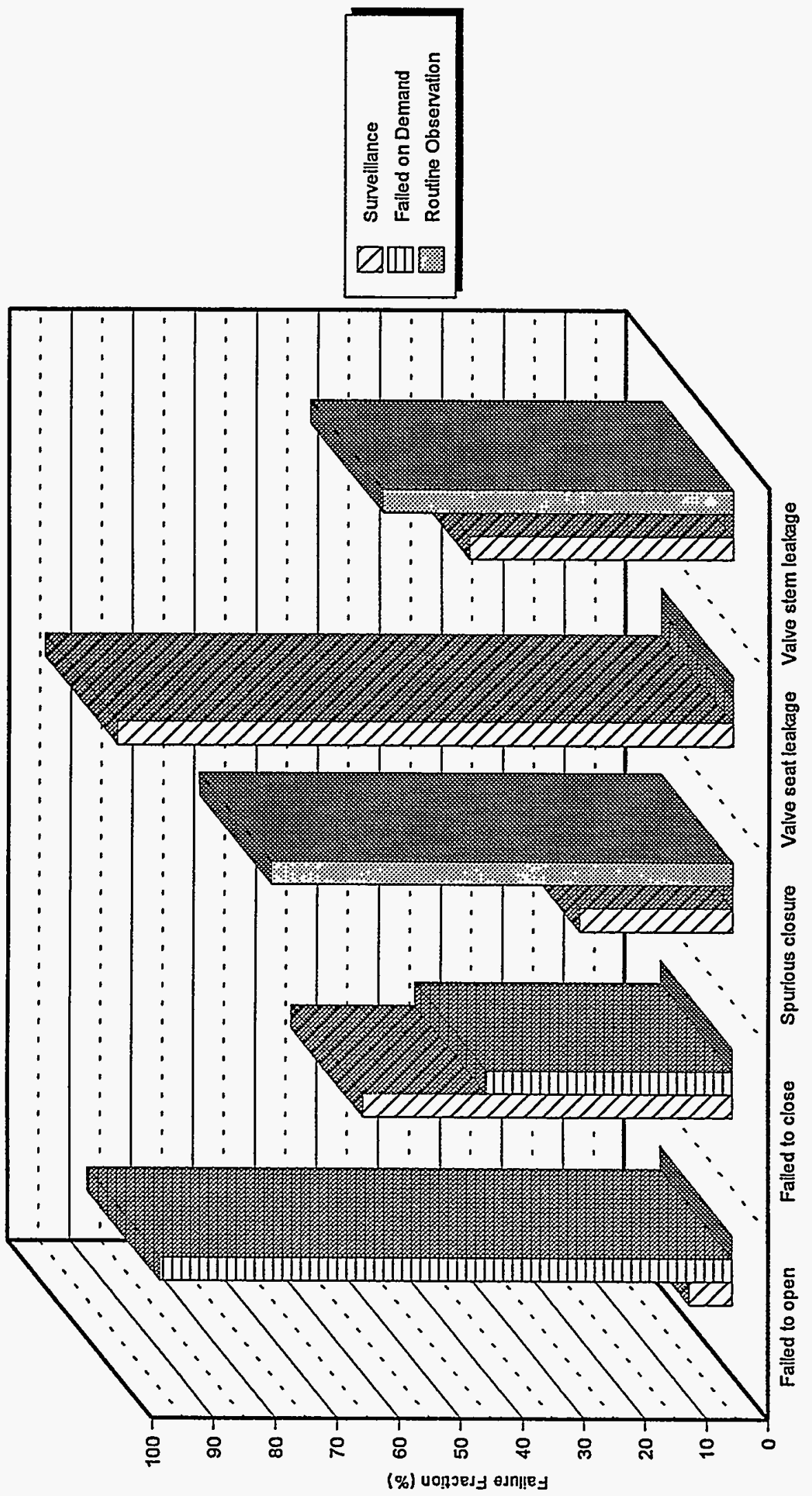

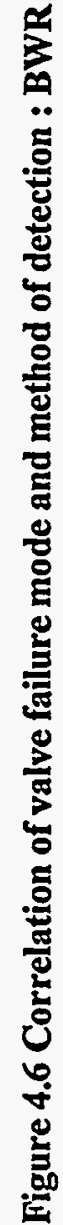




\subsection{Major Stressors Affecting MSIVs : BWR}

A global distribution of major stressors affecting BWR valves is shown in Figure 4.7. The total number of stressors was determined from the NPRDS database to be 472 . The stressors include both normal and error-induced stressors previously defined and published. ${ }^{1}$ The normal stressors were associated with normal aging due to mechanical and thermal cycling, where as, error-induced stressors were associated with maintenance errors and/or design errors. As can be seen from the figure, $56 \%$ of all stressors found in this study identified normal aging as the most significant stressor affecting BWR valves followed by maintenance errors (15\%), design errors (12\%), unknown (8\%), others $(5 \%)$, and scale buildup (4\%). Other stressors include friction, vibration, metal fatigue, and thermal creep.

The majority of the normal aging stressors resulted in valve stem and valve seat leakage. However, maintenance and design errors may have contributed to valve seat leakage at a higher percentage than indicated by the NPRDS data. In many incidents normal aging was apparently listed as the root cause for valve failure simply because no other explanation was available, or because the failure mechanisms or stressors were not well understood.

Most of the maintenance errors were related to pilot valve assemblies not properly installed, binding of the yoke rod guides due to improper clearance between yoke rod guides and bushings, main disc not properly aligned with guide ribs, main disc misaligned with valve stem, and inadequate lubrication of the valve stems and over-torqued packing glands. The source of some of these maintenance problems can be directly traced to inadequate maintenance procedures and training.

\subsection{Major Stressors Affecting Valve Actuators : BWR}

A global distribution of major stressors affecting BWR valve actuators is shown in Figure 4.8. The total number of stressors was determined from the NPRDS database to be 95 . As can be seen from the figure, $44 \%$ of all stressors in this study identified maintenance error as the major stressor affecting BWR valve actuators. The other stressors included normal aging $(28 \%)$, design error $(7 \%)$, vibration $(6 \%)$, congealing $(2 \%)$, high ambient temperature $(1 \%)$, and unknown (12\%). Note that maintenance error, not normal aging, is the principal stressor affecting BWR valve actuators. Root cause analysis performed by the utilities reveal that, in many instances, the MSIVs failed to close or meet TS limits for fast closure because of the following maintenance problems:

- The limit switches were not properly adjusted

- The hydraulic dash pot was not properly adjusted

- The hydraulic fluid had not been changed on a regular bases

- Solenoid valves has been rebuilt or refurbished with the wrong lubricant. (Lubricant would harden on the ports and o-rings causing the solenoid valve to malfunction. This issued was addressed in IN88-43.)

- The valve control circuit malfunctioned because of air and hydraulic system leaks. (In many instances the air leaks were due to improperly installed air control lines and fittings. The hydraulic leaks were also subject to installation problems.)

As with the valves, some of the maintenance problems associated with the valve operator can be traced to inadequate maintenance procedures and training. Note also that the stressors associated with normal aging may be overestimated because for most electrical equipment, high ambient temperature, self heating due to current flow, and high humidity are the primary aging mechanisms. High temperature and humidity will break down electrical equipment insulation resulting in open or short circuits. A more detailed study is necessary to determine which of these stressors are the most responsible for electrical equipment failures. 


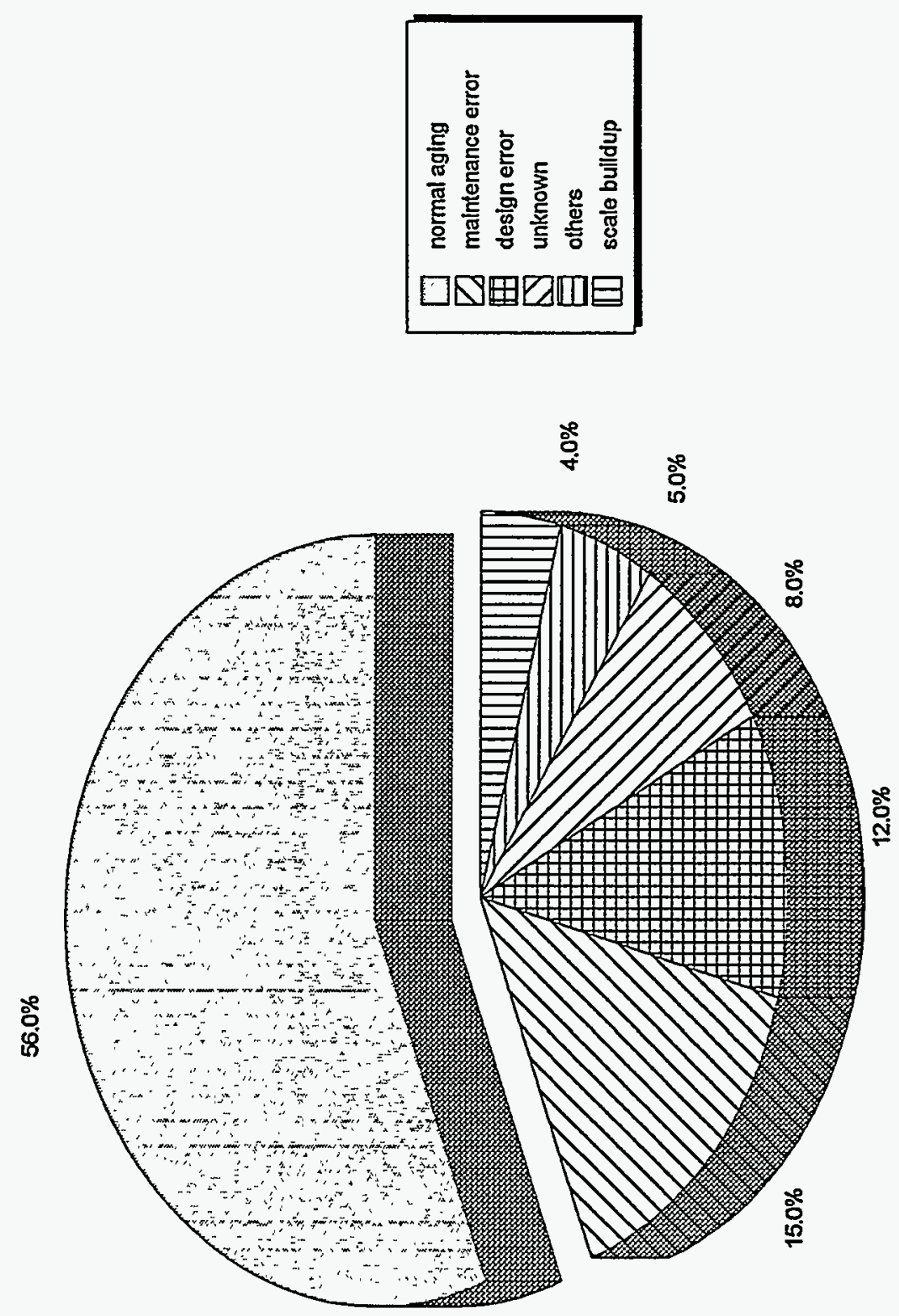

焉 
Operating Experience

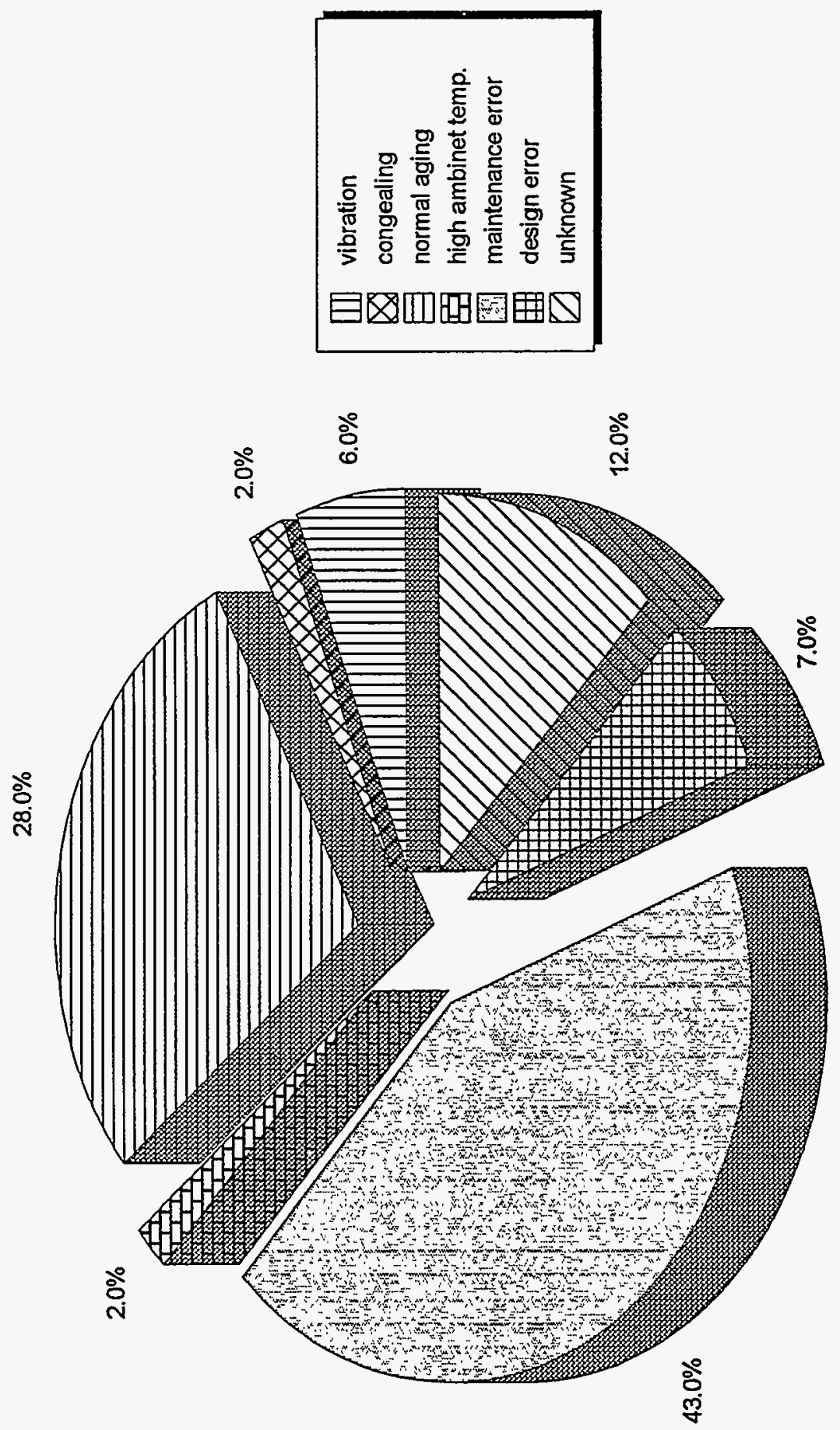

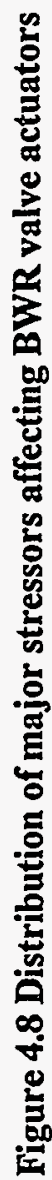




\subsection{MSIV Failure Mode Distribution : PWR}

The MSIV failure mode distribution for PWRs using check, globe, and gate valves is shown in Figure 4.9. The distribution is determined by dividing the number of failures for each failure mode by the total number of failures for that valve type. The total number of MSIV failure modes for all three valve types was determined from the NPRDS database to be 219. The following subsections summarize the results for each valve type.

\subsubsection{Check Valves}

The total number of failure modes related to check valves was determined from the NPRDS database to be 132 . The predominate failure modes affecting these valves are valve failed to close (30\%) and valve stem or shaft leakage (30\%). The other failure modes were associated with body-to-bonnet leakage (15\%), valve failed to open (13\%), spurious valve closures (11\%), and spurious valve openings ( $1 \%$ ).

\subsubsection{Globe Valves}

The total number of failure modes related to globe valves was determined from the NPRDS database to be 29. The predominate failure mode affecting these valves is valve stem leakage (31\%). The second highest number of failures was associated with valve failed to close $(24 \%)$ followed by valve failure to open (21\%), spurious valve closure $(17 \%)$, and body-to-bonnet leakage (7\%). No spurious valve openings were reported.

\subsubsection{Gate Valves}

The total number of failure modes related to gate valves was determined from the NPRDS database to be 58. The predominate failure mode affecting these valves was valve failed to open $(36 \%)$. The second highest number of failures was associated with valve failed to close (26\%), followed by spurious valve closure (19\%), valve stem leakage (12\%), spurious.valve openings ( $5 \%)$, and body-to-bonnet leakage (2\%).

\subsection{Cross Correlation of Valve Failure Modes and Valve Failure Areas : PWR}

The cross correlation of valve failure modes and valve failure areas for PWRs using check, globe, and gate valves is shown in Figure 4.10A, 4.10B, and 4.10C respectively.

\subsubsection{Check Valves}

Figure 4.10A depicts, for each failure mode, the percentage of failures that were due to valve problems and those that were due to actuator problems. The actuators used with these valves are of the air-to-open, spring-to-close type. In most cases, a hydraulic dashpot is used to control valve opening and closing speed. A brief description of each failure mode and its associated failure area is given in the following paragraphs. 


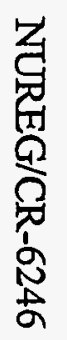

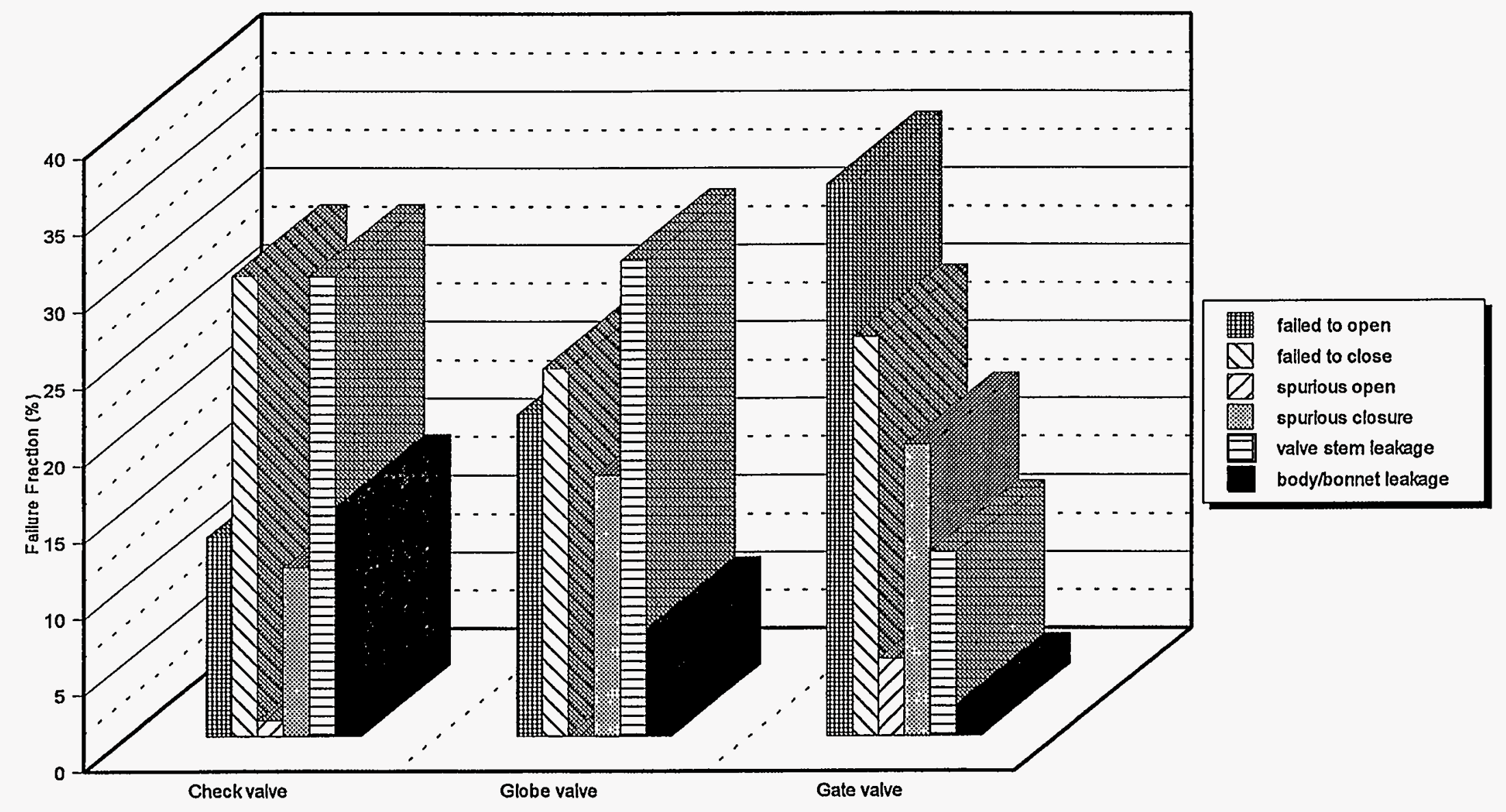

Figure 4.9 MSIV failure mode distribution for three PWR valve types 


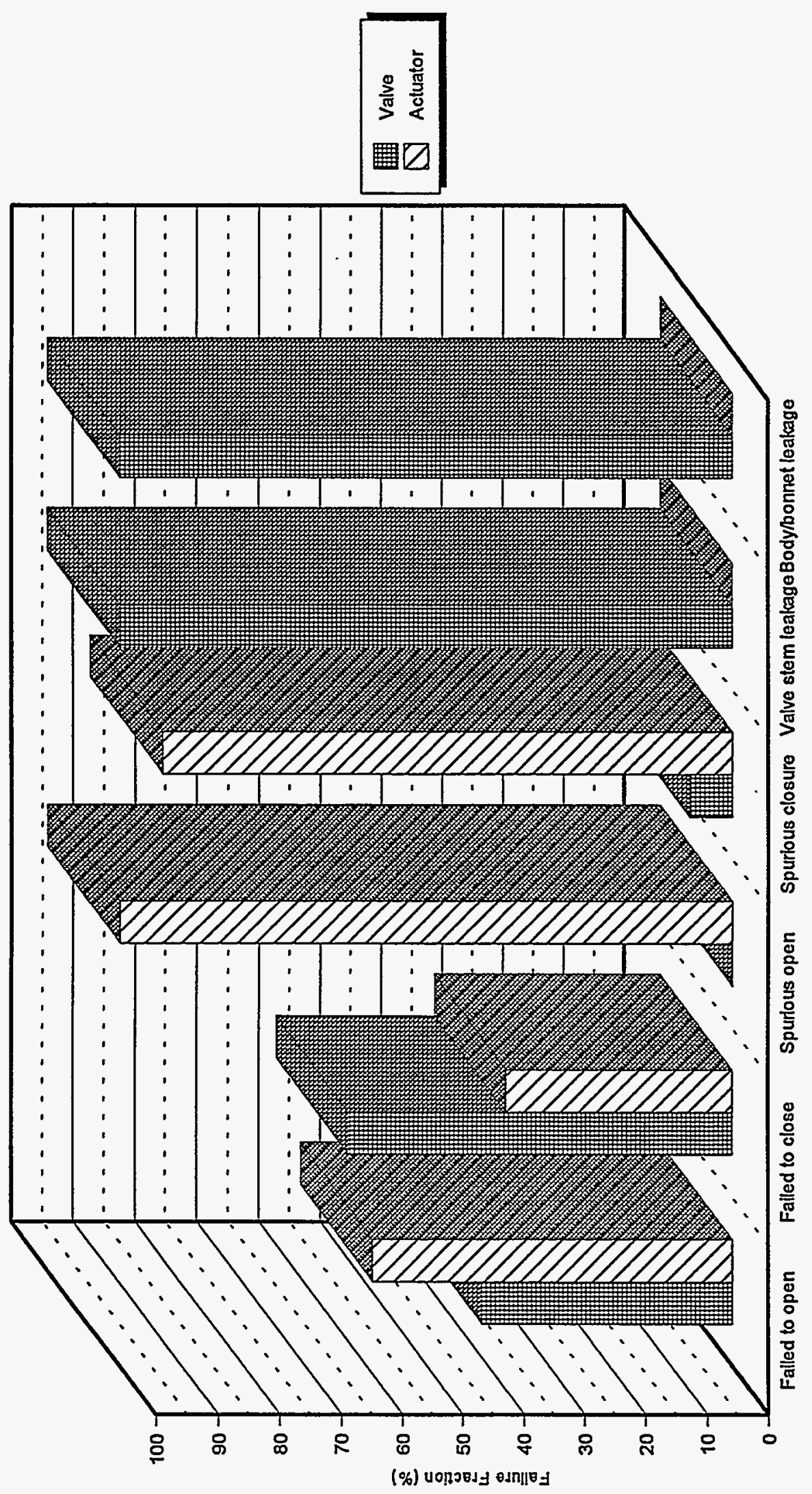

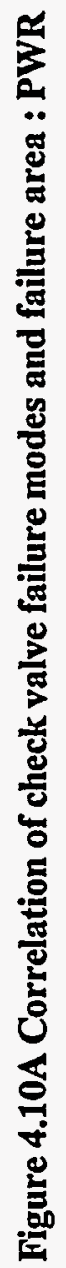




\section{Operating Experience}

\subsubsection{Failure to Open}

As shown in Figure 4.10A, 59\% of all valve failed-to-open events were associated with actuator problems and $41 \%$ were associated with the valve. The actuator problems were related to failed solenoid valves, dirty or closed airmetering valves, and binding in the air cylinder. In many incidents the solenoid coils opened because of hightemperature breakdown (i.e., high ambient temperature and self heating), however, in one incident a solenoid valve froze because of cold weather. In other incidents the solenoid valves failed because they were not properly terminated or lubricated. The slow air metering valves, which control the rate air is admitted to the air cylinders, were either dirty due to lack of preventive maintenance or closed because of maintenance error. The cause of binding in the air cylinder was unknown. However, binding likely occurred for the reasons given in Subsection 4.10.1.2.

The valve problems were related to valve stem binding, internal binding, and loose internal parts. Valve stem binding was the result of packing-induced friction which occurred when the packing gland was over-tightened due to maintenance error. Internal binding was attributed to seized bearings on valve shaft and normal wear, which caused internal parts to misalign. Symptoms of internal misalignment appeared as abrasions or galling on upper and lower hinge pins and on the valve cover bushings. Thermal cycling also contributed to internal binding. This situation usually occurs during plant start-up when the valves are heating up. In other incidents loose internal parts prevented limit switches from making up, causing the valve open circuit to malfunction.

\subsubsection{Failure to Close}

As shown in Figure 4.10A, 63\% of all valve failed-to-close events were associated with valve problems, and $37 \%$ were associated with actuator problems. The valve problems were related to valve shaft binding, disc jamming in the valve body, and internal binding. Valve shaft binding, the predominate failure mechanism, was attributed to excessive friction caused by hardening of the valve packing due to heat, inadequate lubrication of the valve packing, and overtorqued packing glands. With the exception of heat, most of the failures were due to maintenance error. Instances where the valve disc was jammed in the valve body were due to broken valve stops. The reasons for the broken valve stops were unknown, but it is suspected that flow-induced disc oscillations may have caused the valve disc to repetitively impact the valve stop, eventually causing the valve stop to fail. With no valve stop, the disc would overtravel and jam into the valve body. Some plants have attempted to rectify this problem by installing two additional back stops. Internal binding was attributed to worn out internal parts (e.g., tail link and, disc pin) and failure to squarely machine the stuffing box to the valve body.

The actuator problems were related to mechanical failures, failed solenoid valves, failed limit switches, and dirty flow orifices. The majority of the actuator problems, however, were related to mechanical failures such as mechanical binding in the air cylinder, improper installation of operator linkage, worn-out valve springs, and corroded air cylinder shaft, bushings, and seals. The corroded air cylinder shaft, bushings, and seals were due to steam leaking from the valve packing and condensing on the valve operator arm. The moisture then migrated down the operator arm to the operator's internals (see Figure 3.4). Over time the moisture corroded the air cylinder shaft, bushings, and seals, eventually preventing shaft movement. Binding in the air cylinder was attributed to dried, caked lubricant on the cylinder walls, preventing the piston from moving.

\subsubsection{Spurious Opening}

Only one spurious valve opening event occurred. This was when the affected unit was shut down for maintenance and was in the process of performing the monthly safety injection (SI) logic test. During the process of removing DC fuses from the SI logic channels, all MSIVs inadvertently opened. The reason for the failure is unclear. 
However, this event illustrates how operator error and/or undetected equipment failures can lead to abnormal plant transients during surveillance testing.

\subsubsection{Spurious Closure}

As shown in Figure $4.10 \mathrm{~A}, 93 \%$ of all spurious valve closing events were associated with actuator problems, and $7 \%$ were associated with valve problems. The actuator problems were related to failed limit switches, failed solenoid valves, cracked air lines, and blown rupture discs. The limit switches failed because of mechanical binding which was attributed to degradation of the O-rings due to high ambient temperature. The limit switches were not environmentally qualified to operate in a high-temperature environment. The solenoid valves failed due to normal aging. A cracked air line reduced air cylinder pressure which allowed the disc to move in the closed direction. The combined effect of low air cylinder pressure and steam flow eventually caused the valve to close. However, blown rupture discs were mostly responsible for spurious valve closure events. The blown rupture discs dump the air from the air cylinders, causing the valves to close due to steam flow and the force generated by the springs. The reasons the rupture discs blew are unknown, but it was likely a result of fatigue failure caused by air cylinder pressure fluctuations. The pressure fluctuations were thought to be caused by normal variations in the plant air supply pressure and changes in ambient air temperature. The valve problems were related to improper installation of the valve cover (bonnet), which allowed the valve disc to travel only 62 degrees in the open position. The valve was capable of remaining open until a momentary drop in plant air pressure reduced the air cylinder pressure. The drop in air pressure and the valve not being fully open resulted in rapid closure due to steam flow forces. Note that spurious valve closure is a safety issue because these events challenge the steam generator code safety valves, the poweroperated relief valve, and the auxiliary feedwater system. These events force the primary plant heat removal mechanisms to respond rapidly to mitigate the main steam system upset using the above systems and components.

\subsubsection{Shaft Leakage}

Valve stem leakage is predominately associated with the valve and is due to dry and brittle packing caused by heat and normal wear. The problem is controlled by replacing the valve packing on a regular basis.

\subsubsection{Body-to-Bonnet Leakage}

The body-to-bonnet leakage is predominately associated with the valve and is due to failed gaskets and seal rings caused by normal wear and possibly steam erosion. The problem is controlled by replacing the gaskets and seal rings as they deteriorate.

\subsubsection{Globe Valves}

For each failure mode, Figure 4.10B depicts the percentage of failures that were due to valve problems and those that were due to actuator problems. For these valves the majority of the valve actuators are the air-to-open, spring-toclose type. However, one plant did use a hydraulic-to-open, pneumatic-to-close-type actuator. A brief description of each failure mode and its associated failure area is given in the following paragraphs.

\subsubsection{Failure to Open}

As shown in Figure $4.10 \mathrm{~B}, 83 \%$ of all valve failed-to-open events were associated with actuator problems, and $17 \%$ were associated with the valve. The actuator problems were related to a failed solenoid valve, a failed limit switch, a blown fuse, a plugged hydraulic vent orifice, and a faulty air pilot valve. The failed solenoid valve and plugged hydraulic vent orifice occurred on the hydraulic-to-open, pneumatic-to-close-type actuator. All other failures were 
Operating Experience

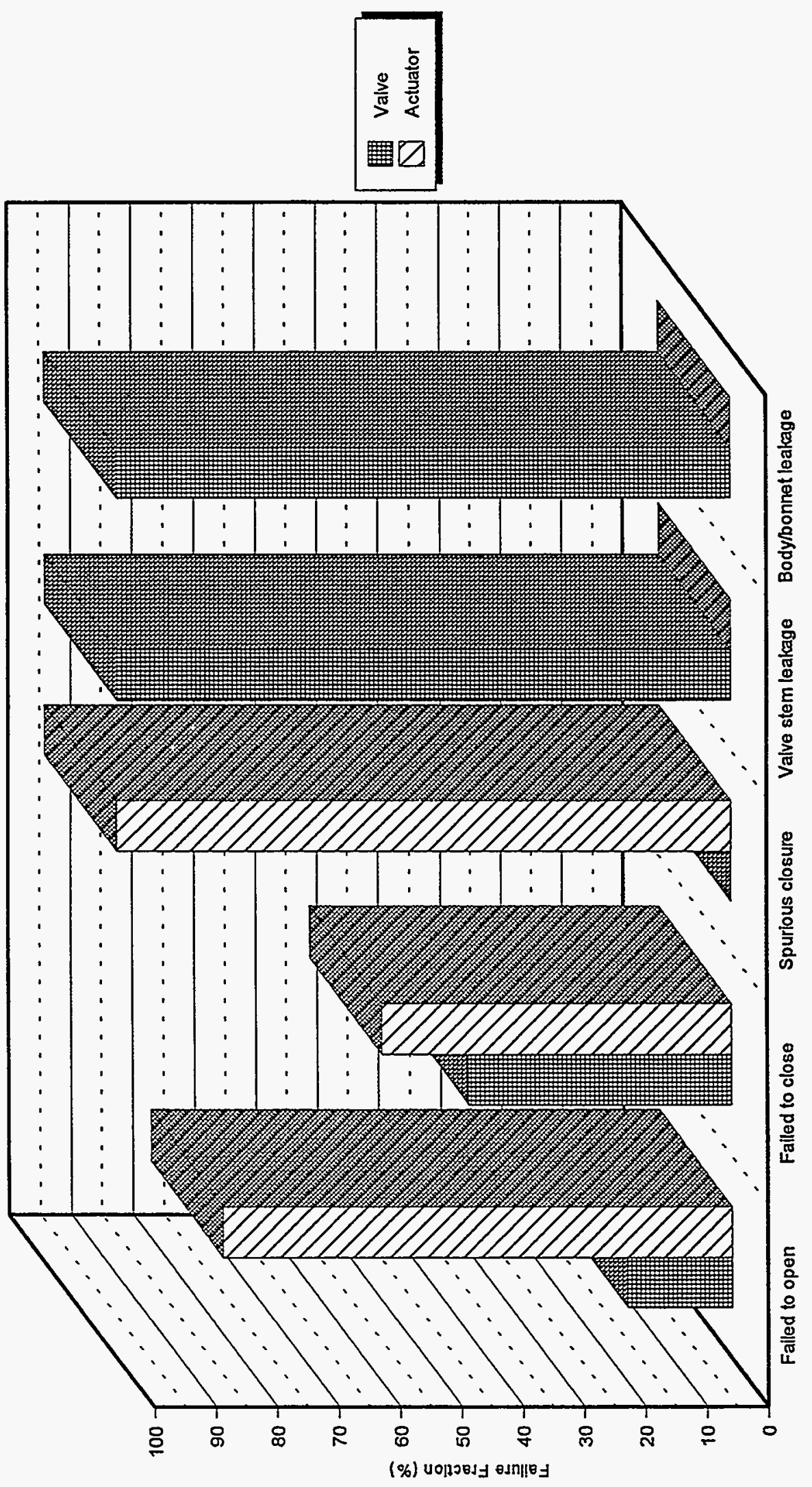

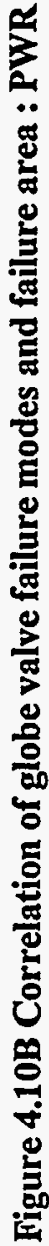


related to the air-to-open, spring-to-close-type actuator. The solenoid valve failed because of improper installation, and the limit switch failed to make up because the limit switch actuator arm was out of adjustment. The blown fuse caused the air supply solenoid valves to close and block air flow to the air cylinder. The faulty pilot valve leaked air excessively, causing the air accumulator to bleed down more than the supply could recover.

The valve problem was related to installation of an oversized rider ring on the valve plug which caused the valve to bind when opened.

\subsubsection{Failure to Close}

As shown in Figure 4.10B, 57\% of all valve failure-to-close events were associated with actuator problems, and $43 \%$ were associated with the valve. The actuator problems were related to electrical and hydraulic failures. The electrical failures were due to loose wiring connections on solenoid valves and a loose actuator arm that prevented the limit switch from making up. The hydraulic failure occurred on the hydraulic-to-open, pneumatic-to-close-type actuator. The pump discharge strainer was installed backwards; this reversed pump action, causing the actuator to indicate that the valve was closed when it was actually full open. This problem was discovered when the unit was shut down for maintenance. The error likely occurred when the actuator was installed during the previous overhaul.

The valve problems were related to binding of the yoke rod guides and to valve stem binding. Binding of the yoke rod guides (i.e., stanchion guides) was related to air-operated globe valves and was the predominate reason the valves failed to close. Binding of the yoke rod guides was attributed to maintenance error and thermal cycling (see Subsection 4.2 .3 for additional information). Valve stem binding was attributed to excessive friction caused by hardening of the valve packing due to heat, inadequate lubrication of the valve packing, and over-torqued packing glands.

\subsubsection{Spurious Closure}

All spurious valve closure events occurred during surveillance testing and were due to actuator problems. In many incidents a limit switch failed to actuate and reopen the valve upon reaching the $90 \%$ open position. Failure of the limit switches to actuate was attributed to the limit switch actuator arm's being out of adjustment and failure of the limit switch itself due to aging. Other spurious valve closure events occurred because of faulty test switches and poorly designed test circuits. In one incident power was interrupted to the solenoid dump valves because of misoperation of a test switch. The test switch momentarily interrupted power to the dump solenoid valves when the operator did not allow the switch to spring-return to the normal position. In another incident a hydraulic dump valve failed open, causing the valve to close; It was suspected that the dump valve stuck open due to contaminated hydraulic fluid. Nearly all spurious valve closure events resulted in a reactor trip due either to a low-low steam generator (SG) level or a high-pressure differential between SG.

\subsubsection{Stem Leakage}

Valve stem leakage was predominately associated with the valve and was due to dry and brittle packing caused by heat and normal wear. The problem is controlled by replacing the valve packing on a regular basis.

\subsubsection{Body-to-Bonnet Leakage}

The body-to-bonnet leakage was predominately associated with the valve and was due to failed gaskets and seal rings caused by normal wear and possibly steam erosion. The problem is controlled by replacing the gaskets and seal rings as they deteriorate. 


\subsubsection{Gate Valves}

For each failure mode, Figure $4.10 \mathrm{C}$ depicts the percentage of failures that were due to valve problems and those that were due to actuator problems. The valve problems included both Type I and II gate valves (see Subsections 3.3.3.1 and 3.3.3.2). The Type I gate valves use hydraulics to open and close, whereas, the Type II gate valves use hydraulics to open and pneumatics to close (see Subsections 3.4.3.1 and 3.4.3.2 respectively). A brief description of the valve failure modes and associated failure area is given in the following paragraphs.

\subsubsection{Failure to Open}

As shown in Figure $4.10 \mathrm{C}, 95 \%$ of all valve failed-to-open events were associated with actuator problems, and $5 \%$ were associated with the valve. The actuator problems associated with the hydraulic-to-open, hydraulic-to-close-type actuator were related to hydraulic pump failures, hydraulic directional control valve failures, leaky pipe fittings, failed gaskets, and a failed solenoid valve. However, the majority of the failures were related to hydraulic pump and hydraulic directional control valve failures. The hydraulic pumps failed because of wear and loss of hydraulic fluid due to system leaks. Hydraulic system leaks were due to fitting failures caused by cyclic fatigue and maintenance error. In most incidents pump failure was not detected until a low-accumulator pressure alarm was activated in the main control room. This alarm was activated on several occasions only after the hydraulic pump lost suction when the oil reservoir was depleted. Failure of the hydraulic pumps due to small hydraulic system leaks could have been avoided if a low-reservoir-level alarm had been provided in the main control room. The main hydraulic control valves and the accumulator hydraulic dump valves failed on many occasions. The failures were attributed to worn out $\mathrm{O}-$ rings and gaskets, which was due to normal aging. However, design and maintenance errors may be the major reasons the directional control valves are prematurely aging. Normally, the inability to open the MSIV is related to failures associated with the main hydraulic control valves. However, spurious operation of the accumulator dump valve in either train will prevent MSIV opening. This event did occur on one occasion. The train B accumulator dump valve spuriously opened dropping train B hydraulic pressure. Because the hydraulic pump is connected to both trains through check valves, the flow demand on the pump from both trains was such that it could not develop sufficient discharge pressure in train A to open the valve. Evidently no flow restrictors are located downstream of the isolating check valves to limit pump flow in each train, or the pump is undersized. For this operating mode the two control trains are not independent of each other. However, failure to open the MSIV is not a safety concern. MSIV fast closure is the only required safety function. The failed solenoid valve prevented operation of the main hydraulic control valve; this, in turn, prevented opening of the MSIV. Solenoid valve failure was attributed to normal aging.

The actuator problems associated with the hydraulic-to-open, pneumatic-to-close-type actuator were related to hydraulic pump failures, air motor failure, solenoid valve failures, and a filter not properly installed. The majority of the failures were related to problems with the hydraulic pump and solenoid valves. In most cases hydraulic pump failures were attributed to normal wear. Hydraulic leakage did not appear to contribute to pump failure as it did for the other type actuator. In some incidents pump failure was attributed to a defected air motor. However, in most cases the pump and air motor were replaced as a unit. The solenoid valves failed due to open coils and air leaks. The solenoid valves are used to control the hydraulic dump and the exercise pilot valves (see Subsection 3.4.2.2). The improperly installed filter created a high-pressure differential across the filter which prevented the pump from developing sufficient head to open the MSIV. The improperly installed filter was due to maintenance error. 


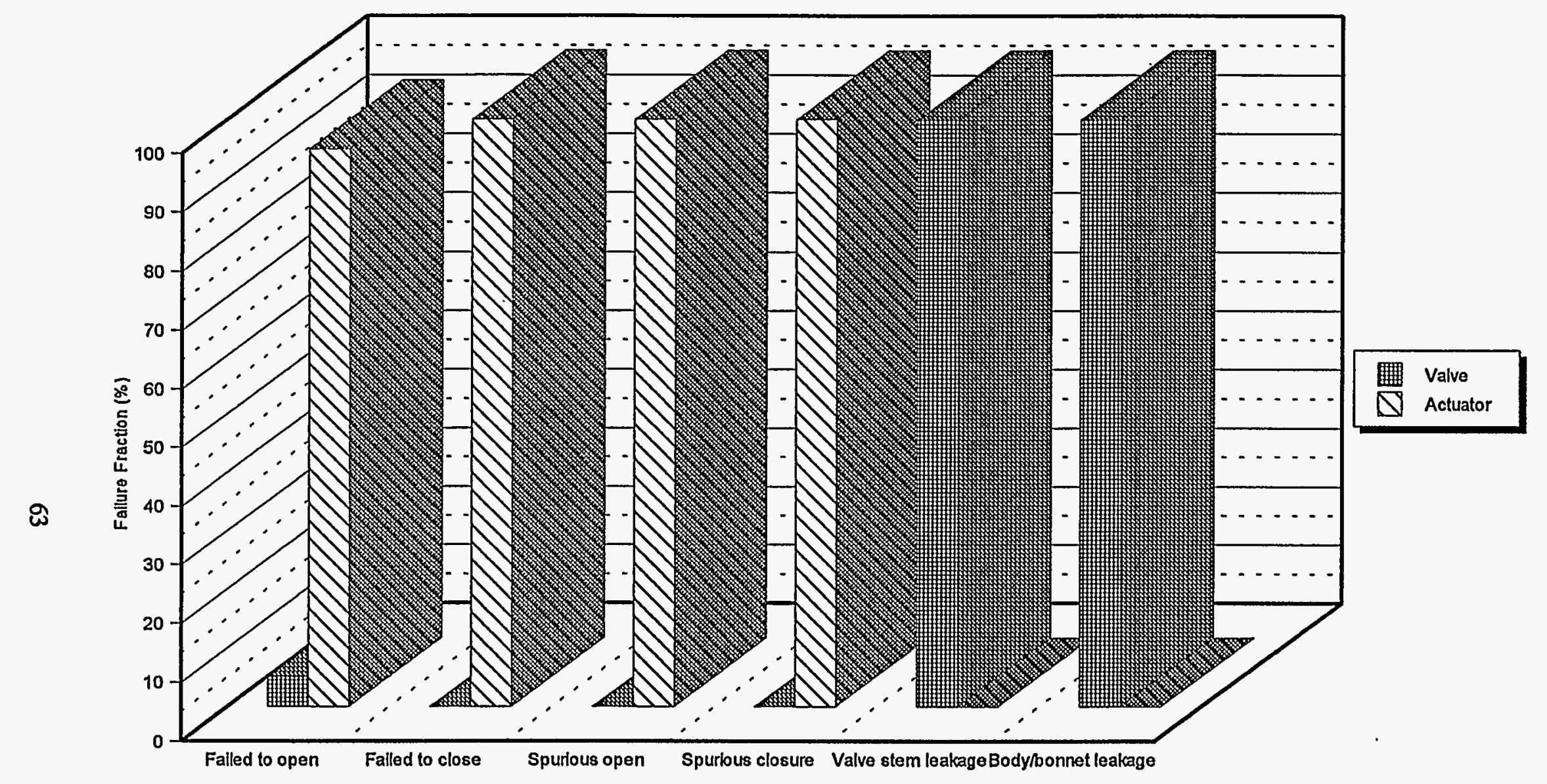

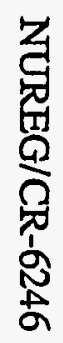

Figure 4.10C Correlation of gate valve failure modes and failure area : PWR 


\section{Operating Experience}

The valve problem was associated with the disc sticking in the valve body. The valve was disassembled, cleaned, checked for proper clearance, and reassembled.

\subsubsection{Failure to Close}

As shown in Figure 4.10C, all valve failure-to-close events were related to actuator problems. The actuator problems associated with the hydraulic-to-open, hydraulic-to-close-type actuator were related to hydraulic control valve failures, defective solenoid valves, defective limit switches, defective air check valves, and failed O-rings.

The hydraulic control valves either failed to operate or leaked. In some cases the control valve would only partially open to align the hydraulic accumulators with the hydraulic cylinder. The partial opening would create large flow resistance, preventing the MSIV from fully closing or meeting Technical Specification limits for fast closure. In other incidents the hydraulic control valves would leak hydraulic fluid due to worn O-rings. The leakage not only depressurizes the hydraulic accumulators but also reduces the amount of hydraulic charge that can be delivered to the MSIV.

The defective solenoid valve prevented proper operation of the main hydraulic control valves. The defective limit switch prevented full MSIV closure because the switch was out of adjustment. The pneumatic check valves leaked over time causing the air accumulators to depressurize. As was discussed in Subsection 3.4.3.1, air pressure must be available to operate the main hydraulic control valves. The MSIVs do not fail closed on loss of air pressure. Failure of the O-rings associated with the hydraulic accumulators also depressurized the accumulators, preventing MSIV fast closure.

The non-safety-related hydraulic pumps are relied upon to provide slow MSIV closure, to provide makeup for small system leakage, and to maintain the hydraulic accumulators charged. They are not relied upon for fast MSIV closure; the accumulators perform this function. Check valves in the hydraulic system should maintain system pressure if no other leaks occur, but because leakage is inevitable, the accumulators will depressurize over time if the hydraulic pump is not available. Low accumulator pressure alarms in the main control room are therefore used to maintain proper surveillance.

The actuator problems associated with the hydraulic-to-open, pneumatic-to-close-type actuator were related to hydraulic pump failures, defective solenoid valves, and improper filter installation. All of these failures resulted in the inability to charge the nitrogen accumulator. The failed hydraulic pump prevented operations from initially charging the nitrogen accumulator, and the failed solenoid valves caused the pilot dump valves to open, depressurizing the accumulator. The improperly installed filter created large flow resistance that prevented the hydraulic pump from developing sufficient head to charge the nitrogen accumulator. All of these failures resulted in the inability to stroke the valve in either the open or closed direction or spurious valve closure.

\subsubsection{Spurious Opening}

As shown in Figure 4.10C, all spurious valve open events were related to actuator problems. The actuator problems were all associated with the hydraulic-to-open, hydraulic-to-close-type actuator. In all incidents, the MSIV drifted off its closed seat because of leaky hydraulic control valves and pilot operated check valves. As shown in Figure 3.11, if the pilot-operated check valve $(R)$ leaks, oil from the top part of the hydraulic cylinder will drain to the oil reservoir, allowing the piston to withdraw. The piston will also withdraw if the main hydraulic control valve (M) leaks. Under these conditions high-pressure fluid will be directed to the lower part of the cylinder, and the fluid in the upper part will be displaced by the piston through the pilot-operated check valve and control valve, causing the piston to withdraw. The leakages were attributed to worn O-rings due to normal aging. 


\subsubsection{Spurious Closure}

As shown in Figure 4.10C, all spurious valve closure events were related to actuator problems. The actuator failures associated with the hydraulic-to-open, hydraulic-to-close-type actuator were related to defective solenoid valves, defective hydraulic control valves, and fitting failures in the hydraulic system.

In one incident several solenoid valves failed to operate during surveillance testing. The defective solenoid valves prevented proper operation of the main hydraulic control valve and the accumulator dump valve. The combination of these failures caused the accumulator to discharge its fluid to the reservoir, resulting in closure of the MSIV. In another event a solenoid valve deenergized, causing the main hydraulic control valve (4-way valve) to align the hydraulic accumulator with the main cylinder, resulting in fast closure of the MSIV. In another incident the main hydraulic control valve in one train leaked, causing the accumulator in both trains to depressurize. Why failure of the main hydraulic control valve in one train caused loss of accumulator pressure in the redundant train is unknown. A similar event occurred again, but the leak was due to a faulty pipe fitting in the hydraulic system.

The actuator failures associated with the hydraulic-to-open, pneumatic-to-close-type actuator were related to failed relays, blown power fuses, worn O-rings, and defective solenoid-operated pilot valves. The faulty relays and blown power fuses deenergized the solenoid dump valves, causing the MSIV to fast close and trip the unit on low SG level. Leaking O-rings on the valve manifold and internal leakage of hydraulic fluid through the pilot-operated dump valves caused the valve operator to depressurize and the MSIV to drift closed.

\subsubsection{Stem Leakage}

As was observed with globe valves, valve stem leakage is predominately associated with the valve and is due to dry and brittle packing caused by heat and normal wear. The problem is controlled by replacing the valve packing on a regular basis.

\subsubsection{Body-to-Bonnet Leakage}

The body-to-bonnet leakage for gate valves was predominately associated with the valve and is due to failed gaskets and seal rings caused by normal wear and possibly steam erosion. The problem is controlled by replacing the gaskets and seal rings as they deteriorate.

\subsection{Major Valve Failure Mechanisms : PWR}

A global distribution of the major MSIV failure mechanisms for PWRs using check, globe, and gate valves is shown in Figure 4.11. These failure mechanisms were identified as:

- valve stem/shaft binding

- internal binding

- worn valve packing

The distribution is determined by dividing the number of failures for each failure mechanism by the total number of failures. The following subsections summarize the results for each valve type. 
Operating Experience

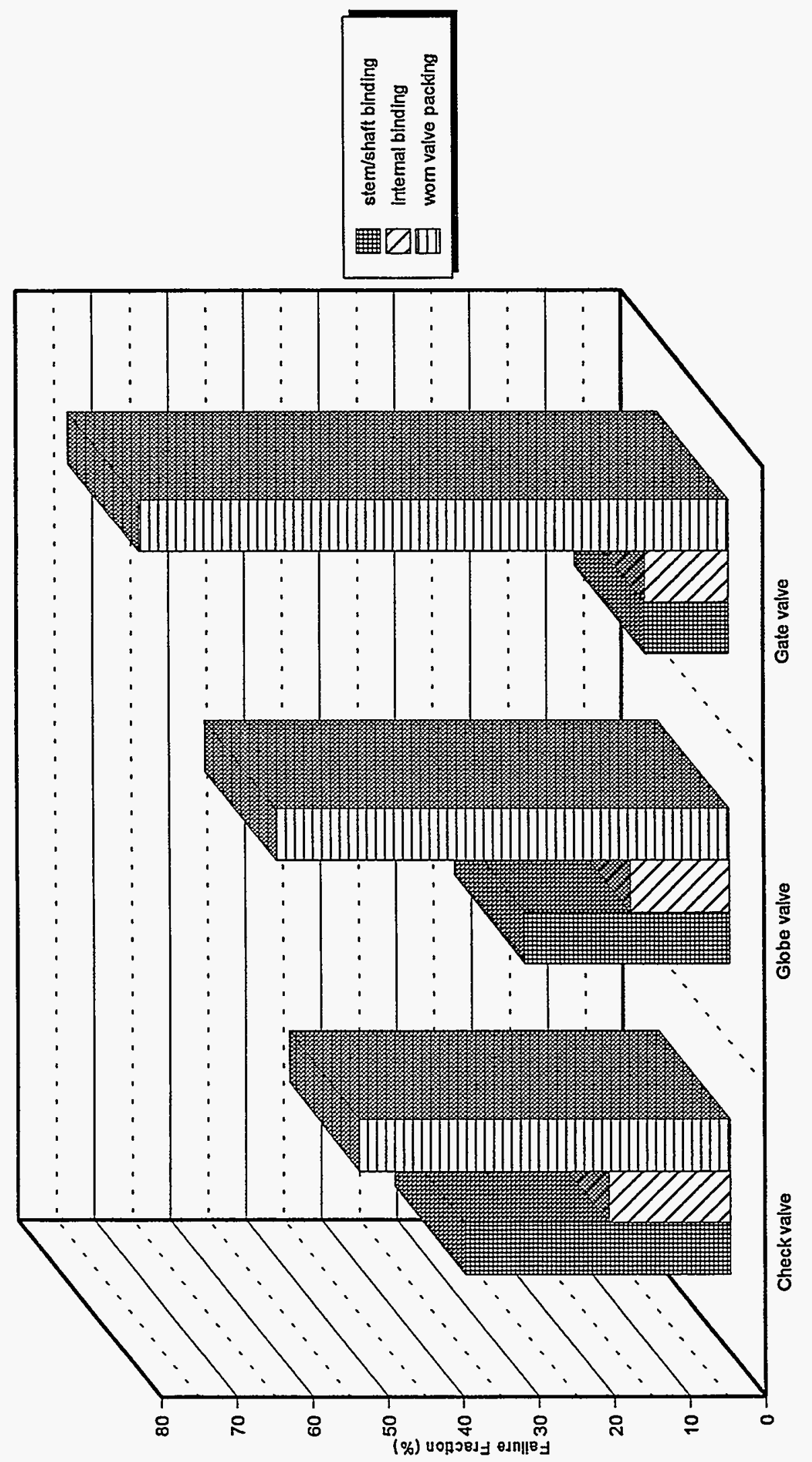

 
Operating Experience

\subsubsection{Check Valves}

The total number of failure mechanisms related to check valve was determined from the Nuclear Plant Reliability Data System (NPRDS) database to be 82 .

As shown in Figure $4.11,49 \%$ of the failure mechanisms were identified as worn valve packing, 35\% were identified as valve stem/shaft binding, and $16 \%$ were related to internal binding. Worn valve packing was the major failure mechanism responsible for valve stem leakage. Valve shaft binding was predominately due to excessive friction caused by hardening of the valve packing due to heat, inadequate lubrication of the valve packing, and over-torqued packing glands. Internal binding was due to disc jamming in the valve body, seized shaft bearings, worn internal parts (e.g., valve disc, shaft, stuffing boxes), thermal cycling, and misalignment of internal parts due to aging and maintenance error. Valve shaft binding and internal binding were the primary failure mechanisms that caused the check valves to fail to close or failure to meet TS limits for fast closure.

\subsubsection{Globe Valves}

The total number of failure mechanisms related to globe valves was determined from the NPRDS database to be 15.

As shown in Figure $4.11,60 \%$ of the failure mechanisms were identified as worn valve packing, $27 \%$ were identified as valve stem binding, and $13 \%$ were related to internal binding. As was noted with check valves, worn valve packing was associated with valve stem leakage. Valve stem binding was also predominately due to excessive friction caused by hardening of the valve packing due to heat, inadequate lubrication of the valve packing, and over-torqued packing glands. Internal binding was primarily due to binding of the yoke rod guides or stanchion guides (see Subsections 4.3 and 4.10.2.2 for detailed information).

\subsubsection{Gate Valves}

The total number of failure mechanisms related to gate valves was determined from the NPRDS database to be 9.

As shown in Figure $4.11,78 \%$ of the failure mechanisms were identified as worn valve packing, $11 \%$ were identified as valve stem binding, and $11 \%$ were related to internal binding. Valve stem binding was predominately due to excessive friction caused by hardening of the valve packing due to heat, inadequate lubrication of the valve packing, and over-torqued packing glands. Internal binding was due to wedging of the disc in the valve body, preventing valve movement. The reasons the disc wedged in the valve body were unknown.

\subsection{Major Valve Actuator Failure Modes : PWR}

The failure mode distribution for three major PWR valve actuators is shown in Figure 4.12. The distribution is determined by dividing the number of failures for each failure mode by the total number of actuator failures. The total number of actuator failure modes for all three actuator types was determined from the NPRDS database to be 300 . Note that many of the actuators had multiple failure modes (e.g., electrical, pneumatic, hydraulic, mechanical). The following subsections summarize the results for each actuator type.

\subsubsection{Type A}

The Type A actuators use pneumatics to open and springs to close MSIVs. These actuators are predominately found on check valves and globe valves. The total number of failure modes for these actuators was determined from the 
Operating Experience

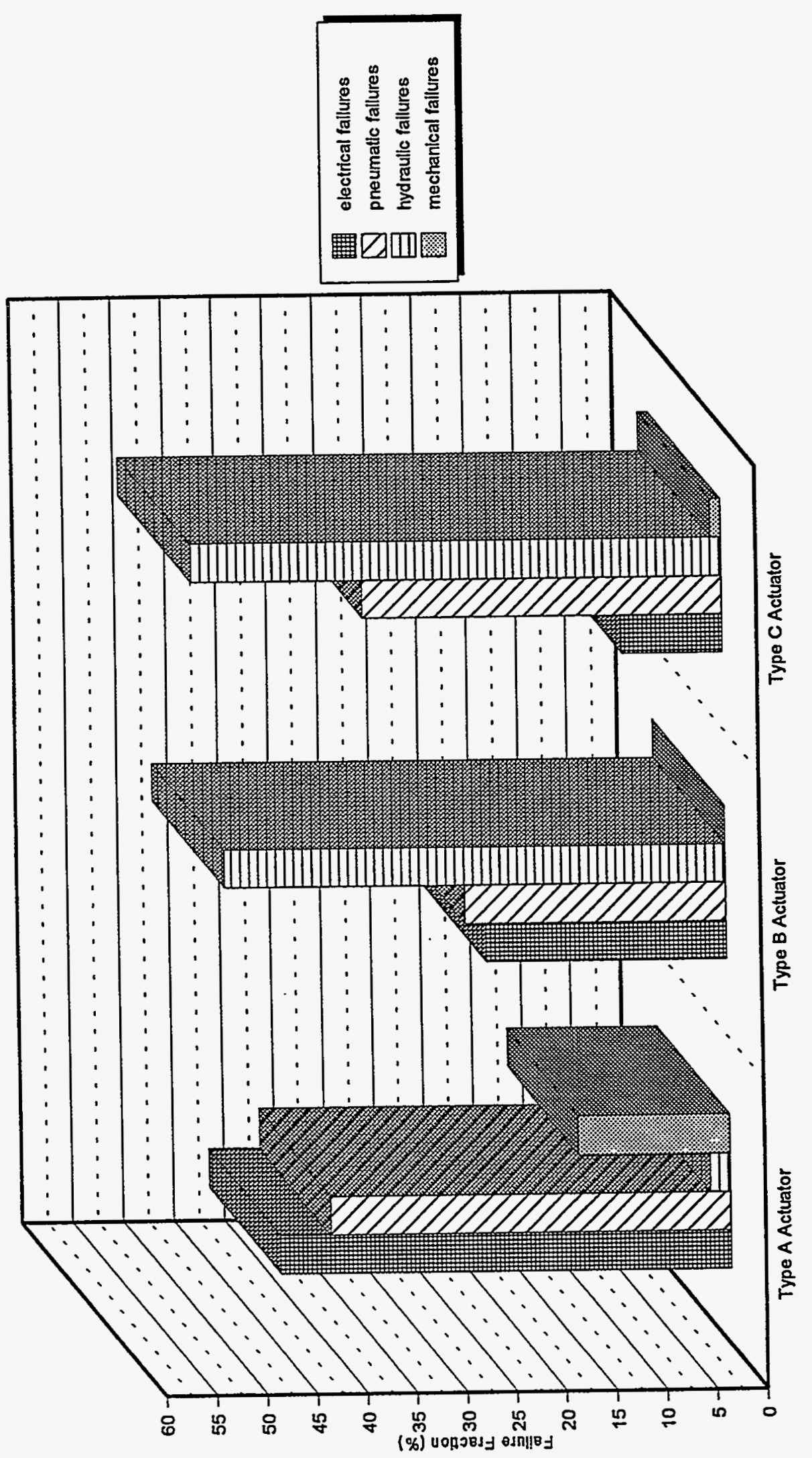

 
NPRDS database to be 115. As can be seen from Figure $4.12,46 \%$ of the failures were related to electrical failures, $40 \%$ were related to pneumatic failures, $12 \%$ were related to mechanical failures, and $2 \%$ were related to hydraulic failures.

The electrical failures were attributed to failed limit switches (31\%), failed solenoid valves (59\%), and miscellaneous failures such as blown fuses and faulty relays $(10 \%)$. The pneumatic failures were attributed to fitting failures $(53 \%)$; failed control valves such as air operated pilot valves, metering valves, and pressure-regulating valves (30\%); and worn seals $(17 \%)$. The hydraulic failures were related to check valves with hydraulic dash pots. The hydraulic failures were attributed to worn seals $(50 \%)$ and leaky fittings $(50 \%)$. The mechanical failures included worn valve springs $(43 \%)$ on both check and globe valves. Other mechanical failures $(57 \%)$ were related to check valves which included binding in the air cylinder, improper operator linkage installation, dry lubricant on air cylinder walls obstructing piston movement, and corroded air cylinder shafts, bushings, and seals. The major stressors affecting these components were normal aging, high ambient temperature, high humidity, and maintenance errors.

\subsubsection{Type B}

The Type B actuators use hydraulics to open and pneumatics to close MSIVs. These actuators are predominately found on gate valves. The total number of failure modes for these actuators was determined from the NPRDS to be 46.

As can be seen from Figure $4.12,24 \%$ of the failure modes were related to electrical failures, $26 \%$ were related to pneumatic failures, and $50 \%$ were related to hydraulic failures. The electrical failures were attributed to failed solenoid valves (58\%) and miscellaneous failures such as blown fuses and faulty relays (42\%). The pneumatic failures were attributed to gas-charging valves leaking nitrogen gas (54\%), failed air motors $(23 \%)$, and leaky fittings (31\%) such as defective pressure gauges, air pressure regulators, and solenoid valves. The nitrogen leaks very often caused a low-accumulator pressure alarm to be activated in the main control room. The hydraulic failures were related to worn seals ( $31 \%$ ), fitting failures (30\%), faulty flow control valves (22\%), hydraulic pump failures (13\%), and leaky hydraulic check valves (4\%). Seal failures included worn accumulator piston O-rings and valve manifold seals. Fitting failures were related to leaky pipe fittings, thermal relief valves, and local pressure indicator gauges. Faulty control valves included defective dump valves, plugged flow control valves, and internal leakage of hydraulic fluid through solenoid-operated pilot valves.

\subsubsection{Type C}

The Type $C$ actuators use hydraulics both to open and to close MSIVs. These actuators are predominately found on gate valves. The total number of failure modes for these actuators was determined from the NPRDS database to be 139.

As can be seen from Figure $4.12,10 \%$ of the failure modes were related to electrical failures, $36 \%$ were related to pneumatic failures, $53 \%$ were related to hydraulic failures, and $1 \%$ were related to mechanical failures. The electrical failures were attributed to failed solenoid valves (57\%) and limit switches (43\%). The pneumatic failures were attributed to fitting failures (44\%), failed check valves (21\%), failed control valves (19\%), and worn seals (16\%). The fitting failures were associated with nitrogen leaks in tube fittings, pressure-sensing lines, flex hoses, and local pressure gauges. Check valve failures were predominately due to internal seat leakage, causing the air accumulators to depressurize. Failed control valves included leaky pressure regulators, relief valves, nitrogen shutoff valves, needle valves, and solenoid valves. Seal failures included worn accumulator piston O-rings and valve manifold seals. In most incidents the nitrogen leaks caused a low-accumulator pressure alarm to be activated in the main control room. The hydraulic failures were attributed to pump failures (27\%), control valve failures (27\%), fitting failures (25\%), 


\section{Operating Experience}

seal failures (17\%), and check valve failures (4\%). The pump failures were attributed to continuous cycling due to hydraulic leaks and normal wear. Control valve failures were associated predominately with the main hydraulic control valves (4-way valves). On many occasions these valves would malfunction due to O-ring failures, causing the valves to leak hydraulic fluid internally and externally. On other occasions the control valve would bind and not shift position when required, or if it did shift position, it would do so only slowly or incompletely. Fitting failures were predominately due to tube fitting leaks which were attributed to cyclic fatigue, maintenance error, and worn O-rings. Check valve failures were attributed to internal seat leakage. The mechanical failure was due to a broken bolt used to attach a check valve to the valve operator. The broken bolt was attributed to abnormal stresses.

\subsection{MSIV Failure Consequences on Plant Operations : PWR}

The distribution of MSIV failure consequences on plant operations for three different valve types (i.e., check, globe, and gate) is shown in Figure 4.13. The distribution is determined by dividing the number of failures for each category by the total number of failures in all categories. The total number of failure consequences for all three types was determined from the NPRDS database to be 418 , which is the total number of PWR failure records reported in Section 4 . The following subsections summarize the results for each valve type.

\subsubsection{Check Valves}

The total number of failure consequences related to check valves was determined from the NPRDS database to be 187.

As can be seen from Figure 4.13,56\% of the failure consequences resulted in "Degraded MSIV Train/Channel." The MSIV degradations described in Section 4 normally manifest themselves in the form of lost channel redundancy, adverse local environmental conditions due to steam leakage, and decreased plant availability if the incident required plant shutdown for repairs.

The second largest percentage of failure consequences affecting plant operations was related to the "Loss of Fast Valve Closure Capability," representing $23 \%$ of the total. These consequences were a direct result of the MSIV failed-to-close events discussed in Subsection 4.10.1.2 where $63 \%$ of the failures were due to valve problems and $37 \%$ were due to actuator problems.

The third most prevalent failure consequence was related to "Failed Fast Valve Closure Test" with $13 \%$ of the total. These consequences were the direct result of failure of the MSIVs to close within the plant's TS limits. Normally, the valve stroke time requirement for closure is 3 to 5 seconds. In most cases, the failure to meet TS requirements was due to defective solenoid valves, worn valve springs, internal binding, and valve shaft binding.

The fourth most prevalent failure consequence was related to "Reactor Trip" with 7\% of the total. The Reactor Trips were due to spurious valve closure events. These events cause the reactor to trip on either high asymmetric SG pressure or low SG level. The majority of the spurious valve closure events were due to blown rupture discs as described in Subsection 4.10.1.4.

The last failure consequence was related to "Failed Partial Stroke Test" with $1 \%$ of the total. Failure to perform this surveillance requirement was due to defective limit switches that prevented the valves from moving into the test position. 


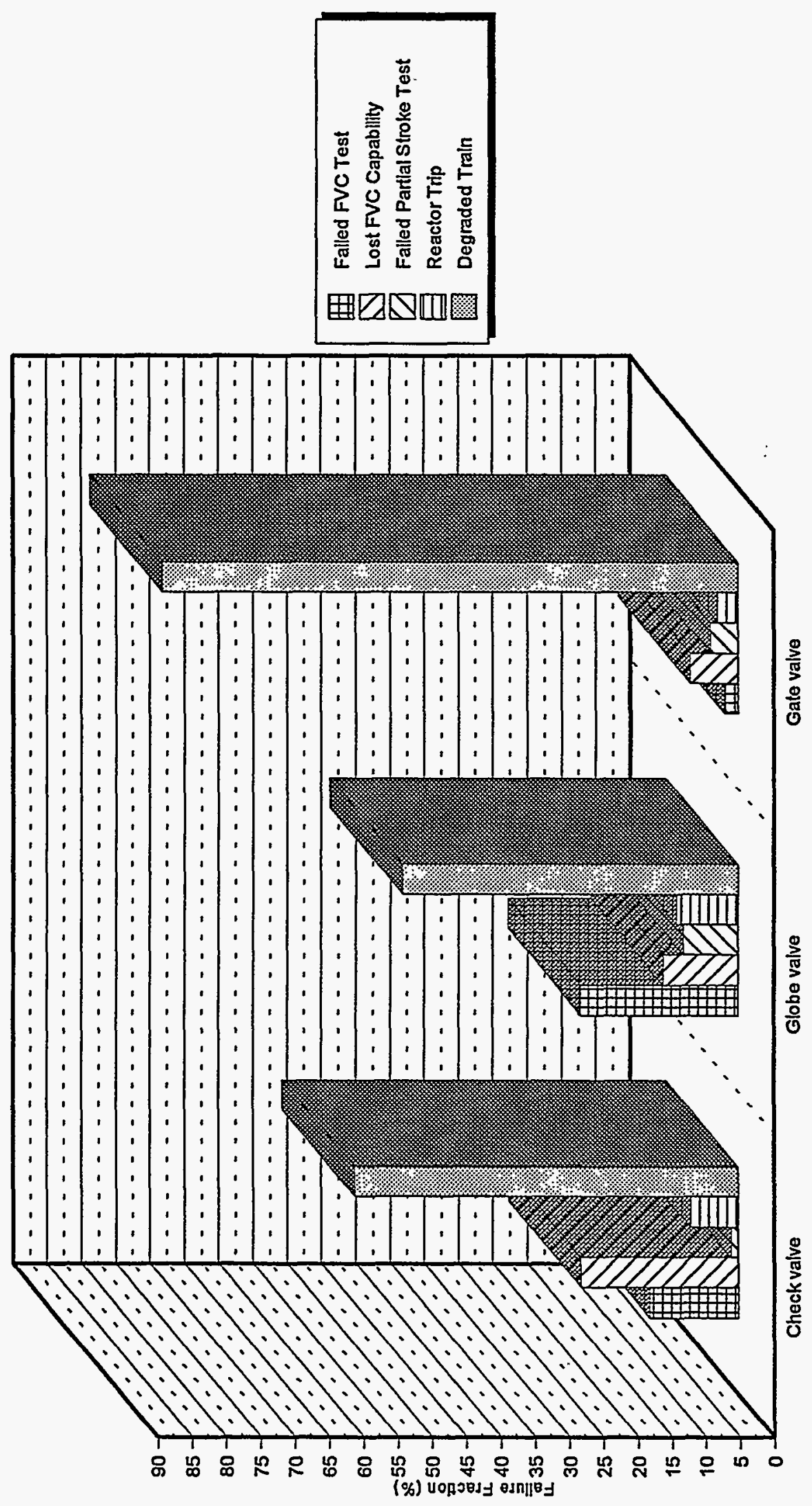

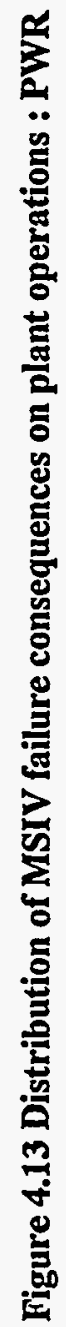




\section{Operating Experience}

\subsubsection{Globe Valves}

The total number of failure consequences related to globe valves was determined from the NPRDS database to be 47 .

As can be seen from Figure 4.13, 49\% of the failure consequences resulted in "Degraded MSIV Train/Channel." The MSIV degradations described in Section 4 normally manifest themselves in the form of lost channel redundancy, adverse local environmental conditions due to steam leakage, and decreased plant availability if the incident required plant shutdown for repairs.

The second largest percentage of failure consequences affecting plant operations was related to "Failed Fast Valve closure test" with $23 \%$ of the total. As was the case with the check valves, these events were the result of failure of the MSIVs to close within the plant's TS limits. Normally, the valve stroke time requirement for closure is 3 to 5 seconds. In most cases the failure to meet TS requirements was due to defective solenoid valves, worn valve springs, internal binding, and valve stem binding.

The third most frequent failure consequence was related to "Lost Fast Valve Closure Capability" with $11 \%$ of the total. These consequences were a direct result of the MSIV failure-to-close events discussed in Subsection 4.10.2.2 where a significant number of failures were due to binding of the yoke rod guides (i.e., stanchion guides) and valve stem binding.

The last two failure consequences were related to "Failed Partial Stroke Test" and "Reactor Trip." Each of these groups represented $9 \%$ of the total. The "Failed Partial Stroke Test" was due to defective limit switches that caused the MSIV to go full close and defective solenoid valves that would not allow the MSIV to close or reopen after reaching the $90 \%$ open position.

The Reactor Trips were due to spurious valve closure events. These events cause the reactor to trip on either high asymmetric SG pressure or low SG level. The reasons for the spurious valve closure events were described in Subsection 4.10.2.3.

\subsubsection{Gate Valves}

The total number of failure consequences related to gate valves was determined from the NPRDS database to be 184 .

As can be seen from Figure $4.13,85 \%$ of the failure consequences resulted in "Degraded MSIV Train/Channel." As with the check and globe valves, the MSIV degradations associated with gate valves normally resulted in the loss of channel redundancy, adverse local environmental conditions due to steam leakage, and decreased plant availability if the incident required plant shutdown for repairs.

The second most prevalent failure consequence was related to "Lost Fast Valve Closure Capability" with 7\% of the total. These consequences were a direct result of the MSIV failure-to-close events discussed in Subsection 4.10.3.2 where a significant number of failures were due to defective hydraulic control valves, solenoid valves, limit switches, check valves, and O-rings. Although the number of component failures is relatively high, the total number of events related to complete loss of fast valve closure capability is low owing to the redundancy built into the valve actuators.

The third most prevalent failure consequence was related to "Failed Partial Stroke Test" with $4 \%$ of the total. The "Failed Partial Stroke Test" failures were due to defective limit switches which prevented stroking the MSIVs and defective solenoid valves which would not allow the MSIV to close or, in some events, would not allow the valve to reopen after reaching the $90 \%$ open position. 
The fourth most frequent failure consequence was related to "Reactor Trips" with 3\% of the total. The Reactor Trips were due to spurious valve closure events. These events caused the reactor to trip on either high asymmetric SG pressure or low SG level. The reasons for the spurious valve closure events were described in Subsection 4.10.2.3.

The last failure consequence was related to "Failed Fast Valve Closure Test" with $2 \%$ of the total. These events were the result of failure of the MSIVs to close within the plant's TS limits. Normally, the valve stroke time requirement for closure is 3 to 5 seconds. In most cases the failure to meet TS requirements was due to out-of-adjustment limit switches and defective hydraulic control valves. In some incidents the defective hydraulic control valves (4-way valves) would only partially open. The partially opened valves created large flow resistance in the hydraulic circuit, decreasing the flow rate to and from the actuator cylinder.

\subsection{Method of Failure Detection : PWR}

Figure 4.14 shows the cross correlation of major valve failure modes and their method of detection. The major failure modes consisted of failed to open, failed to close, spurious open, spurious closure, and valve stem leakage. The method of detections consisted of surveillance testing, failed on demand, routine observation, and routine maintenance. Surveillance testing included partial stroke testing and fast valve closure tests. For Type B and C actuators, testing may also include accumulator precharge test. Failure detection by routine observation is predominately related to MSIVs with Type $B$ and $C$ actuators. The observations included acknowledging and responding to low-accumulator pressure alarms in the main control room and the detection of hydraulic leaks during system walkdowns. Failure detection by routine maintenance usually involves post-modification testing, in-service testing, and preventive maintenance checks.

For the "failed-to-open" event, $32 \%$ were detected by surveillance testing, $45 \%$ failed on demand, $7 \%$ were detected by routine observation, and $16 \%$ were detected during routine maintenance.

For the "failed-to-close" event, $29 \%$ were detected by surveillance testing, $56 \%$ failed on demand, $5 \%$ were detected by routine observation, and $10 \%$ were detected during routine maintenance.

For the "spurious valve open" event, $25 \%$ were detected during surveillance testing, and $75 \%$ were detected by routine observation. Spurious valve open during surveillance testing was the result of personnel error and equipment malfunctions (see Subsection 4.10.1.3).

For the "spurious valve closure" event, $35 \%$ were detected during surveillance testing, and $65 \%$ were detected by routine observation (i.e., reactor trips). The spurious valve closure during surveillance testing occurred during partial stroke testing. The MSIVs failed to stop and reopen at the $90 \%$ open position because of actuator problems. This problem was common to all actuator types. For all other incidents, spurious valve closure events occurred for the reasons given in Subsections 4.10.1.4 and 4.10.3.4. In all cases the spurious valve closure events caused the reactor to trip on high asymmetric SG pressure or low SG level. These events can occur during surveillance testing.

For the valve stem leakage event, $7 \%$ were detected by surveillance testing, $84 \%$ were detected by routine observation (plant walkdowns), and $9 \%$ were detected during routine maintenance. Although the majority of valve stem leakage events were detected by plant walkdowns, in one event the valve stem leakage was so extensive that the heat generated caused a fire alarm to be initiated in the main control room. The packing had disintegrated into powder and blown out of the gland. The root cause was due to lack of preventive maintenance. Detection of valve stem leakage during surveillance testing was primarily observed during functional leak tests, 10-year in-service system pressure tests, and observations during performance of fast valve closure tests. 
As can be seen from Figure 4.14, 56\% of the valve failure-to-close events were detected by "failed on demand." This high percentage indicates that the current MSIV monitoring, inspection, and maintenance program for PWRs may not be adequate.

\subsection{Major Stressors Affecting MSIVs : PWR}

A global distribution of major stressors affecting PWR valves is shown in Figure 4.15. The total number of stressors was determined from the NPRDS database to be 183. The stressors include both normal and error-induced stressors as previously defined and published. ${ }^{1}$

As can be seen from the figure, $39 \%$ of all stressors found in this study identified normal aging as the most significant stressor affecting PWR valves. The other stressors affecting PWR valves were identified as maintenance errors $(29 \%)$, friction (15\%), unknown (6\%), high ambient temperature (4\%), stress corrosion (4\%), and design errors (3\%). Most of the normal aging stressors were related to valve stem leakage. Friction was primarily associated with tight valve packing and binding of the yoke rod guides due to maintenance errors. Stress corrosion and design errors were predominately associated with check valves, resulting in cracked valve shafts. Design errors were related to internal binding due to thermal cycling, loose internal parts, and inadequate coupling between valve stem and air cylinder piston.

For globe valves the majority of the maintenance errors were related to binding of the yoke rod guides; this was attributed to improper setting of the clearance between yoke rod guides and bushings and inadequate lubrication of the valve stems and over-torqued packing glands.

In this study no significant maintenance errors were found to be associated with gate valves.

For check valves the majority of the maintenance errors were related to internal binding and valve shaft binding due to improper installation and inadequate preventive maintenance. Internal binding was attributed to disc jamming in the valve body due to broken valve stops, seized shaft bearings, and worn internal parts, all of which could be traced to inadequate preventive maintenance. Valve stem or shaft binding was attributed to excessive friction due to inadequate lubrication and over-torqued packing glands.

\subsection{Major Stressors Affecting Valve Actuators : PWR}

A global distribution of major stressors affecting PWR valve actuators is shown in Figure 4.16. The total number of stressors was determined from the NPRDS database to be 331. The stressors include both normal and error-induced stressors as previously defined and published. ${ }^{1}$

As can be seen from the figure, $38 \%$ of all stressors found in this study identified normal aging as the major stressor affecting PWR valve actuators. The other stressors included unknown (23\%), maintenance error (19\%), design error $(12 \%)$, vibration (3\%), high humidity (3\%), and high ambient temperature (2\%).

For valve actuators associated with globe valves, the majority of the maintenance errors were related to improper installation such as loose fittings, solenoid valves not properly lubricated, and pump strainer installed backwards on hydraulic actuators. Failure to perform appropriate preventive maintenance, such as not changing hydraulic fluid on a regular bases (hydraulic actuators), caused some solenoid valves to stick open due to contaminated fluid. In other instances, limit switches were not properly adjusted and were responsible for valves going full close during partial stroke testing. 


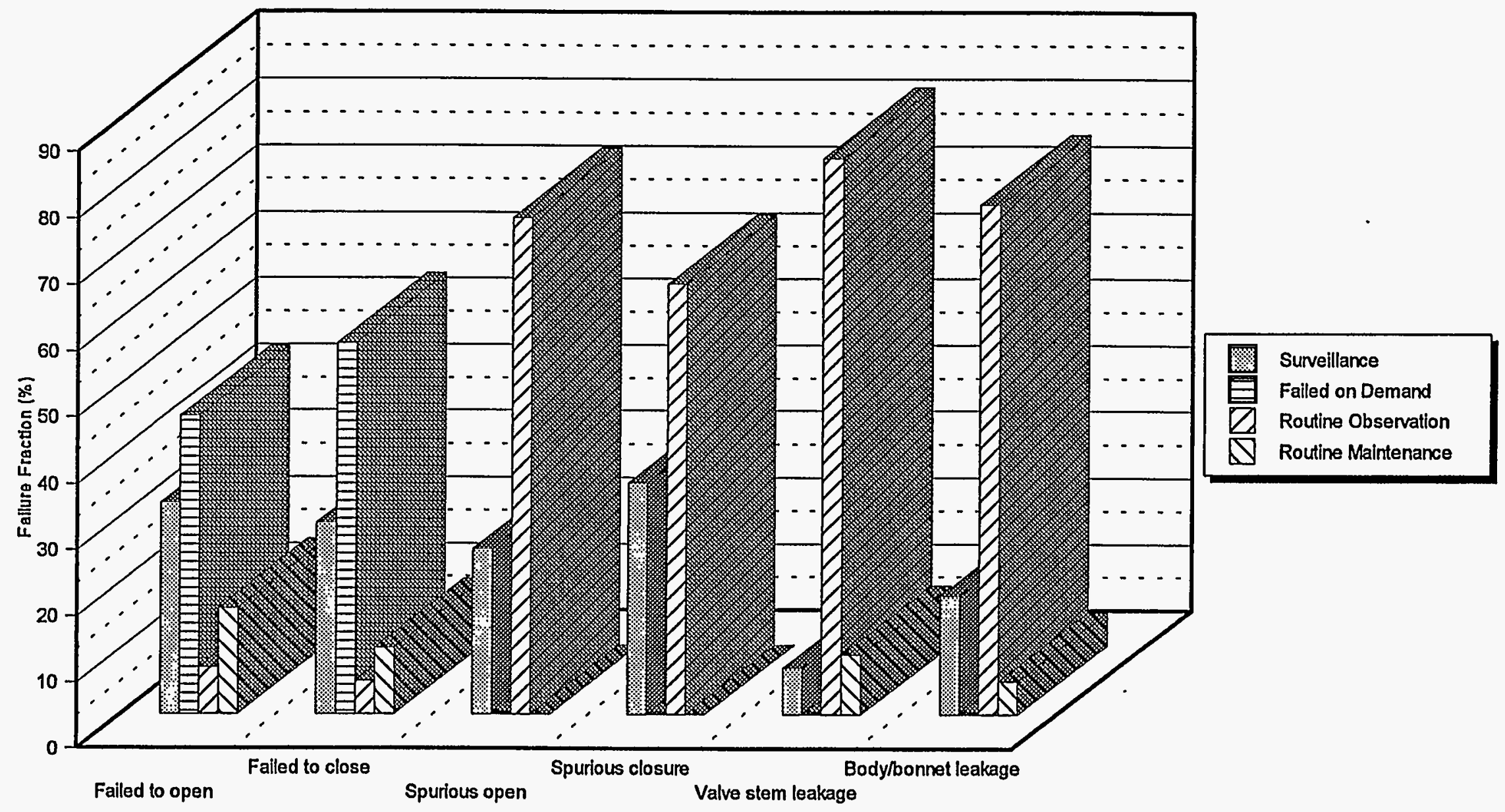

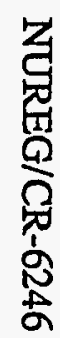

Figure 4.14 Correlation of valve failure modes and method of detection : PWR 


\section{Operating Experience}
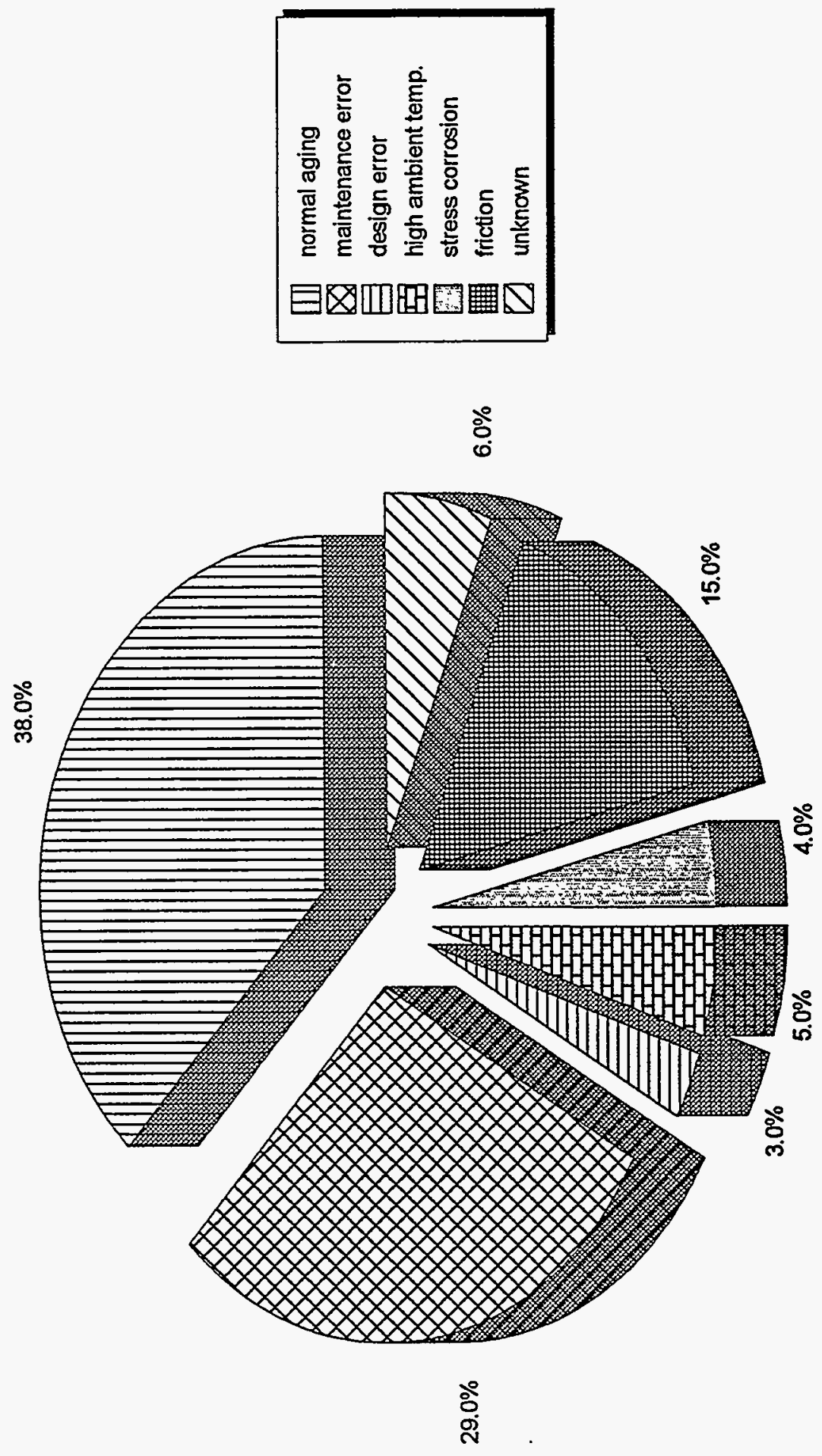

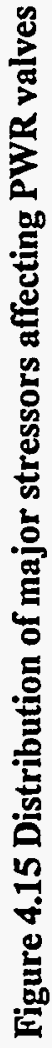




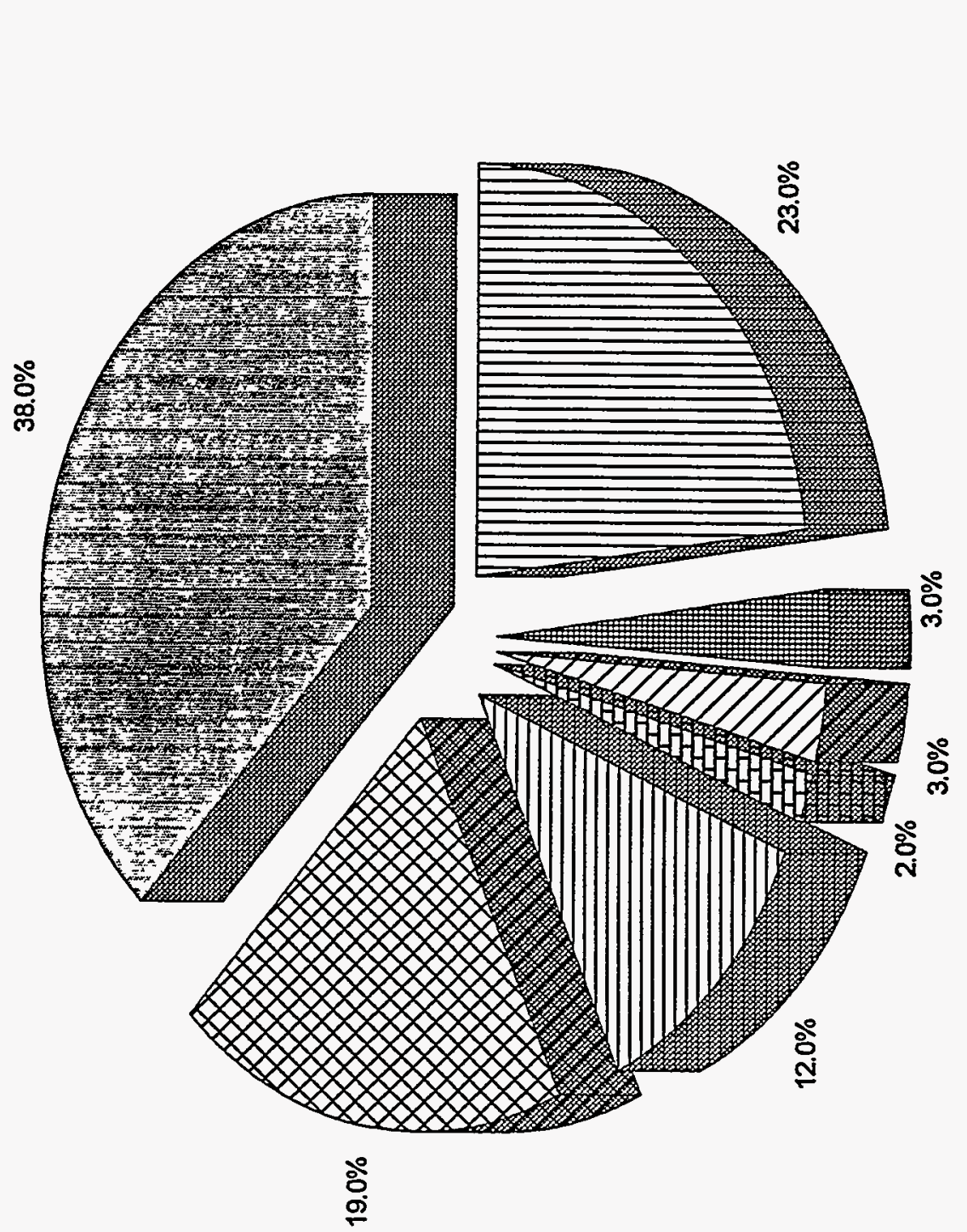

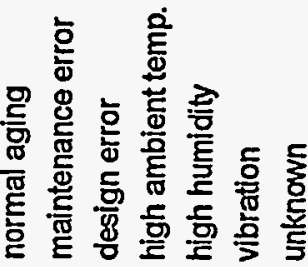

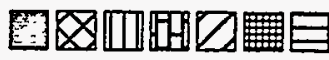


For valve actuators associated with gate valves, the majority of the maintenance errors were related to hydraulic, air, and nitrogen leaks. Most of these leaks were due to defective O-rings, blown gaskets, and loose fittings that could be traced to improper installation. In at least one instance hydraulic system leaks depleted the oil reservoir, causing the hydraulic charging pump to fail. Failure of the charging pump eventually resulted in low-accumulator pressure. This problem could have been avoided if a preventive maintenance program had been implemented to control system leaks and if the oil reservoir level had been checked on a regular bases. Air leaks were predominately due to failed check valves and loose fittings. Nitrogen leaks were mostly due to improperly installed tube fittings and failure to apply recommended sealant. However, in one instance a flow isolation valve in the nitrogen supply line to the accumulators failed due to abnormal stress. The abnormal stress was caused by an increase in nitrogen pressure as plant heatup was occurring. To preclude this event from recurring, plant operating procedures were revised to reduce nitrogen pressure during plant heat-up. Although this event was not due to maintenance errors, it does illustrate that for some plants, the operating requirements for the valve actuators may need to be integrated into the plant operating procedures.

For valve actuators associated with check valves, the majority of the maintenance errors were related to improperly installed solenoid valves, misaligned valve operator linkage, and the lack of preventive maintenance for limit switches and air cylinders. The solenoid valves failed due to moisture and water accumulation which was attributed to the inadequate tightening of the solenoid valve cover. Misalignment of the valve operator linkage caused internal binding, preventing the valves from closing within TS limits. The misalignment was attributed to inadequate procedures and training. The lack of preventive maintenance resulted in out-of-adjustment limit switches and, in some instance, incorrect installation. In at least one instance the valve failed to close because the limit switches were not properly connected. Air cylinder damage occurred on several valves due to steam leaks from the valve packing. The steam would condense on the valve operator, and the moisture would then migrate down the operator arm and linkage to the air cylinder. The moisture corroded the air cylinder shaft, bushing, and seats and obstructed shaft movement. This is one reason valve stem leakage should not be ignored. In another instance the MSIVs would not close within TS limits because the air cylinders had dried lubricant on the cylinder walls, preventing the piston from moving. Presumedly, the wrong lubricant was used to service the air cylinders.

\subsection{MSIV Relative Failure Rate Distribution}

The relative failure rate for each valve type, as reported in the NPRDS, was determined by a normalization process that consisted of the following general steps:

(1) For each valve type calculate the number of valve years of service during the reporting period between January 1984 and January 1993. For example, if a particular valve was placed in service in 1982 and remained in service through 1993, it would have accumulated a total of 9 valve years of service. Alternatively, if the valve was placed in service in 1990, it would have accumulated 3 valve years of service.

(2) From the NPRDS database determine the number of failures in each of the following categories for each valve type:

- valve failed to open

- valve failed to close

- spurious valve opening

- spurious valve closure

(3) For each valve type calculate the failure rate for each category listed above by dividing the number of valve type failures in each category by the number of valve type years of service. 
(4) For each valve type calculate the overall failure rate. The overall failure rate is determined by dividing the total number of failures characterized by the total number of valve years. The result is the normalizing value that is applied to the individual category failure rates to determine the "Relative Failure Rate."

(5) For each valve type calculate the "Relative Failure Rate" by dividing the failure rate for each category by the overall failure rate determined in step 4.

The results of this normalization process are shown in Figure 4.17. Note that the information given is the Relative Failure Rate for the complete MSIV (i.e., valve and valve actuator). The Relative Failure Rate for various types of MSIV actuators is discussed in Subsection 4.18. As can be seen from Figure 4.17, globe valves used for MSIV application on BWRs have the lowest failure rates. One possible explanation is that the MSIVs on BWRs receive more corrective maintenance because of failure to meet Local Leak Rate Tests. The globe valves in PWRs have the second lowest failure rates, followed by check valves and then gate valves. For all valve types the failure to close is the most important safety concern. The globe valves used on BWRs have a relative failure rate of 0.44 ; this means that its failure rate is $44 \%$ of the overall failure rate or average failure rate. Globe valves used on PWRs have a relative failure rate of 0.73 ; this means that its failure rate is $73 \%$ of the overall failure rate and nearly twice as much as for BWRs. Check valves and gate valves have a relative failure rate of 2.05 and 2.08 respectively. For these valves the failure rate is over two times the average failure rate, which is roughly 5 times greater than the globe valve failure rate for BWRs.

Of all valve types note also that gate valves (because of actuator problems) are more likely to spuriously open, to spuriously close, or to fail to open.

\subsection{MSIV Actuator Relative Failure Rate Distribution}

The four major types of valve actuators used for MSIV application are designated as Types A, B, C, and D. Type A actuators are predominately found on BWRs. These actuators control MSIV valve stroke by using air to open and both spring and air to close. Type B actuators are found on PWRs that use both globe valves and check valves for MSIV application. These actuators control MSIV valve stroke by using air to open and spring to close. Air is not normally used to assist with valve closure. However, note that for check valves, the actuators are normally equipped with hydraulic dashpots to control valve closing speed. Type $C$ actuators are predominately found on gate valves. These actuators control MSTV valve stroke by using hydraulics to open and pneumatics to close. Type D actuators are found on gate valves only. These actuators control MSIV valve stroke by using hydraulics both to open and close the valve.

The Relative Failure Rate for each actuator type is shown in Figure 4.18. The Relative Failure Rate for each actuator type was determined by first calculating the individual failure rate for each actuator type. The individual failure rate is the sum of all failures (i.e., electrical, pneumatic, hydraulic, mechanical) divided by the number of valve actuator years. The actuator failures were determined from the NPRDS database and are discussed in Subsection 4.4 for BWRs and Subsection 4.12 for PWRs. After determining the individual failure rates, the Relative Failure Rates were then determined by the same normalization process described in Subsection 4.17.

As can be seen from Figure 4.18, a Type A actuator has the lowest Relative Failure Rate. Its Relative Failure Rate is roughly 0.40 times the average or overall failure rate. A Type B actuator has a Relative Failure Rate of 0.84 times the average failure rate, which is over two times greater than Type A. A Type C actuator has a Relative Failure Rate of 3.45 times the average failure rate, which is over eight times greater than Type A. A Type D actuator has a Relative Failure Rate of 5.7 times the average failure rate, which is over 14 times greater than Type A actuators. Although Type $C$ and $D$ actuators have much higher Relative Failure Rates then Types $A$ and $B$, the overall effect on plant 
Operating Experience

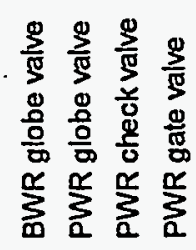

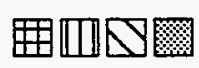

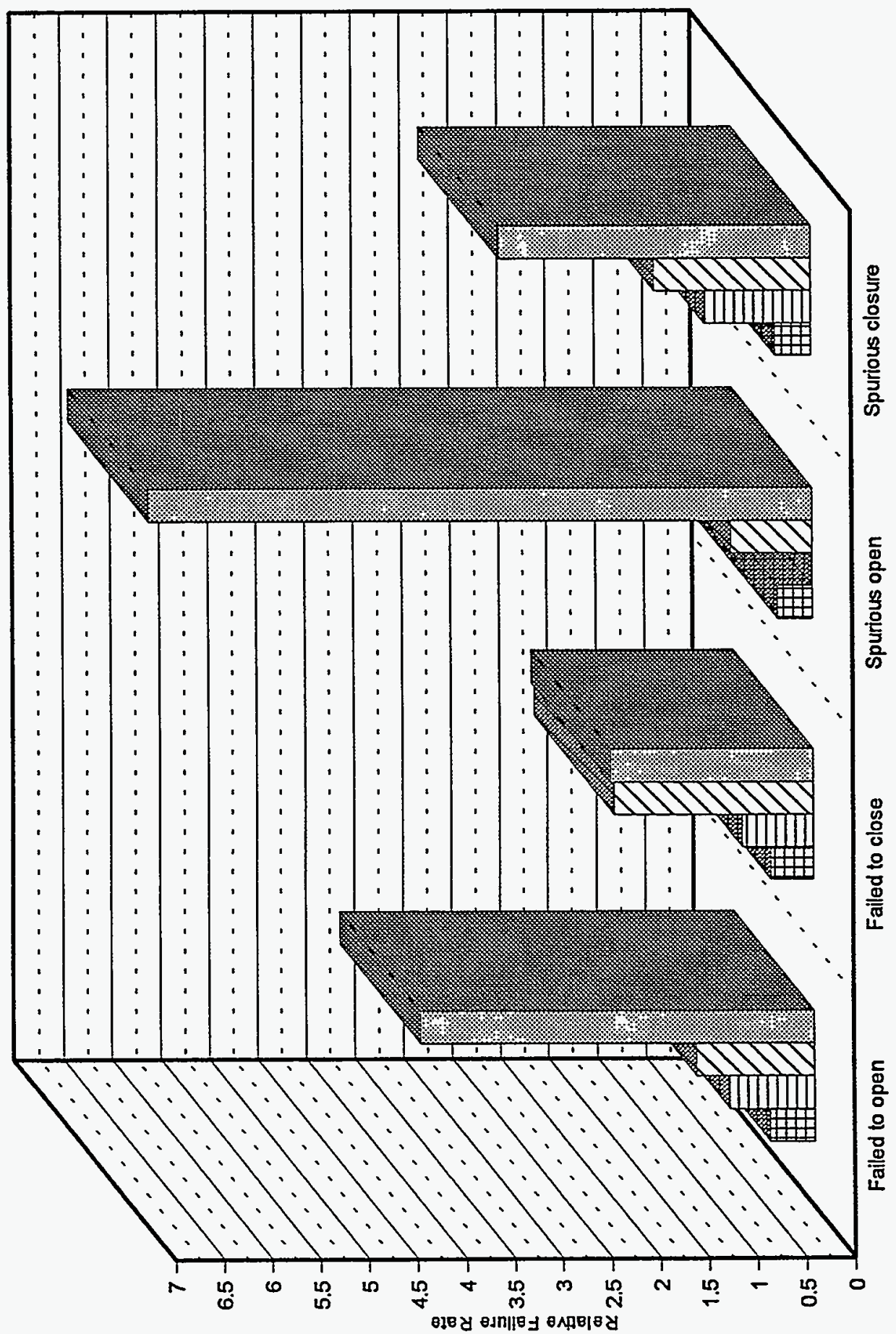

 
Operating Experience

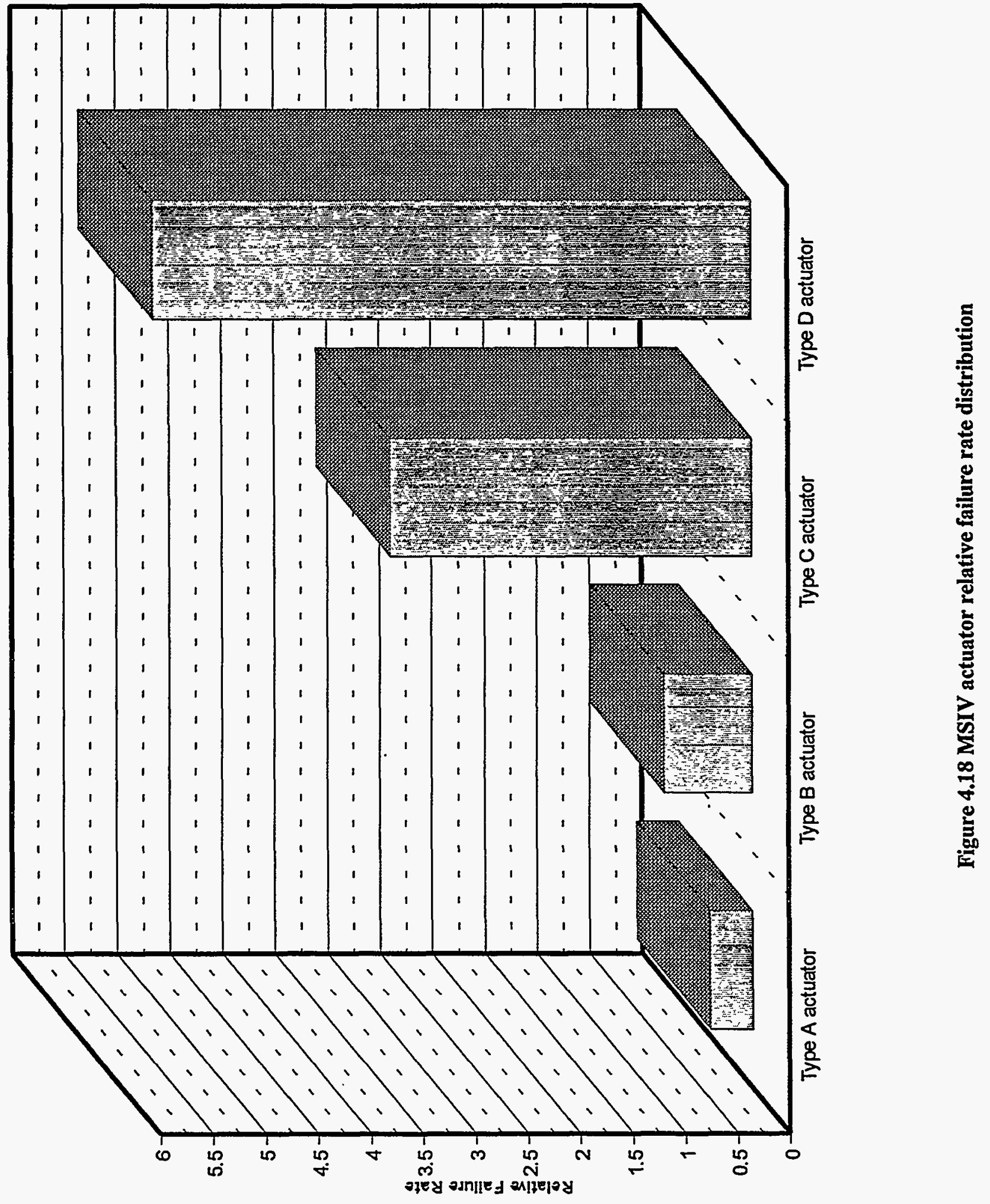


Operating Experience

operation is minimized because of the surveillance testing, preventive maintenance, and redundance built into these actuators. As can be seen from Figure 4.13, the total percentage of failed fast valve closure tests, lost fast valve closure capabilities, and reactor trips are all less than those shown for check and globe valves. 


\section{Main Steam Isolation Valve Surveillance Requirements}

General descriptions of the surveillance requirements for both boiling-water reactors (BWRs) and pressurized-water reactors (PWRs) are discussed in this section.

\subsection{BWR MSIVs}

Surveillance testing for typical BWR air-operated globe valves used for main steam isolation consists of a functional full stroke examination test, a partial stroke test, and a Local Leak Rate (LLR) Test of the valve seats (pilot and poppet). These surveillance test requirements are specified in the plant's Technical Specification TS and are consistent with the Inservice Testing (IST) Valve Plan requirements for MSTVs (ASME Class 1, Category A valves) at BWR plants. The BWR Plants' IST Valve Plan is developed in accordance with the requirements of $A S M E$ Boiler and Pressure Vessel Code, Section XI, Subarticle IWV-3000 (or the newer ISTC code) and 10 CFR Sect. 50.55a. The LLR testing is additionally implemented for BWRs to meet the requirement in $10 \mathrm{Pt}$. CFR 50, Appendix J, "Primary Containment Leakage Testing for Water Cooled Power Reactors". The full stroke examination and LLR tests are normally performed during shutdown or refueling conditions. A Full Stroke Test may be performed on a single steam line MSIV provided reactor power is reduced sufficiently to avoid a scram from reactor over-pressure or high flow through the other steam line flow restrictors. The partial stroke examinations for MSIV operability are performed during power operation on each MSIV individually.

\subsubsection{Partial Stroke Test}

Partial stroke exercises of BWR MSIVs are performed as part of the IST Plan, as well as a technical inspection surveillance requirement, while the plant is operating. This test is conducted to demonstrate that the valve is functional and will not malfunction due to valve or actuator problems. The test is performed by stroking the valve to the $90 \%$ open position and then re-opening the valve to the full open position. The reasons why the valves can be stroked to the $90 \%$ open position without decreasing steam flow or increasing reactor vessel pressure is because steam flow is choked by the flow restrictor located upstream of the MSIVs. During partial stroke testing, the closing force acting on the main disc due to steam flow is balanced by the opening force created by the actuator. However, if the opening force provided by the actuator is insufficient or if a malfunction occurs within the actuator, a valve closure event will most likely occur. For this reason the bases for MSIVs and main feedwater isolation valves in the revised Standard Technical Specification (STS) recommended that the partial stroke exercising test not be performed at power "since even a partial stroke exercise increases the risk of a valve closure event." Although the risk of valve closure during partial stroke testing exists, it must be balanced against the risk of "failure-to-close" for all design bases accidents requiring MSIV closure. This risk, at present, can be minimized only by performing partial stroke testing under actual operating conditions. It should also be noted that for many plants, MSIV partial stroke testing not only verifies valve operability, it also verifies that the MSIV limit switches that provide input signals to the reactor protection system are functioning properly. These signals are used to initiate reactor scram if reactor power is above a specified limit and more than one MSIV is less than $90 \%$ open. If the valve actuators are properly designed and maintained, spurious valve closure should not occur during partial stroke testing. Even if it did occur, it would be a significant safety risk only if all steam lines were to isolate and if the reactor subsequently failed to scram. This event is an example of an Anticipated Transient Without Scram (ATWS) event, a very severe transient. However, because the test is performed on each steam line one at a time and because a common mode failure would also have to occur within the reactor protection system, the possibility of an ATWS event initiated by spurious MSIV closure during partial stroke testing is very remote. This rationale is also applicable to PWRs.

At least once every quarter ( 92 days), each MSIV is partially stroked using available test controls and valve position indications for each individual MSIV. Credit for this surveillance may be taken for any recent acceptable full stroke 
test when determining the date the next surveillance test is due. These tests are normally performed at stable main turbine loads with all MSIVs fully open ("full-open" indication light only is illuminated). Using the available test hand switch, the test "close" position for the MSIV is selected. The position-indicating lights (i.e., "open" and "close") should both illuminate to indicate that the valve position has changed to an intermediate position as it starts to close. The $90 \%$-open indicating light is observed to illuminate next. The test hand switch is immediately switched to "Re-Open." Verification of any annunciator alarm such as "MSIV NOT FULL OPEN" should also occur. The operator should observe that the $90 \%$-open light should go out, indicating that the valve is returning to the full open position. Next the associated annunciator alarm should clear, and the "close" position indication light should go out to indicate that the valve has returned to its full open position. Verify that only the full "open" indication lights are illuminated and return the test hand switch to the "normal" position.

\subsubsection{Full Stroke Test}

The BWR MSIVs are tested at least once per 18 months for full closure within the specified time limit (between 3 and 5 seconds, typically). Full stroke exercise testing of MSIVs is normally performed as the plant is shut down for refueling and maintenance. This test is performed by measuring the time interval required for an MSIV to stroke from the fully "open" position to the fully "closed" position after its manual control hand switch was positioned to "close" or an isolation signal has been initiated.

\subsubsection{Local Leak Rate Test}

Leak rate testing for through valve seats is performed during a plant outage, normally refueling. The TS surveillance testing interval is 18 months. An accurately measured leak rate is obtained using the following typical test procedure:

(1) With the reactor between approximately $125^{\circ} \mathrm{F}$ to $200^{\circ} \mathrm{F}$, and normal water level and decay heat being removed by the RHR System in the shutdown cooling mode, all MSIVs are closed, utilizing both spring force and air pressure on the operating cylinder.

(2) Nitrogen is introduced into the reactor vessel above normal water level and into the connecting main steam lines with pressure raised to 20 to $30 \mathrm{psig}$. An alternate means of pressurizing the upstream side of the inner MSIV may also be used.

(3) A pressure gauge and flow meter are connected to the test tap between each set of MSIVs. Pressure is held below $1 \mathrm{psig}$, and flow out of the space between each set of valves is measured to establish the leak rate of the inside MSIV.

(4) To leak-test the outer MSNs, the reactor and connecting steam lines are flooded to a water level that gives a hydrostatic head at the inner MSIVs slightly higher than the pneumatic test pressure to be applied between the valves. This ensures essentially zero leakage through the inner valves. If necessary to achieve the desired water pressure at the inlet to the inner MSIVs, gas from a suitable pneumatic supply is introduced into the reactor vessel top head. Nitrogen pressure ( 20 to $30 \mathrm{psig}$ ) is then applied to the space between the MSIVs. Any stem leakage is corrected by performing maintenance on the valve packing. The Seat Leakage Test is conducted by shutting off the pressurizing gas and observing any pressure decay. The volume between the closed valves is accurately known. Corrections for temperature variation during the test period are made if necessary. An alternate means of leak-testing the outer MSIV using pressure decay or inflow measurement of the test medium may also be used. 
The LLR measurement program ensures that the MSIVs are operating properly in their isolation state and that a leakage trend is detected for each valve. Allowable seat leakage rates are tested at $1.1 \mathrm{~Pa}$ (i.e., calculated peak DBA containment internal pressure) and are dependent on the combined leakage for all isolation group valves in lines penetrating the primary containment as specified in plant-specific TS.

\subsection{PWR MSIVs}

Surveillance testing for PWR MSIVs consists of full stroke examinations at cold shutdown or refueling conditions and operability testing using the Partial Stroke Test when the unit is at power. These surveillance test requirements are specified in the plant's TS and are consistent with the Inservice Inspection (ISI) Plan requirements for MSIVs (ASME Class 2, Category B valves) at PWR plants. The ISI Valve Plans are developed in accordance with the requirements of ASME Boiler and Pressure Vessel Code, Section XI, Subarticle IWV-3000 (or the newer ISTC code) and 10 CFR Sect. 50.55a.

\subsubsection{Partial Stroke Test}

Partial stroke testing for PWR MSIVs is conducted similar to those conducted at BWR plants described in Subsection 5.1.1. The required test interval per TS is also quarterly (i.e., once every 92 days).

\subsubsection{Full Stroke Test}

Full stroke testing for PWR MSIVs is conducted similar to those conducted at BWR plants described in Subsection 5.1.2. The surveillance test interval for the Full Stroke Test is 18 months. 


\section{U.S. Nuclear Regulatory Commission Notices and Generic Letters}

The NRC Office of Nuclear Reactor Regulation (NRR) routinely issues reports related to operating experience at licensed nuclear facilities. Formerly published by the Office of Inspection and Enforcement, these reports include (1) NRC Bulletins (approximately 5 per year), which require remedial actions and/or responses from licensees and (2) NRC Information Notices (approximately 100 per year), which are for information purposes and do not require licensee response. The NRR also publishes Generic Letters, which are also issued for licensee information.

Listed below are eleven information Notices and one Generic Letter that are related to main steam isolation valve (MSIV) operating experience. No NRC Bulletins were located that pertained to MSIVs. The report number, title, and a brief summary are shown for each report.

\section{Information Notices}

IN 81-28 Failure of Rockwell-Edward Main Steam Isolation Valves. Seven failures were reported at boiling-water reactor (BWR) facilities involving a mechanical separation of valve internals. This separation occurred either at the stem-to-stem disk-threaded connection or at the main-disc-to-piston threaded connection, permitting the main disk to be free of the stem. Possible causes: inadequately torqued connections, improperly installed antirotation pins, and vibration-induced disc rotation. Corrective actions included increasing stem pin size, increasing the number of antirotation pins, and increasing the hole depth into the stem.

IN 81-33 Locking Devices Inadequately Installed on Main Steam Isolation Valves. During inspection at a BWR facility, valves manufactured by Atwood \& Morrill Company were found to be deficient in installation of the locking plates on the hexagonal fasteners which are used to secure the actuator shaft to the valve stem. The locking plates prevent rotation of the hexagonal fasteners due to vibration. Failure of the locking plates could eventually result in improper opening or closing of the valves. Licensees with this model valve were asked to verify that the locking plates were correctly installed to perform their locking function.

IN 82-23 Main Steam Isolation Valve (MSIV) Leakage. After an examination of operating performance during a 3-year period at BWR facilities, the NRC determined that 19 of $25 \mathrm{BWRs}$ had MSIVs that failed to meet Limiting Condition of Operation ( $\mathrm{LCO}$ ), which specifies the maximum permissible leak rate. The failures occurred with Rockwell International, Crane, and Atwood \& Morrill Company valves. No specific corrective actions were suggested by the NRC at the time.

IN 83-54 Common Mode Failure of Main Steam Isolation Nonreturn Check Valves. A PWR facility reported that all four nonreturn check valves had stuck open after the plant had shut down and steam flow had been stopped. The apparent cause was that increased friction, due to over-tightening of the packing gland, was sufficient to prevent valve closure under no-flow conditions. Corrective actions taken by the licensee consisted of check valve packing replacement after each refueling, additional engineering evaluations, and inclusion of the MSTVs in the Inservice Testing (IST) Program. Other licensees were expected to review the event for possible applicability to their facilities.

IN 85-21 Main Steam Isolation Valve Closure Logic. The licensee at a pressurized-water reactor (PWR) facility discovered and reported a logic fault related to MSIV closure. Both B and C MSIVs had the opening solenoid valves controlled by train B only. This situation could have resulted in both MSIVs failing to close due to a single failure of the B closure signal. Corrective action by the licensee was to modify the control circuitry so that either a train A or a train B closure signal would ensure proper closure of the MSIVs. 
USNRC

IN 85-84 Inadequate Inservice Testing of Main Steam Isolation Valves. During NRC inspection it was determined that two PWR facilities had violated 10 CFR Sect. $50.55 \mathrm{a}(\mathrm{g})$ in that MSIV surveillance testing procedures did not call for the securing of the nonsafety-related instrument air supply to the MSIV Control System during a test. Upon investigation by the licensee, it was determined that the MSIVs could possibly fail to close under low steam flow conditions because of insufficient air stored in the safety related air accumulators. Certain design modifications were implemented to ensure proper MSIV closure and to resolve the testing deficiency.

IN 86-81 Broken Inner-External Closure Springs on Atwood \&Morrill Main Steam Isolation Valves. During MSIV inspection after leakage testing at a BWR, the licensee noted that four closure springs were broken into two to seven pieces, apparently a result of quench cracking caused by the heat treatment process. Possible results of the spring failure include increased difficulty in meeting leakage testing requirements and increased closure time in both PWR and BWR units. The manufacturer recommended that affected licensees perform visual inspections and, in some cases, load tests of the springs.

IN 88-51 Failures of Main Steam Isolation Valves. Following an event at a BWR plant in which the 1B MSIV failed to close, and on subsequent spring-closure testing by the licensee, it was determined that all eight MSIVs were inoperable. Testing demonstrated that the 20 -inch, air-spring-operated Crane globe valves would not close with spring force alone, which is contrary to the plant's design basis. The root cause of failure was attributed to excessively tight MSIV chevron packing.

IN 88-59 Main Steam Isolation Valve Guide Rail Failure at Waterford Unit 3. During routine inspection MSIV debris was found in the main turbine throttle valve strainer. Further inspection revealed that the downstream guide rails in one of the valves had become dislodged and that several bolt heads had been completely severed. The force of the lever lock arm assembly contacting the rail was the cause of the failure. A similar problem was discovered at another PWR facility. Possible corrective actions include verifying bolt alignments, increasing valve closure time, changing the angles of the rails, and periodic fiberscope examinations of valve internals.

IN 94-08 Potential for Surveillance Testing To Fail to Detect an Inoperable Main Steam Isolation Valve. During maintenance at a BWR facility to repair a presumed faulty limit switch on an MSIV, it was discovered that the valve was mechanically bound and would not close properly. The cause of the 24-inch, poppet-type globe valve failure was attributed to excessive wear of the guide ribs, which resulted in mechanical binding of the valve poppet. The valve manufacturer, Atwood \& Morrill Company, had recommended in 1989 that licensees install an antirotation modification, which may have prevented the excessive wear. Previous partial stroke testing failed to detect that the valve was mechanically bound. The surveillance test failed because the test did not consider limit switch tolerance and the design characteristics of the pilot valve assembly.

IN 94-44 Main Steam Isolation Valve Failure To Close on Demand Because of Inadequate Maintenance and Testing. A main steam isolation valve failed to close on demand, resulting in steam generator (SG) dry-out condition. A second valve failed to close fully at the onset of the event and had leaked excessively. The second valve eventually closed, and the associated S/G did not reach a dry-out condition. Failure of the valves to close as designed was attributed to inadequate setting of clearances between yoke rod guides and yoke rods and also to inadequate testing. Similar problems were subsequently discovered at two other PWR facilities. Additional testing, supplemental to that required by the IST Program, will be initiated by the licensees to determine proper valve performance. 


\section{Generic Letter}

GL 86-17 Availability of NUREG-1169, Technical Findings Related to Generic Issue C-8; Boiling Water Reactor Main Steam Isolation Valve Leakage and Leakage Treatment Methods. This report summarizes the findings of the BWR Owners Group. Committee related to MSIV leakage control systems and difficulty of some of these valves to meet Technical Specification guidelines for leakage control. The report represents technical findings associated with the Generic Issue C-8, and the NRC staff expects it to be used in the regulatory resolution of the issue. 


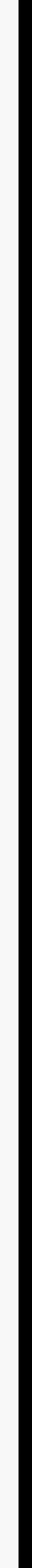




\section{Conclusions and Recommendations}

This section summarizes the MSIV operating experiences for both boiling-water reactors (BWRs) and pressurizedwater reactors (PWRs). Recommendations that may improve main steam isolation valve (MSIV) reliability are given, along with suggestions for further study.

\subsection{Conclusions}

For BWRs the major MSIV failure modes affecting plant operations were valve seat leakage in excess of Technical Specification (TS) limits, valve failure to close within TS limits, and the loss of MSIV closure capability.

The failure of the MSIVs to meet TS limits for valve seat leakage is the predominate failure mode affecting.BWRs and was due to improper valve seating. Failure to seat the valves properly was attributed to normal valve seat wear, internal binding, valve stem binding, and maintenance error. Valve stem binding was attributed to packing-induced friction and binding of the yoke rod guides. The packing-induced friction was attributed to hardening of the valve packing due to heat, inadequate lubrication, and over-torqued packing glands. Binding of the yoke rod guides was attributed to maintenance error, as discussed in Subsection 4.2.1, and thermal cycling.

Failure to meet TS limits for fast closure was attributed to valve and actuator problems. The valve problems were related to many of the same failure mechanisms associated with valve seat leakage (i.e., internal binding, valve stem binding, maintenance error). The actuator failures were predominately due to problems with the hydraulic speed control system.

MSIV failure to close was related to valve and actuator problems. The valve problems were related to internal binding, valve stem binding, and maintenance error. The actuator problems had multiple failure modes (i.e., electrical, pneumatic, hydraulic, mechanical). The electrical failures were related to defective solenoid valves and limit switches. The pneumatic failures were related to air leaks due to worn-out pilot valves, solenoid valves, seals, and pipe fittings. The hydraulic failures were related to hydraulic leaks due to defective speed control valves, pipe fittings, and worn seals. The mechanical failures were mostly related to broken valve springs. As indicated in Figure 4.6 , only $60 \%$ of the "failed-to-close" events were detected by surveillance testing, and at least two NRC Information Notices were written to address this concern in BWRs. For example, IN94-08 determined that for one BWR facility, the valve failed to closed because of excessive wear of the guide ribs which resulted in mechanical binding of the valve poppet. This failure mechanism (i.e., internal binding) is consistent with the findings of this report. Surveillance testing (i.e., partial stroke testing) failed to detect this condition because the test did not consider limit switch tolerance and the design characteristics of the pilot valve assembly. In another instance described in IN85-84, the safety-related air accumulators at one plant were not capable of closing the MSIVs under low-steam-flow conditions concurrent with loss of plant instrument air. This problem was not recognized during surveillance testing because the test did not call for securing the non-safety-related instrument air supply from the MSIV control system as required by Section XI of the ASME Boiler and Pressure Vessel Code. These events clearly illustrate that a review of MSIV partial stroke and full stroke surveillance testing should be performed to evaluate the effectiveness of current MSIV surveillance testing.

The three types of valves used for MSIV applications in PWRs are check, globe, and gate valves. For all valve types, the major failure modes affecting plant operations were related to failure to meet TS limits for fast closure and loss of MSIV closure capability.

For check valves the major failure modes were due to problems with both the valve and actuator. The valve problems were related to internal binding and valve shaft binding. Internal binding was attributed to disc jamming in the valve body, seized shaft bearings, and worn internal parts. Valve stem or shaft binding was attributed to excessive friction caused by hardening of the valve packing due to heat, inadequate lubrication, and over-torqued packing glands. 


\section{Conclusions}

Actuator problems were related to failed solenoid valves, failed limit switches, blocked flow orifices, binding in the air cylinder, operator linkage improperly installed, worn valve springs, and corroded air cylinder shafts, bushings, and seals. In addition to these failures, blown rupture discs accounted for the majority of the spurious valve closure events.

For globe valves the major failure modes were due to problems with both the valve and actuator. The valve problems were related to internal binding and valve stem binding. Internal binding was predominately due to binding of the yoke rod guides (i.e., stanchion guides). Valve stem binding occurred for the same reasons given for check valves (i.e., excessive friction caused by hardening of valve packing and over-torqued packing glands). The actuator problems were related to defective solenoid valves, worn valve springs, and maintenance errors.

For gate valves the major failure modes were all due to actuator problems. There were no significant valve problems. The actuator problems were predominately due to hydraulic, air, and nitrogen leaks caused by defective control valves, check valves, O-rings, and pipe fittings. In many instance hydraulic leaks were responsible for several hydraulic pump failures. Other problem areas were related to defective solenoid valves and limit switches out of adjustment. In many cases these components failed due to normal aging, but a significant portion of these problems could be traced to inadequate maintenance procedures and training.

As indicated in Figure 4.14, only 44\% of the "failed-to-close" events for PWRs were detected by surveillance testing and at least one NRC Information Notice (IN94-44) was written to address this concern on three PWRs. This information notice determined that the globe valves failed to close because of inadequate setting of clearance between the yoke rod guides and the yoke rods and inadequate testing. This failure mechanism (i.e., binding of the yoke rod guides) is consistent with the findings of this report. Surveillance testing (i.e., full stroke testing) failed to detect this condition because the test was performed during cold shutdown conditions and did not consider during plant startup how thermal expansion of the valve internal parts would effect the clearance between the yoke rod guides and yoke rods. As with the BWR experience, this event clearly illustrates that a review of MSIV partial and full stroke surveillance testing should be performed to evaluate the effectiveness of current MSIV surveillance testing. In particular, the plant operating conditions during which surveillance testing is being performed should be investigated (i.e., the valves may pass surveillance testing under cold shutdown conditions but not at normal operating conditions).

As shown in Figure 4.17, the BWR globe valves have the lowest Relative Failure Rate of all MSIV types. One possible explanation of this is that these valves are subjected to much more maintenance because of failure to meet Local Leak Rate Test (LLR) requirements. The second lowest Relative Failure Rate was associated with PWR globe valves, followed by check valves, and then gate valves. The Relative Failure Rate for gate valves is the combined failure rate for both Type I and II gate valves, as discussed in Subsection 4.17. Type II gate valves, which use hydraulic pressure to open and pneumatics to close, are considered to be more reliable, as indicated by Figure 4.18. 


\section{References}

1. Electric Power Research Institute, Nuclear Power Plant Common Aging Terminology, EPRI TR-100844, Palo Alto, CA, November 1992.

2. River Bend Station FSAR, Section 5.4.5, "Main Steam Isolation System," ENTERGY Inc., P.O. Box 220, St. Francisville, LA 70775."

3. Sequoyah Nuclear Plant FSAR, Section 10.0, "Steam and Power Conversion System," Tennessee Valley Authority, Chattanooga, TN.†

4. Virgil C. Summer Nuclear Station FSAR, Section 10.0, "Steam and Power Conversion System," South Carolina Electric \& Gas Company, P.O. Box 88, Jenkinsville, SC 29065."

5. Mc Guire Nuclear Station FSAR, Section 10.0, "Steam and Power Conversion System," Duke Power Company, 12700 Hagers Ferry Rd., Huntersville, NC 28078."

6. Vogtle Electric Generating Plant Units $1 \& 2$ FSAR, Section 10.0, "Steam and Power Conversion System," Southern Nuclear, Waynesboro, GA.

7. St. Lucie Plant Unit I FSAR, Section 10.0, "Steam and Power Conversion System," Florida Power and Light Company, P.O. Box 128, Ft. Pierce, FL 34951 ."

8. Joseph M. Farley Nuclear Plant Units $1 \& 2$ FSAR, Section 10.0, "Steam and Power Conversion System," Southern Nuclear, P.O. Box 2625, Birmingham, AL. $\dagger$

9. Catawba Nuclear Station FSAR, Section 10.0, "Steam and Power Conversion System," Duke Power Company, 4800 Concord Rd., York, SC 29745.

10. Calvert Cliffs Nuclear Power Plant Units $1 \& 2$ FSAR, Section 10.0 "Steam and Power Conversion System," Baltimore Gas and Electric Company, 1650 Calvert Cliffs Pkwy, Lusby, MD 20657-4702."

11. James A. FitzPatrick Nuclear Power Plant FSAR, Section 4.6, "Main Steam Isolation Valves," Power Authority of the State of New York, P.O. Box 41, Lycoming, NY.

12. North Anna Power Station Units I\&-2 FSAR, Section 10.0, "Steam and Power Conversion System," Virginia Electric \& Power Company, P.O. Box 402, Mineral, VA."

13. Vogtle Electric Generating Plant Units 1\&2 System Training Manual, revision 1, Southern Nuclear, Waynesboro, GA." (not dated)

14. Instruation Manual for 32" Main Steam Isolation Valves, Rev. 3 Document 13408, Atwood \& Morrill Company, Salem, MA, May 8, $1990 \ddagger$

15. Atwood \& Morrill Company, n.d. Instruction Manual for 24" Main Steam Isolation Valves, Document 13564, Salem, MA (not dated). $\ddagger$ 


\section{References}

16. Anchor/Darling Valve Company, "Main Steam Isolation Valve Maintenance Guide," EPRINP-7211, Research Project 2814-27, final report, EPRI, Palo Alto, CA, May 1991.‡

17. Brown Ferry Nuclear Plant FSAR, Section 4.6, "Main Steam Isolation Valves," Tennessee Valley Authority, Chattanooga, TN. $\dagger$

*Available from individual plant site.

$\dagger$ Available from corporate headquarters for the utility.

$\ddagger$ Available from individual valve vendors. 


\section{Internal Distribution}

1. D. A. Casada

2-7. R. L. Clark

8. D.F. Cox

9. E.C. Fox

10. R. G. Gilliliand

11. H. D. Haynes

12. J.D. Kueck

13. P. J. Otaduy
14-15. A. B. Poole

16. C. E. Pugh

17. C. C. Southmayd

18-23. R H Staunton

24. ORNL Patent Office

25. Document Reference Section

26-27. Laboratory Records Department

28. Laboratory Records (RC)

\section{External Distribution}

29. G. Sliter, Electric Power Institute, P.O. Box 10412, Palo Alto, CA 94303

30. J. W. Tills, Institute for Nuclear Power Operations, 1100 Circle 75 Parkway, Atlanta, GA 30339-3064

31. R. J. Lofaro, Brookhaven National Laboratory, Bldg. 130, Upton, NY 11973

32. R P. Allen, Battelle-PNL, MS P8-10, P.O. Box 999, Richland, WA 99532

33. J.P. Vora, U.S. Nuclear Regulatory Commission, Office of Nuclear Regulatory Research, Electrical and Mechanical Engineering Branch, MS T-10 E10, Washington, DC 20555

34. G. H. Weidenhamer, U.S. Nuclear Regulatory Commission, Office of Nuclear Regulatory Research, Electrical and Mechanical Engineering Branch, MS T-10 E10, Washington, DC 20555

35. M.E. Mayfield, U.S. Nuclear Regulatory Commission, Office of Nuclear Regulatory Research, Materials and Engineering Branch, MS T-10 E10, Washington, DC 20555

36. O. P. Gormley, U.S. Nuclear Regulatory Commission, MS T-10 E10, Washington, DC 20555

37. C.F. Nelson, Sandia National Laboratory, P.O. Box 5800, MS 0737, Albuquerque, NM 87185

38. H. L. Magleby, Idaho Engineering Laboratory, MS 2406, P.O. Box 1625, Idaho Falls, ID 83415

39. Office of Assistant Manager for Energy Research and Development, Department of Energy, Oak Ridge Operations, OakRidge, TN 37831

40-41. Office of Scientific and Technical Information, P.O. Box 62, Oak Ridge, TN 37831 


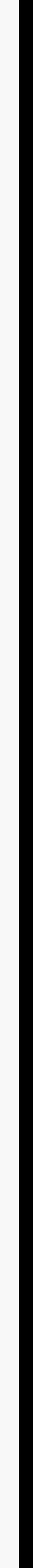


Effects of Aging and Service Wear on Main Steam Isolation Valves and Valve Operators

3. DATE REPOAT PUSLISHED

MONTH I 'EAR

March 1996

4. FIN OR GRANT NUMBEF

$\mathrm{BO} 828$

5. AUTHORIS

6. TYPE OF REPORT

R. L. Clark

Technical

7. PERIOD COVERED IInClusuve Dor:

8. PERFORMING ORGANIZATION - NAME AND ADDRESS IIf NRC, provide Division, Office or Region, U.S. Nuclear Regulazor, Commission, and mailing address, if contractor, provior name and mailing addressi

Oak Ridge National Laboratory

Oak Ridge, TN 37831-6285

9. SPONSORING ORGANIZATION - NAME AND ADDRESS IIf NRC, ivpe "Same as above"; if contractor, provide NRC Division, Otfice or Region. U.S. Nuclear Regulatory Commission. and mailing address.)

Division of Engineering Technology

Office of Nuclear Regulatory Commission

U.S. Nuclear Regulatory Commission

Washington, DC 20555-0001

10. SUPPLEMENTARY NOTES

J. Jackson, NRC Project Manager

11. ABSTRACT 1200 viords or lessl

In recent years main steam isolation valve (MSIV) operating problems have resulted in significant operational transients (e.g., spurious reactor trips, steam generator dry out, excessive valve seat leakage), increased cost, and decreased plant availability. A key ingredient to an engineering-oriented reliability improvement effort is a thorough understanding of relevant historical experience. A detailed review of historical failure data available through the Institute of Nuclear power Operation's Nuclear Plant Reliability Data System has been conducted for several types of MSIVs and valve operators for both boiling-water reactors and pressurized-water reactors. The focus of this review is on MSIV Failures modes, actuator failure modes, consequences of failure on plant operations method of failure detection, and major stressors affecting both valves and valve operators.

Main Steam Isolation Valves

MSIV

Valve failures

Valve Reliability

Valve Operator

\begin{tabular}{l} 
Unlij mi ted \\
14. SECURITY CLASSIFICATION \\
\hline TThis Pagel \\
Unclas ified \\
(This Reponl \\
Unclas ified \\
15. NUMBER OF PAGES \\
16. PRICE
\end{tabular}




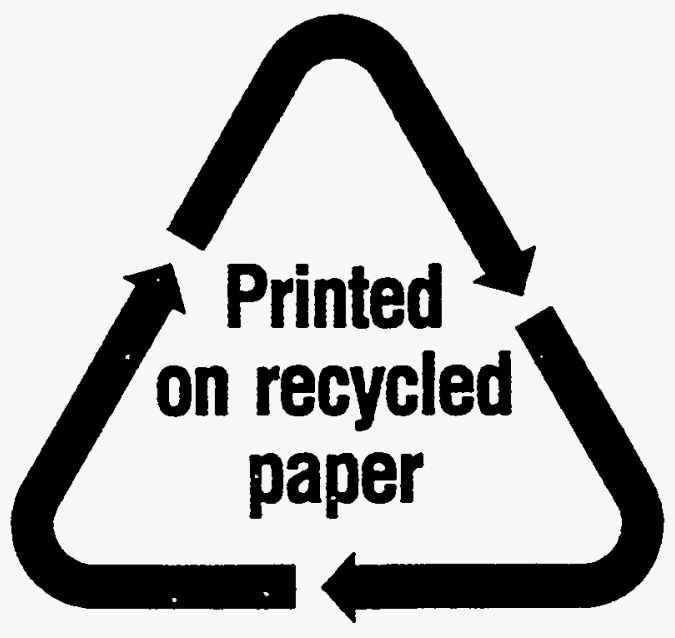

Federal Recycling Program 